\title{
Article
}

\section{Human Capital and Sustainability}

\section{Ivo Šlaus ${ }^{1}$ and Garry Jacobs ${ }^{2, *}$}

1 South East European Division (World Academy of Art and Science), Ruder Boskovic Institute, P.O. Box 1016, Zagreb 10000, Croatia; E-Mail: Šlaus@irb.hr

2 The Mother's Service Society, 5, Puduvai Sivam Street, Venkata Nagar, Pondicherry 605011, India

* Author to whom correspondence should be addressed; E-Mail: garryjacobs@ gmail.com; Tel.: +91-9840098608; Fax: +91-4132212338.

Received: 9 November 2010; in revised form: 6 December 2010 / Accepted: 15 December 2010 / Published: 7 January 2011

\begin{abstract}
A study of sustainability needs to consider the role of all forms of capital—natural, biological, social, technological, financial, cultural—and the complex ways in which they interact. All forms of capital derive their value, utility and application from human mental awareness, creativity and social innovation. This makes human capital, including social capital, the central determinant of resource productivity and sustainability. Humanity has entered the Anthropocene Epoch in which human changes have become the predominant factor in evolution. Humanity is itself evolving from animal physicality to social vitality to mental individuality. This transition has profound bearing on human productive capabilities, adaptability, creativity and values, the organization of economy, public policy, social awareness and life styles that determine sustainability. This article examines the linkages between population, economic development, employment, education, health, social equity, cultural values, energy intensity and sustainability in the context of evolving human consciousness. It concludes that development of human capital is the critical determinant of long-term sustainability and that efforts to accelerate the evolution of human consciousness and emergence of mentally self-conscious individuals will be the most effective approach for ensuring a sustainable future. Education is the primary lever. Human choice matters.
\end{abstract}

Keywords: human capital; social capital; education; employment; evolution; inequality; individuality; knowledge; population 


\section{Introduction}

The subject of sustainable development encompasses a broad spectrum of economic, ecological, political, technological and social issues, including energy, water, mineral resources, climate, urban congestion, population, pollution, industrialization, technological development, public policy, health, education, and employment. A compartmentalized piecemeal approach to the subject, such as one focusing on technological solutions or public policy issues, may shed light on specific aspects, but the complex interactions between various dimensions preclude such an exclusive concentration. Problems are compounded when any of these subsystems and elements is regarded as if it were separate and independent from the choices and actions of human beings.

When the time dimension is also considered, the challenge becomes even more complex, because over decades many of the underlying assumptions on which our view of social phenomenon is predicated may be radically altered by new and unforeseen evolutionary trends, high-impact and hard-to-predict black swans. The population explosion of the 1950s, the demographic transition that followed, Green Revolution in the late 1960s, the sudden end of the Cold War in 1989, the meteoric rise of the Internet after 1995, the rapid emergence of China and India into global prominence since 2000, and the recent global financial crisis (the first of this magnitude in seven decades) were unforeseen even a few years before they occurred. Entering the 21st century, the speed of change has only accelerated. Therefore, this study is founded upon an evolutionary perspective of social development.

The term 'capital' implies a usable productive resource. The concept of human capital refers to human beings as one of the means and contributing factors in economic growth and social development. This paper views human welfare and well-being as both ends and means. It regards the development of human consciousness as the real source of wealth creation. It views the goal of development, not as economic growth or even sustainable economic growth per se, but as sustainable development of human beings. While human, social, cultural, scientific and technological capital are often distinguished in the literature, human capital as discussed here is broadly defined to include the knowledge, skills, attitudes and capacities of individuals as well as the social and cultural endowments of the collective, including our capacity for discovery, invention, innovation and resourcefulness. This paper treats human and social capital by examining the sustainable development of human capabilities as well as the role of these capabilities in the overall sustainability of human and social evolution. It views conscious, evolving human beings as the pivotal determinant of sustainable development. It concludes that sustainability can best be achieved by giving primacy to the development of human capacity, the education of human choice, and the evolution of human consciousness.

Human capital consists of many dimensions, which have been examined in-depth by other researchers. The objective of this article is to consider the role of human capital, not merely as one essential component but as the primary determinant of the process of social, economic and ecological development, and to explore important relationships between its various dimensions that are critical to sustainability. 


\section{Wider Conception of Capital}

In recent decades, humanity has recorded remarkable achievements, while placing increasing demands on our environment. The challenge now facing humanity is to find ways to harness all available forms of capital in a manner that promotes human welfare, well-being and sustainable development for all. Until recently the notion of capital was largely confined to financial assets utilizable for commercial and industrial investment. But a broader conception of capital can be traced back to Adam Smith, who defined four types of fixed capital-land, buildings, machinery and human abilities [1]. In this paper, the term 'capital' is used even more broadly to include all forms of assets and capabilities - natural, biological, financial and human-that can be harnessed for human development. Natural capital consists of minerals, energy sources and other environmental resources that exist independently of human beings. Biological capital consists of all species of plants and animals that serve as the basis for other life, as well as their by-products and waste-products, such as coral reefs and the organic content of soil. Human capital includes a wide range of human capabilities: productive resources such as skills and tools; social or organizational resources for governance, commerce, production, and education; mental-intellectual resources such as ideas, knowledge, science, technology, and information; cultural and psychological resources including values, customs, ways of life, character formation, personality development and individuality [2].

The different forms of capital are interrelated and interdependent. All forms of life depend on natural capital for their survival. But the reverse is also true. Natural capital is enhanced or destroyed by the impact of biological life forms, e.g., photosynthesis of atmospheric $\mathrm{CO}_{2}$ into $\mathrm{O}_{2}$, which are in turn dependent on human activity and vice versa. Financial capital is itself a product of human relationships based on exchange and trust and has no independent existence of its own. Money can be utilized to make any other resource more useful or productive. It can be used to educate people, develop and apply technology to natural or social processes, etc. This implies that the sustainability of human capital is interwoven with the sustainability of all other forms of capital.

The interdependence goes still deeper. The very notion of capital is a human conception. Other species do survive on the basis of natural resources, but no other species consciously applies its mental capacities to identify and utilize different forms of capital for its development. In this sense, anything becomes a resource by the action of the human mind. Resources are perceived and developed. Materials exist in nature, but anything becomes a resource only when its potential value is recognized by the human mind. Human mental activity creates resources by discovering new productive relationships between existing elements. For centuries, uranium was considered an undesirable by-product of silver mining, appropriately called pitchblende from the German pechblende ('pech' meaning failure, nuisance). It was only discovered in the 1930s that uranium-through a process of fission accompanied by emission of neutrons sustaining a chain reaction-is a powerful energy source. It is in this vein that the International Commission on Peace and Food (ICPF) observed that "for millennia we have tended to overlook or, at best, grossly underestimate the greatest of all resources and the true source of all the discoveries, inventions, creativity and productive power found in nature - the resource that has made minerals into ships that sail the skies, fashioned grains of sand into tiny electronic brains, released the energy of the sun from the atom, modified the genetic code of plants to increase their vigor and productivity - the ultimate resource, the human being" [3]. 
Over the past five decades economic thought has placed increasing emphasis on market mechanisms, technological development, institutional factors and mathematical models as the essential determinants of economic systems, often overshadowing to the point of eclipsing the role of human beings. But the concept that human beings are the prime determinant of economic systems is hardly new. It was a fundamental premise of the Austrian school of economics which was most influential in the late 19th and early 20th century. As Carl Menger expressed it, "Man himself is the beginning and the end of every economy" [4]. Ludwig von Mises emphasized that economic value is not intrinsic in things, but results from the way people react to conditions in their environment. "Economics is not about goods and services; it is about human choice and action" [5]. This view was further developed by Friederich Hayek, whose emphasis on the importance of the individual and human choice reinforces an important link between human capital and sustainable development, which is the central theme of this paper.

\section{Individual and Social Capital}

Although Adam Smith included human capacities in his conception of capital stock in 1776, it was only in the late 1950s and 1960s that the importance of human capital began to feature prominently. Becker, Minzer and Schultz argued that investment in education and training builds up a stock of skills and abilities (a capital) in the population that can benefit national economies and fuel economic growth [6,7]. Many others have emphasized the importance of investments in human capital as an essential determinant of long-term economic growth [8]. Harbison argues that human resources constitute the ultimate basis for the wealth of nations. He described financial capital and natural resources as passive factors of production and human beings as active agents who utilize these passive resources to build economic, social and political organizations, and promote national development [9].

The term 'human capital' is most often used in a narrow sense with reference to the innate talents, abilities, skills and acquired knowledge of individual human beings. Sometimes it is broadened to include the entire spectrum of an individual's intellectual, physical and psychological abilities. Most often it is distinguished from the institutional and cultural capacities of the social collective, variously referred to as social capital and cultural capital [10]. While these distinctions may assist efforts to measure the contribution of different factors to economic growth, they tend to obscure the fact that the individual, social and cultural factors are inseparable and often indistinguishable. Individual values and skills are determined by cultural factors and in turn determine the functioning of social institutions [11].

Social development is a product of individual development and vice versa. Social progress begins with the generation of new ideas, higher values, more progressive attitudes leading to pioneering initiatives by individuals, which are later accepted and imitated by other individuals, organized and multiplied, and eventually assimilated by the social collective. Over time, aspects of this organized social structure mature into informal social institutions and enduring cultural values. So too, the development of individuality is itself a product of social organizations, institutions and a cultural atmosphere, which impart knowledge, skills and values, make available to each member the cumulative advances of the collective, and provide freedom and opportunity for unique individual characteristics to develop. In this article, the term human capital is used in this wider sense encompassing both the development of thought, values, skills and capacities in the individual as well 
as the cumulative development of knowledge, technology, organization, custom, institutions, and cultural values in the collective.

Some forms of social organization actively support the development and flowering of individual capacity, whereas others retard, suppress or stifle it altogether. The sustainability of human capital depends on finding the right balance and relationship between these two poles of human existence. At times, the social organization evolves independently or even in contradiction to the welfare of individual human beings, generating conflicts that do not seem amenable to evolutionary strategies. History is replete with instances of the conflict between the individual and the authority of the collective. As R.J. Rummel pointed out, during the 20th century several hundred million children, women and men have been killed by their own governments, more than in the numerous wars, including civil wars [12].

Human capital can be destroyed, misused or extravagantly wasted. All forms of violence are examples of human capital directed for self-destruction as well as for destruction of other forms of capitals. Lack of education and education that degenerates into indoctrination prevents the effective development and utilization of human capital. Social structures that demand conformity and uniformity can suppress both the development and expression of human capacity. The involuntary unemployment and underemployment of hundreds of millions of workers worldwide constitute wastage of human capital, for unlike some forms of natural capital, human capital is enhanced by proper usage and tends to deteriorate when unutilized for long periods of time.

\section{Characteristics of Human Capital}

In 1961, Theodore Schultz proposed a five-fold strategy for investment in human resources that included improvements in health facilities and services to increase life expectancy, strength, and stamina; in-service or on-the-job training organized by firms to cater for their new and old workers; formal education at the primary, secondary and tertiary levels; adult literacy programs organized for those that missed formal education; and migration of individuals and families to adjust to changing job opportunities [13].

The central role of human beings prompted Paul Crutzen to label the current period in the evolution of earth as the Anthropocene Epoch [14,15]. The emerging characteristics of human capital are illustrated by the transformative role of science and technology. Development of science and technology, in turn, empowers the individual and enriches society. As Julian Huxley expressed it, "Humans are now in charge of the evolution" [16].

The constant interaction, exchange, mutual dependence and reinforcement between the individual and the collective give human capital the unique capacity for self-development and self-augmenting. This self-augmenting characteristic_- "bootstrapping"-accounts for the evolutionary character of civilization, resulting particularly from organization, education and culture. Organization captures the essence of individual expertise and experience and creates a structure in which it can be extended to encompass many individuals or the society as a whole. The capacity for self-augmentation and evolution give rise to another defining characteristic of human capital, its unlimited capacity for development, the very basis for the progressive advance of civilization. Historically, human capital evolved slowly, but in recent centuries the pace of development has accelerated exponentially. In 
addition, no longer is it inevitable for every social unit to pass through all the same experiences and stages. Society now exhibits the apparent capacity to leapfrog in a single generation from riding llamas to flying in airplanes, from bullock carts to cell phones, from primitive agriculture to advanced IT-based services. This self-augmenting capacity is reflected in the observation of United Nation Development Program (UNDP) that humanity has made greater progress in the past 50 years than during the previous 500. Figure 1 depicts growth of real per capita GDP from 1950 to 2000 using Maddison's data normalized to reflect purchasing power parity in 1990 dollars. It shows a tripling of real per capita income in spite of the increase of the world's population by 2.5 times during this same period.

Figure 1. Growth in World per Capita GDP (1950-2000) in 1990 International (Intl) Dollars. Data from [17].

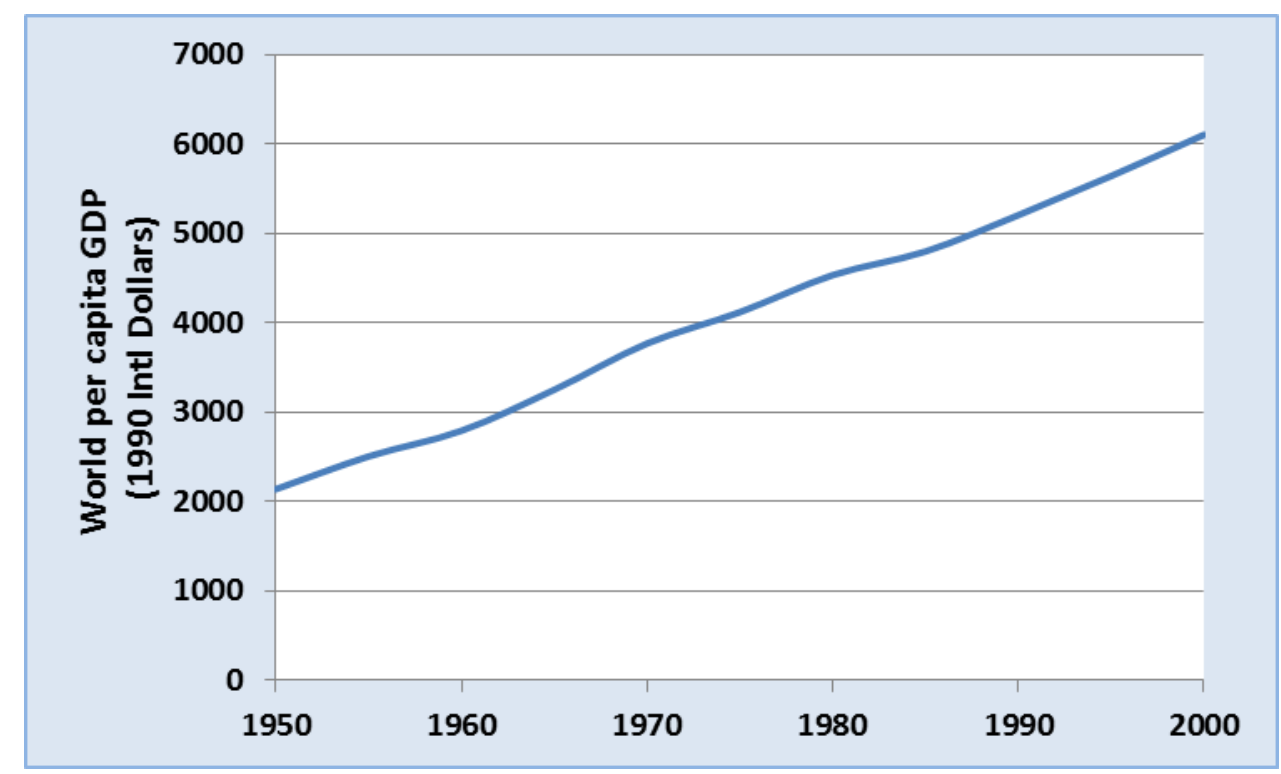

These characteristics of human capital prompted Harlan Cleveland, former President of the World Academy of Art and Science, to observe that "the only limits... are the limits to imagination and creativity" [18]. They led Aurelio Peccei, founder of the Club of Rome, to argue that human capital is the most underutilized of all forms of capital [19]. Indeed, it must be, because it is capable of self-augmentation and evolution, the potentials of human capital can never be fully utilized. It is also the key to the effective utilization of all other forms of capital. Human choice is the basic mechanism for liberating and productively harnessing the potential energy in society.

\section{Evolution of Human Capital}

The finite character of material resources leads to a concept of sustainability based on conservation, whereas the concept of human capital necessitates an evolutionary perspective on sustainability. Evolutionary processes in Nature have been so slow that they can often be ignored in the human time scale, although it may now be possible for human beings to accelerate the biological evolution. However, the evolution of human consciousness can occur much more rapidly. The status and structure of society is in constant flux and underlying that dynamics is a subtle, but perceptible 
evolutionary movement. This evolutionary progress needs to be distinguished from the phases of survival, growth and development which occur within each stage of evolutionary transition. Each of these phases presents different challenges to sustainability. The phase of survival is static and conservative. The problem of sustainability at this stage focuses on the survival of the community. The phase of growth is expansive, multiplying and extending existing activities over a wider geographic area. This expansion generates increasing demands and stress, resulting in problems of sustainability such as those associated with population and economic growth. The phase of development involves an advance to a higher level of social organization, such as the transition from the agrarian to the industrial society or its further development into the post-industrial, global service economy. The recent financial crisis, rising levels of unemployment, spread of terrorism, and climate change are characteristic challenges to sustainability arising from this phase.

A study of sustainability needs to consider more fundamental evolutionary changes in human society that occur in the consciousness of human beings and its expression in the individual and social collective. Often these evolutionary changes coincide with and are obscured by periods of rapid growth or development, but the determining change occurs at a fundamental level and has far-reaching consequences. Survival requires social energy to maintain the status quo. Growth requires social energy concentrated as a force for expansion. Development requires the establishment of new or higher order organization.

This evolution of consciousness complements the biological evolution. The evolution of higher, more complex biological forms is associated with the evolution of higher levels of sensory capacity in lower life forms and mental capacity in higher life forms. Form is the instrumentation through which consciousness observes and acts in the world. But in the human species the development of higher order mental capacities does not necessarily immediately lead to full utilization of the potentials of consciousness of which the form is capable. The evolution of human consciousness has necessitated the progressive development of other instruments (social forms) such as language, family, education, mathematics, etc., which make possible the acquisition and transmission of knowledge and skills, more intimate, cooperative relationships among individuals, the conscious organization of social activities, scientific discovery, technological innovation, recorded history of the past, planning for the future, bonds of relationship and association based on shared goals, beliefs and cultural values, symbolic thinking, logic, pure ideas and ideals. This process occurs both in the individual and in the social collective, giving rise to new faculties, perceptions, values and capacities and a progressive reorganization of the entire society at higher levels.

Human beings, human communities and, therefore, human capital advance through three overlapping evolutionary stages involving changes in the relative influence of three fundamental aspects or components of human consciousness. The Indian philosopher Sri Aurobindo termed these three components physical, vital and mental (the term 'vital' is used in this context to connote the intense life energy and dynamism that arise from relationships between people and the social activities and interactions that arise from those relationships) [20]. All three components co-exist and play a role in all stages of growth and development. The intensity of each and their relative predominance create a series of overlapping stages, rather than clearly demarcated steps. Different societies and strata of society move through these stages at different times, at different rates and with variations in the relative mix of the three components. Yet despite these differences, three distinct stages can be 
discerned in the development of every society and in the overall development of the human community. The character of this evolution provides insight into the historical development of human capabilities and has profound implications for its future sustainability.

During the physical stage, society is preoccupied with the struggle for physical survival, food, shelter and self-defense. Family, village and tribe are the primary units. "Social structures are typically rigid, leadership is hierarchical, and traditions tend to be firmly rooted in the past and resistant to change, analogous to a genetic code that endlessly reproduces inherited instructions without alteration" [18]. During this phase, land is the primary productive resource. Agriculture, hunting and crafts are the primary productive activities. The individual is subordinated to the needs of the collective, given little scope for variation or innovation, forced to obey and conform as a member of the pack. The maturation of the physical stage occurs when the physical organization of society develops to the point where the increasing productivity of physical resources generates surplus produce, energy and wealth. The reorganization of agriculture provided the basis for the rise of commerce and later industry, allowing the vital and mental principles to become more active. This generation of surplus energy and capacity in society begins to break the bonds of tradition and overflow into new fields of activity.

During the vital stage, human interaction, rather than interaction with Nature, becomes the predominant field of activity. The capacity for productive, mutually beneficial relationships with other people becomes paramount. Markets develop to support a vast expansion of trade. Commerce replaces agriculture as the main source of wealth. Money replaces land as the most precious and productive resource. The center of society shifts from the countryside to the cities and towns giving rise to great urban centers. The merchant class wrests power from the hereditary rulers. New types of social organization proliferate. Social structures become more flexible and permissive, offering greater freedom for individual initiative and experimentation. Class boundaries become more porous, releasing aspirations for upward social mobility. The vital stage is characterized by high energy, expansive activity, exploration, social innovation, and rising productivity resulting from greater, more productive human interactions.

Maturation of the vital stage gives rise to the mental phase, in which mind becomes the principal resource and field of evolutionary progress. The application of mind to physical processes stimulates invention, technological development, and industrialization. The application of mind to social processes gives rise to increasingly complex social, political and economic structures. Political systems become more democratic and participative. Economic systems become more flexible and inclusive. Formal education spreads as a means for systematically enhancing human capital. Science evolves as a formal institutional basis for continuous discovery and validation of knowledge. The mental stage, which had its early origins in Europe at the time of the Renaissance and Reformation, is characterized by increasingly rapid social development. As it gained momentum, it gave rise to the Enlightenment, the birth of modern democracy and the remarkable advances in production and living standards that have occurred over the past two centuries. Duane Elgin and Coleen LeDrew describe this evolutionary progression in these terms. "A new global culture and consciousness have taken root and are beginning to grow in the world. This represents a shift in consciousness as distinct and momentous as that which occurred in the transition from the agricultural era to the industrial era roughly three 
hundred years ago...the most distinctive feature of this emerging era is not technological change, but a change in human consciousness" [21].

Each of these stages places emphasis on a different type of resource. During the physical stage, land is the most important resource. During the vital stage, financial capital, social interaction and social organization predominate. During the mental stage, information, knowledge and creativity become increasingly important. Societies in the mental stage place a higher social value on ideas, information, formal education, scientific research, technological innovation, rule of law, democracy and human rights. "Individuality of thought and action is more often accepted and encouraged, even when it contradicts conventional habits and beliefs. Competition tends to mature into cooperation ... Productivity soars, surpluses abound - partly because information, unlike natural resources, expands as it is used and gives rise not to exchange transactions but to sharing arrangements in a new kind of commons. The excess energy pours into the development of ever newer, more complex forms of organization-technological organization of material processes, social organization of life processes, mental organization of information, knowledge, even intuition and wisdom" [18]. Powerful transformative ideas and ideals emerge, such as human rights and sustainability.

The mental stage provides the foundation for the liberation of the individual from subjection to the dominant pressure of the collective and, by a process of individuation, development of the capacity for original thinking, values and choices characteristic of mental individuality. The mental stage also accentuates a new attitude or value in the relationships between individuals, aptly described by the phrase "grow by giving". Giving is the characteristic principle of the mental stage. Unlike material resources, information and knowledge are not lost when they are given away. Knowledge multiplies by exchange. This is the principle behind the success of Internet-based businesses such as Facebook, Google and Yahoo, which attract visitors by giving away useful information or services and convert that traffic into profit. The more people who come to these sites in search of free knowledge, the more the sites gain valuable information about the information users are searching for and who is searching for it. Information begets more information. Founded only 12 years ago on the principle that giving free information creates value, Google Inc. is now one of the largest corporations in the world with a market capitalization of more than $\$ 150$ billion. Knowledge begets more knowledge. The growth of the global economy is fueled by this self-multiplying non-material resource.

No society strictly falls within any one stage. The stages overlap. Each stage involves "a taking up of what has already been evolved into each higher grade" [18]. Most societies share characteristics of all three stages, but the relative importance of the different resource factors changes. Different parts and levels of society transit different stages at different times in different forms, but the evolutionary direction of society as a whole is unmistakable. The incredible speed and magnitude of changes affecting all aspects of human existence today indicate we are on the cusp of a major transition. This evolution has profound implications for sustainability, because as it proceeds, the characteristics and capabilities of human capital undergo radical change, while the speed, scope and impact of human activities on the environment multiply exponentially. 


\section{Human Evolution and Sustainability}

Various authors distinguish between strong and weak sustainability [22-25]. Strong sustainability requires that both natural and human-made capital have to be maintained, while weak sustainability holds that utility of the sum of all capitals has to be maintained for future generations. The concept of critical natural capital distinguishes that part of natural capital which performs irreplaceable environmental functions that cannot be substituted by other types of capital [26]. Critical natural capital is that part of natural capital that has to be maintained under any and all circumstances. Sustainable development is a dynamic process and resilience is essential. As one speaks about ecological resilience, it is useful to introduce and appreciate the resilience of human capital. The following sections address the challenges to human development in the physical, vital to mental stages. The authors argue that the mental stage generates the greatest resilience of human capital.

As society evolves, the challenge of sustainability changes. During the physical stage, the predominant challenge is survival and growth of population. Shortages of food severely restrict the size of population. Before the advent of agriculture about 10,000 years ago, the entire population of humanity probably did not exceed 10 million. Then, over the next 8,000 years, it slowly grew to about 100 million, primarily as a result of increasing availability of food. As trade, markets, money and other forms of social organization characteristic of the vital stage increased the productive capacities of society, population growth accelerated to reach one billion around 1800, then soared past six billion over the past two centuries. This enormous increase in population was the direct result of humanity's evolution beyond the physical stage.

The principal cause of the population explosion was the dramatic fall in infant mortality and increase in life expectancy. Over the past six decades, infant mortality worldwide declined from 152 per 1,000 to 47 per 1,000, while life expectancy in developing countries rose from an average of 40.9 years to 63 years [27]. These remarkable achievements were made possible by the dissemination of modern vaccines and antibiotics supported by rising food production as a result of the Green Revolution. That is, advances in science and technology and improvements in social organization, both characteristic of the mental stage, dramatically increased the carrying capacity of the earth and human civilization. Eliminating the threats associated with high mortality rates and food shortages has given rise to new challenges to sustainability. Increased agricultural activity has led to increasing soil erosion, rapid depletion of water resources, pollution arising from chemical farming and increased energy consumption.

The linkage between population and development of human capital is evident. Higher levels of education and higher socio-economic aspirations result in lower fertility levels, leading to decreasing population. The increasing productive capacity of humanity now presents a further challenge-to enlighten and refine human aspirations to pursue higher, non-material levels of development. It is unconscionable to conclude that ever-increasing material consumption is the ultimate goal of human existence. Education is the principal means for overcoming this challenge. Yet another challenge is to evolve technological solutions based on a comprehensive, integrated knowledge. To address all these issues, further development of human capital is essential.

Population came to be considered the world's most serious problem in the $1970 \mathrm{~s}$, because the quantitative increase in numbers placed an increasing burden on the physical environment and 
undermined efforts to raise living standards in developing countries. Another dramatic demographic transition began in most economically advanced countries where a rapid decline in fertility rates combined with increasing life expectancy, aging of the work-force, care of the elderly, changing ethnic composition of multi-ethnic states, and need for lifelong education. The solution to the population 'problem' necessitates concerted efforts to enhance the quality of human capital $[28,29]$.

Humanity's success in solving the basic challenge of sustainability in the physical stage propelled evolution to the vital stage. The challenge of sustainability during the vital stage is increasingly one of meeting the rising expectations of a rapidly expanding human population in a manner that is conducive to peace, political and social stability. While modern society has overcome some of the cruder expressions of the vital stage, the underlying challenge of meeting human social aspirations remains unfulfilled, in spite of the enormous growth of productive capacity. Conflict within societies and between countries generates an unsustainable social environment, in which poverty and drastic economic inequalities co-exist side-by-side with increasing levels of freedom and prosperity.

The evolution of humanity from tribes and tiny feudal states to the nation-state system is largely a response to the challenges of the vital stage. Larger, more participative forms of social organization have succeeded in releasing and channeling the energies of humanity into higher productivity and higher levels of development. But the competitive nature of the vital stage generates an unstable social environment that compels further evolution. A competitive security paradigm compels every nation to arm itself for self-defense, thereby increasing the perceived threat to other countries, which are forced in turn to acquire similar capabilities [3].

Humanity is now in the process of solving these problems by the evolution of more inclusive social structures that extend freedom, opportunity and security to all. Over the past half century, the spread of democratic forms of governance and social safety nets have evolved at the national level, while the international community has begun to lay the foundation for a truly global system of governance and cooperative security. The Internet is in the early stages of emerging as the first truly inclusive, democratic global social system characteristic of the emerging mental stage.

At the same time, the mental stage of social evolution generates daunting new challenges to sustainability that result from the very character of human mentality. Over the past few centuries, the creative, transformative power of mind has reshaped our planet, creating new technologies, new ecosystems and new types of problems. Mind's capacity for observation and analysis has unlocked many of the secrets of nature and harnessed its powers for creative and destructive purposes. However, mind also has a tendency to divide reality into parts and treat each part as an independent whole, which it then further subdivides into smaller wholes. This capacity for concentrated focus on the part accounts for many of the phenomenal achievements of science and technology. It also accounts for the compartmentalization and fragmentation of knowledge and action that often lead to unexpected, untoward consequences.

The problem of sustainability has now evolved to the stage where it endangers not only human life but threatens to undermine the natural capital on which human civilization is based. A solution to the problem necessitates further social evolution. The challenge is not merely to control or curtail human activity. At its root it is about altering the way people perceive the world around them and think about solving problems. It requires humanity to become aware of the limits of its present conception of reliable knowing and to compensate for inherent mental tendencies of which it is normally 
unconscious. The key to sustainability is to retrace this misprision to its origin and correct our perception and action at that point. Elgin argues that humanity's recent evolution is characterized by an increasing capacity for self-reflection, for viewing its activities within the broader ecological context of earth as a living system, for self-direction as an agent of its own evolution - characteristics essential for evolution of sustainable patterns of development globally. This concurs with the view of Sri Aurobindo a century ago, who emphasized the need for further evolution to transcend the divisive aspects of the egoistic, mental consciousness. Thus, a confluence of eastern and western thought is emerging that arrives from different starting points at a similar conclusion.

\section{Sustainability of Human Capital}

The development of human capital over time is a function of the quantity and quality of human capital (which includes all forms of social capital as well-denoted here by $\Psi$ ), natural capital (e.g., ecosystem, air, water - denoted by $\Phi_{\mathrm{N}}$ ) and human-made capital (e.g., money, infrastructure, building, roads - denoted by $\Phi_{\mathrm{hm}}$ ) and their evolution. Though resources exist outside and independent of human beings, they are recognized as resources only by human beings. Knowledge is a resource that exists only within human beings. Human capital, natural and human-made capital are interconnected.

Improving healthcare, education and employment augments human capital in a way that is proportional to the human capital $(\lambda \Psi)$. Equally, improving socio-economic and political conditions and facilitating and stimulating creativity, as emphasized above, augment human capital even more than proportionally $\left(\mu \Psi^{\mathrm{a}}\right)$. Inadequate healthcare, inadequate education and low employment rates not only decrease $\lambda$, but can make it negative, resulting in exponential destruction of human capital. Similarly socio-economic and political conditions can have beneficial and destructive effects.

In addition there are sudden changes, black swans, labeled $\mathrm{P}$ for those having positive and $\mathrm{D}$ for those having destructive effects. All scientific breakthroughs fall in category $\mathrm{P}$, as do most of technological advances, as well as social-political events such as the end of Cold War and nuclear disarmament. War, any form of violence, injustice, large income inequalities, violation of human rights and terrorism destroy human capital. Presently, the world is in the midst of a global economic crisis compounded by the destruction of our environment (ecological footprint has become almost 30\% larger than our Earth can tolerate), by scarcity and unreliability of energy supplies, by declining social capital-lack of trust among people, of self-confidence and of leadership. These crises are interconnected and interdependent. Each one of these crises and the totality of all of them destroy human capital. All of them are represented by a function D. Nuclear war and climate change can lead to catastrophes or even to an end of civilization, and are also represented by D.

This relationship can be expressed mathematically by Equation (1):

$$
\mathrm{d} \Psi / \mathrm{dt}=\lambda \Psi+\mu \Psi^{\mathrm{a}}+\mathrm{P}-\mathrm{D}+\alpha\left(\mathrm{d} \Phi_{\mathrm{N}} / \mathrm{dt}\right) \Psi+\beta\left(\mathrm{d} \Phi_{\mathrm{hm}} / \mathrm{dt}\right) \Psi+\gamma\left(\Psi, \Phi_{\mathrm{N}}, \Phi_{\mathrm{hm}}\right)
$$

The interdependence among various forms of capital is represented by the last three terms in equation (1). The term $\alpha\left(\mathrm{d} \Phi_{\mathrm{N}} / \mathrm{dt}\right) \Psi$ demonstrates that human capital decreases if natural capital decreases, i.e., if $\left(\mathrm{d} \Phi_{\mathrm{N}} / \mathrm{dt}\right)$ has a large negative value. The term $\beta\left(\mathrm{d} \Phi_{\mathrm{hm}} / \mathrm{dt}\right) \Psi$ shows that human capital also decreases if human-made capital decreases, e.g., as a result of destructive human activity such as war. The complex interdependence of all forms of capital is shown by the last term $\gamma\left(\Psi, \Phi_{\mathrm{N}}, \Phi_{\mathrm{hm}}\right)$. 
$\lambda, \mu, \mathrm{P}, \mathrm{D}, \alpha, \beta$ and $\gamma$ are time dependent. Equation (1) is fairly complex.

Sustainable development is development that meets the needs of the present generation without compromising the ability of the future generations to meet their needs [30]. That means that human capital increases over time, i.e., $(\mathrm{d} \Psi / \mathrm{dt})$ is positive.

Although adequate means for measurement of human capital are yet to be developed, there is ample evidence to demonstrate that the productivity of human capital has substantially increased over the last two centuries. This suggests that the first two terms in Equation (1) are positive and that positive black swans (P) more than outweighed the destructive ones (D). Since the ecological footprint is increasing, the term $d \Phi_{N} / d t$ is becoming negative and that, of course, can cause a decrease in the productivity of human capital as well as the human capital itself.

This attempt at quantitative discussion of human capital is impeded by the inadequacy of existing measures for human capital. All forms of capital are currently usually "measured" by money, and money is not an appropriate measure for human capital.

The self-augmenting character of human capital is dramatically illustrated by the growth of per capita GDP in recent centuries. In spite of a 22-fold rise in world population over the last 1000 years, per capita GDP has grown 13-fold as shown in Figure 2. Since the advent of the Industrial Revolution, both population and per capita GDP have increased six-fold, signifying a 36-fold rise in productive capacity in two centuries, challenging the very notion of scarcity and economic limits.

Figure 2. World Population and Per Capita GDP (PPP) 1000 AD to 2001. Data from [17].

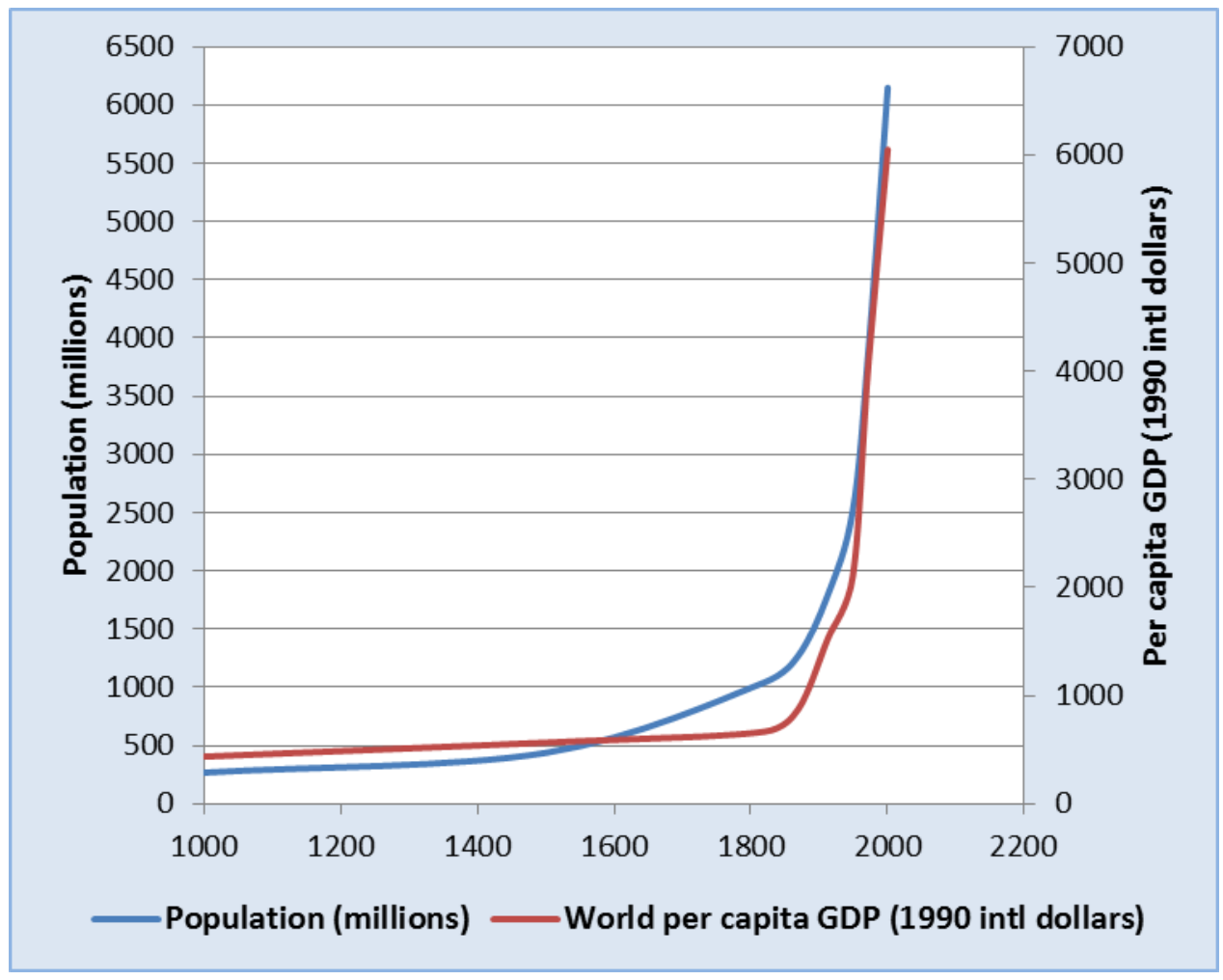

\section{Human Capital and Sustainable Economic Growth}

Research on sustainability focuses largely on the carrying capacity of the environment and the deleterious impact of human activity on it. This paper argues that the development and evolution of 
human capital are the most critical determinants of sustainable development. The evolution of human capital to a more mental stage impacts on sustainability in a variety of ways. It accelerates the process of technological innovations with the capacity to mitigate environmental damage. It spurs the evolution to a less material-resource-intensive, service-based economy. Through an increasing emphasis on higher levels of education, it fosters the emergence of a more informed, socially conscious population capable of understanding and responding to the challenge of sustainability. Further, as Elgin and others argue, it creates conditions favorable to the evolution from a resource-intensive consumer culture to more sustainable cultures that give far greater importance to non-material needs and achievements.

\subsection{From the Industrial Age to Post-Industrial Service Economy}

Throughout history, humanity has suffered from shortages that imposed severe limits on its capacity for survival and enjoyment, justifying economics as a science of scarcity. Then, after millennia of slow, incremental progress, human history embarked on a radical and accelerating departure from previous trends. Technological, organizational and social innovation combined to generate unprecedented levels of economic growth and prosperity, which seemed to abolish the limits to growth. But as human productive capacity increased, it began to confront more fundamental limits to the resource base and carrying capacity of the planet. In the report to the Club of Rome Limits to Growth in 1972, Meadows et al. cited evidence that the earth's carrying capacity imposes strict limits to sustainable growth. The report was written with reference to the high rates of growth, averaging 6\% a year, achieved by most industrialized countries during the period immediately following the Second World War and based on the concept of manufacturing-intensive economic growth.

Little understood at the time, the world was already transiting from traditional manufacturing to a knowledge-intensive service economy in which 'production' and incomes become progressively less dependent on material resources. Perceiving this radical evolutionary transition to what he called the post-capitalist society, Peter Drucker observed, "Every few hundred years in Western history there occurs a sharp transformation. Within a few short decades, society rearranges itself-its worldview, its basic values, its social and political structures, its arts, its key institutions. And the people born then cannot even imagine a world in which their grandparents lived and into which their own parents were born. We are currently living through such a transformation [31].

Fundamental differences between the industrial economy and the post-capitalist service economy have profound implications for both economy and ecology [32]. Manufacturing itself has become largely a service-based field of activity in which research, information technology, financial services, education, healthcare, marketing and other services represent an increasing proportion of 'production' and employment. The service economy now accounts for 77\% of GDP in the U.S., $73 \%$ in the EU and $63.4 \%$ globally.

\subsection{Energy-Intensity and Economic Growth}

The emergence of the post-industrial service economy is in the process of altering the equations concerning resource consumption, forcing us to reexamine basic postulates regarding sustainable economic growth. Services represent a non-material plane of activities to promote human welfare, 
while generating employment and creating money. The term service economy encompasses a very broad range of human activities, including basic research, education, health care, transport, communication, retailing, entertainment and tourism. What they have in common is a relatively lesser dependence on material resources to different degrees. The service economy still functions on the foundation of an industrial economy that requires raw materials, infrastructure, machinery and energy for service delivery, but its dependence on material resources is significantly lower in relation to GDP. Figure 3 shows the declining energy intensity of GDP growth over the last century as technology has become more energy efficient and the service economy has become increasingly predominant.

Figure 3. Decrease in Energy Intensity 1830-2000. Reproduced with permission from [33].

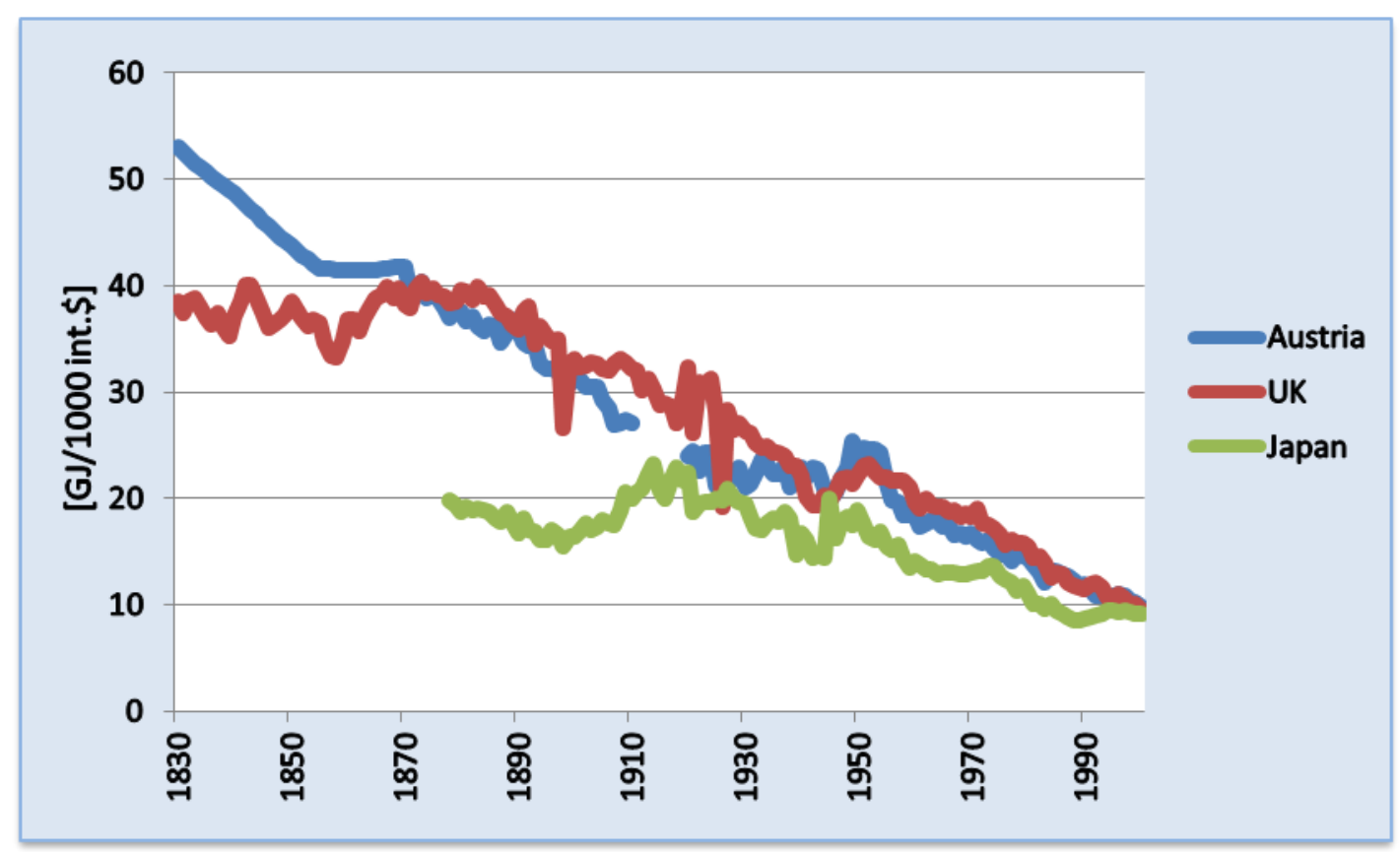

In recent decades, this trend has accelerated. For example, the amount of energy needed to produce a dollar's worth of goods and services in the U.S. and U.K. declined by 40\% from 1980 to 2005 [34]. Between 1980 and 2005 the amount of energy needed to produce a dollar's worth of goods and services declined by $63 \%$ in China, $47 \%$ in Ireland, $40 \%$ in U.S. and U.K. In Japan, which already had very low energy intensity, it fell by another $15 \%$. Energy and sustainability are closely related, because non-renewable fossil fuels remain the primary source of energy of production and the burning of fossil fuels is the main contributor to rising levels of the $\mathrm{CO}_{2}$ in the earth's atmosphere. The substitution of renewable energy sources combined with continued improvements in energy efficiency have dramatically increased fossil fuel energy intensity (FFEI). Figure 4 shows the substantial increase in FFEI (fossil fuel consumption per unit of GDP measured in 1990 international dollars) for 12 OECD countries from 1970 to 2008 , a period normally denoted as the beginning of the era of the post-industrial service economy. It depicts a $64 \%$ decline FFEI in the U.S., $62 \%$ in U.K., 58\% in France, $46 \%$ in Japan. The average decline is $43 \%$. In spite of these gains, the scope for greater global energy efficiency is still considerable. A study by McKinsey in 2008 found that a global effort to boost energy efficiency with existing technologies could eliminate more than $50 \%$ of world energy demand 
by 2020 and that investment in energy productivity across all major sectors generates excellent returns on investment [35].

Figure 4. Fossil Fuel Energy Intensity for Selected Countries 1970-2008. Data from [36].

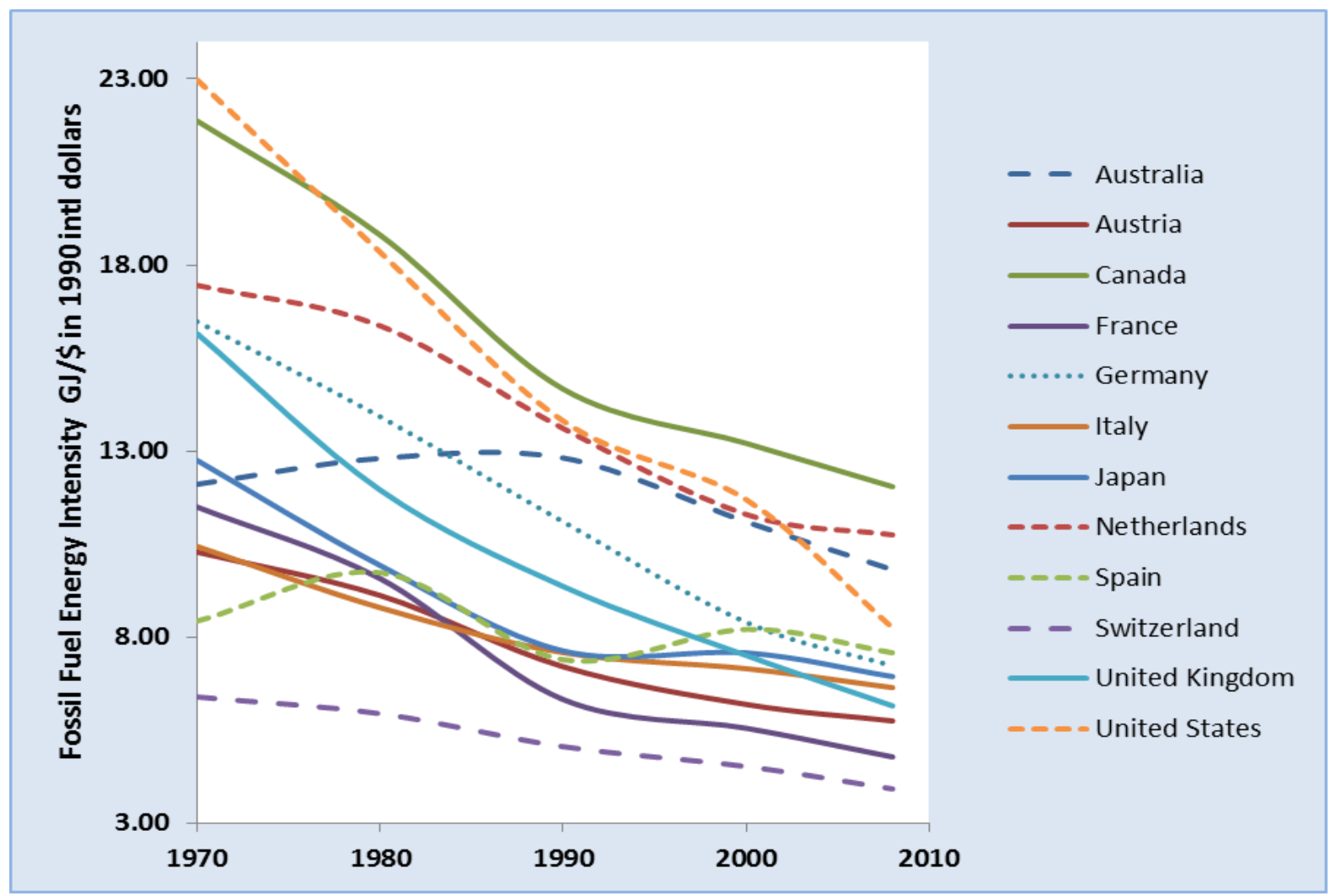

The growing emphasis on education, health and welfare are major elements of the emerging economy, as well as central pillars in the development of human capital. The continued evolution toward a service economy based more on human capital and less on material resources does not mean that the problem of sustainable energy supplies will be solved merely by a shift in the nature of economic activity. On the contrary, advances in technology, greater public awareness and commitment, changes in public policy and changes in culture are all essential. The wholesale shift from manufacturing to services is more apparent in high income countries than in those at an earlier stage of economic development. It has long been assumed that full-scale industrialization is a necessary presage to the modern service economy and, therefore, that reduced energy intensity in the most economically advanced nations would have little impact on rising energy consumption in the developing world. The remarkable progress of countries such as India in developing highly sophisticated IT and financial sectors suggests the possibility that emerging nations may be able to leapfrog from agrarian to post-industrial economies, avoiding at least some of the excessive energy demands of industrialization. The emphasis placed on raising levels of education and increasing research is one crucial determinant of this transition.

Although the service economy requires less energy and material resources consumption than industrial manufacturing economy to generate an equivalent unit of GDP, human energy demand will still continue to rise. The transition from the physical to vital to mental stages has a beneficial impact on energy intensity and other material resource consumption, producing more value with less material 
inputs as well as a greater awareness and capacity for conservation [37]. The sustainability of both human capital and the human environment necessitates a rapid, radical change of consciousness. Thus, the evolution of human capital must be taken into account in any long-term projections and strategies regarding environmental sustainability. Human choice matters. It matters most of all.

\section{Sustainable Livelihoods}

The concept of human capital focuses on the productive and creative capabilities of human beings which can be harnessed to achieve higher and more sustainable levels of human welfare and well-being. In the prevailing economic system of market economies, employment is the principal means by which people express their productive capabilities to acquire the means for their survival and economic welfare. Thus, access to remunerative employment opportunities is a crucial determinant of the productive utilization of human capital. Together with education, employment is a principal means for the development of human capital. The knowledge, skills and values acquired through work experience enhance the capabilities of people for constructive, organized activity that contribute to their own welfare and that of the society. In addition, employment in modern society is also an important source of social identity, acceptance and respect, as well as a source of self-esteem and psychological fulfillment.

\subsection{Employment: The Historical Record}

Conventional wisdom tells that the combination of a population explosion, rapid technological advancement, urbanization and free trade over the past century must inevitably be leading toward a severe imbalance between the supply and demand of work, resulting in higher and higher levels of unemployment globally. The actual facts tell a surprisingly different story, which compels us to re-examine basic assumptions about employment.

Figure 5. Growth of Global Population and Employment 1950 to 2007. Data from [38-41].

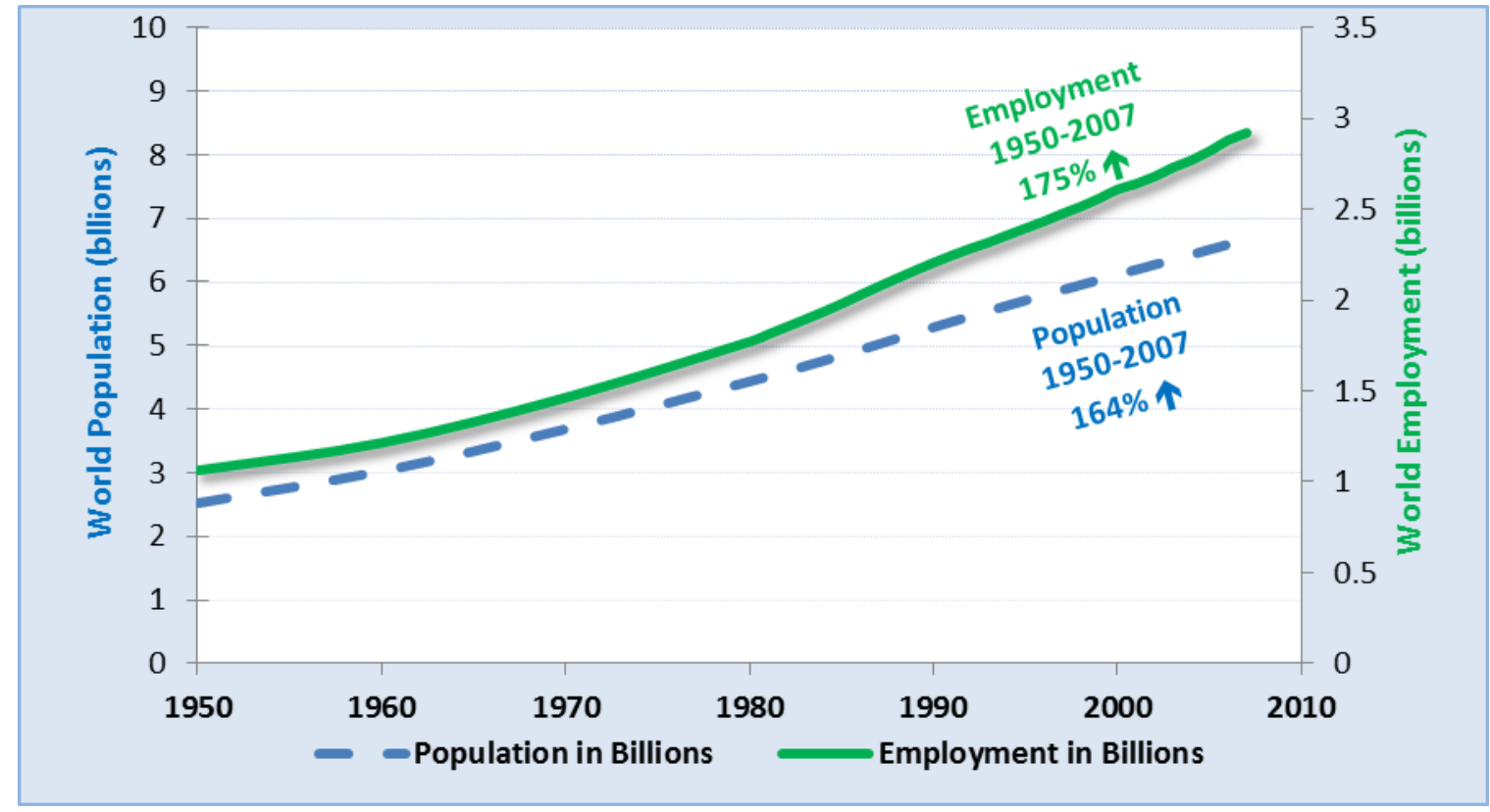


Historically, humanity has done surprisingly well in generating employment opportunities to meet the needs of a rapidly expanding population. Over the past six decades, the world economy has generated nearly two billion jobs, nearly three times as many jobs as during the previous five centuries [38]. Global job creation has been taking place at record rates for the past six decades. Figure 5 depicts growth in global population and employment since 1950. Between 1950 and 2007, global population increased by $164 \%$ from 2.53 billion to 6.67 billion, whereas total global employment rose $175 \%$ from 1.06 billion to 2.92 billion. From 1996 to 2007, global population increased by $16 \%$, while total global employment grew 17\% [42]. The world added approximately 400 million more people, yet the global employment to population ratio (age 15+) remained virtually constant, as shown in Figure 6.

Figure 6. Global Employment and Employment-Population Growth 1996-2007. Data from [43].

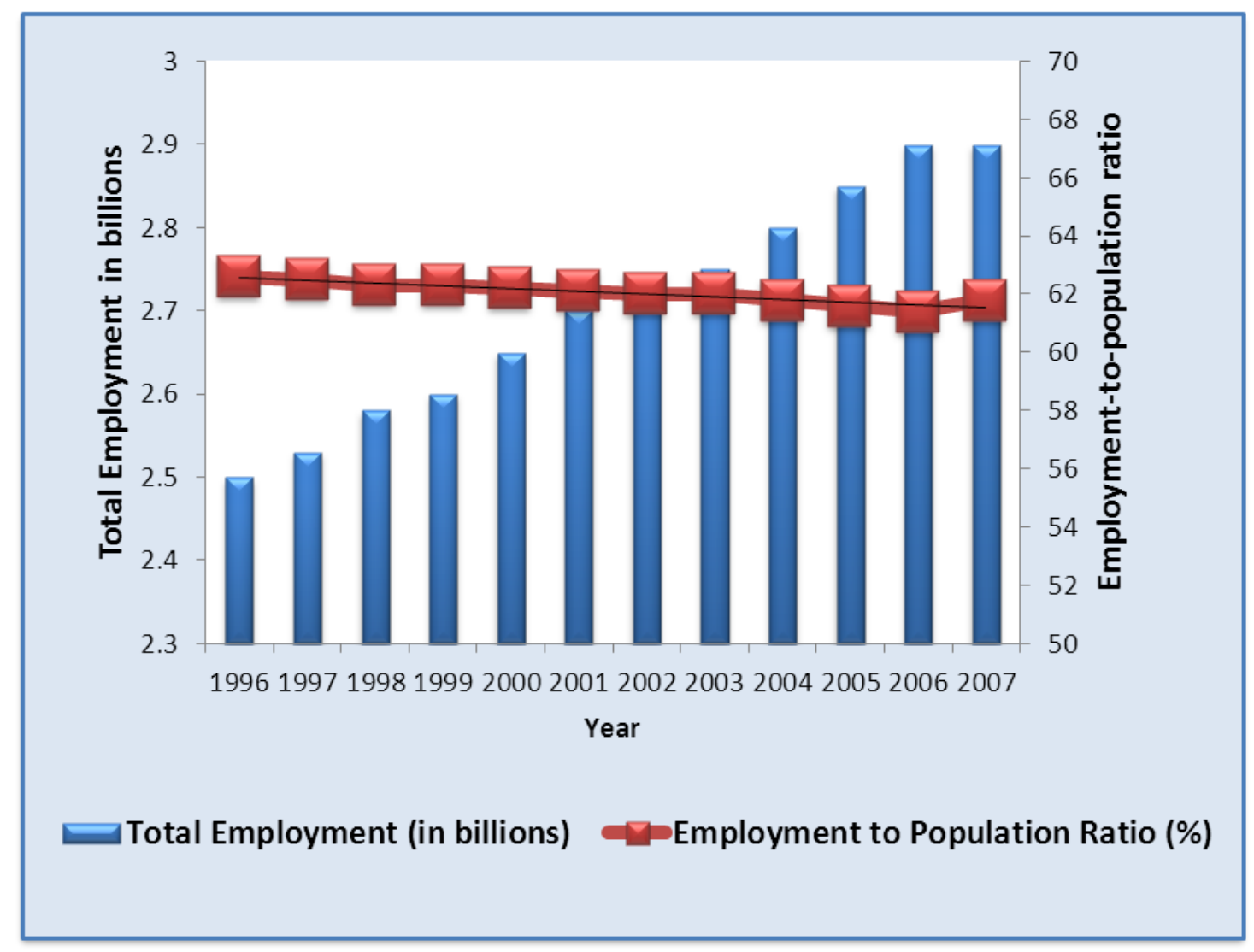

\subsection{Transformation of Work and Economy}

The remarkable expansion of employment opportunities since 1950 is itself the result of a more fundamental social transformation that has radically altered the nature of work and economy over the past two centuries and is now shaping the future of work. Employment as we know it today is a relatively recent concept, the result of a multidimensional transformation that began in Europe at the beginning of the 19th century. Table 1 depicts important dimensions of that transformation. 
Table 1. Transformation of Society and Work.

\begin{tabular}{|c|c|}
\hline 1800 & 2010 \\
\hline - World population 978 million & - World population 6.9 billion \\
\hline - $3 \%$ urban population & - $49 \%$ urban population \\
\hline - Life expectancy 29 years & - Life expectancy 67 years \\
\hline - Land-based work & - People and society-based work \\
\hline - Manual labor & - Mechanized and automated work \\
\hline - $85 \%$ of global workforce engaged in agriculture & $\begin{array}{l}\text { - } 33.5 \% \text { of the global workforce is engaged in } \\
\text { agriculture, } 5 \% \text { in OECD, } 2 \% \text { in U.K. and U.S. }\end{array}$ \\
\hline - World trade was $3 \%$ of global GDP & World trade is now $27 \%$ of global GDP \\
\hline
\end{tabular}

Individually and in combination these changes have had a profound impact on the nature of work. A near seven-fold increase in population has necessitated an enormous expansion in work opportunities in order to absorb new entrants to the work force. At the same time work has migrated along with people from rural to urban areas. As agricultural productivity has risen, a declining percentage of the population is engaged in agriculture and entirely new fields of employment have been generated in industry and services concentrated in cities. This was made possible by the mechanization of agriculture. Mechanization spurred the Industrial Revolution, as automation and computerization are now transforming manufacturing and many types of services. Over this period, and especially after 1990, world trade has grown enormously, facilitating the movement of jobs to lower wage countries. In combination these factors have radically transformed the nature of economy and employment.

As job creation in Europe and North America shifted from agriculture to manufacturing during the latter half of the 19th and first half of the 20th century, since 1950 it has shifted even more dramatically from manufacturing to services in the most economically advanced nations and to a lesser extent even in developing countries. Over the past half century, the share of employment in agriculture worldwide has declined steadily from $67 \%$ in 1950 to $34 \%$ in 2008 as shown in Figure 7 [44,45]. Meanwhile employment in the industrial sector expanded its share of employment from $15 \%$ in 1950 to $20 \%$ in 1990 , reaching $23 \%$ in 2008 . The service sector, in contrast, has grown steadily in share of jobs since 1950, when it accounted for $18 \%$ of total employment globally, growing to $31 \%$ in 1990 and reaching 43\% in 2008 [45]. In the US, employment in the service sector rose from 53\% of total jobs in 1956 to $70 \%$ in 1977 and $81 \%$ in 2009, accounting for virtually all U.S. job growth since 1972. Services now are the source of $77 \%$ of all jobs in the U.K. and France, $71 \%$ for all OECD countries, 69\% in EU-27, 69\% in Japan and Korea, 33\% in China, and 31\% in India. Services also account for $77 \%$ of GDP in U.S., $73 \%$ in EU, $70 \%$ in OECD countries and $68 \%$ globally. 
Figure 7. Worldwide Employment by Sector: 1950-2008. Data from [46].

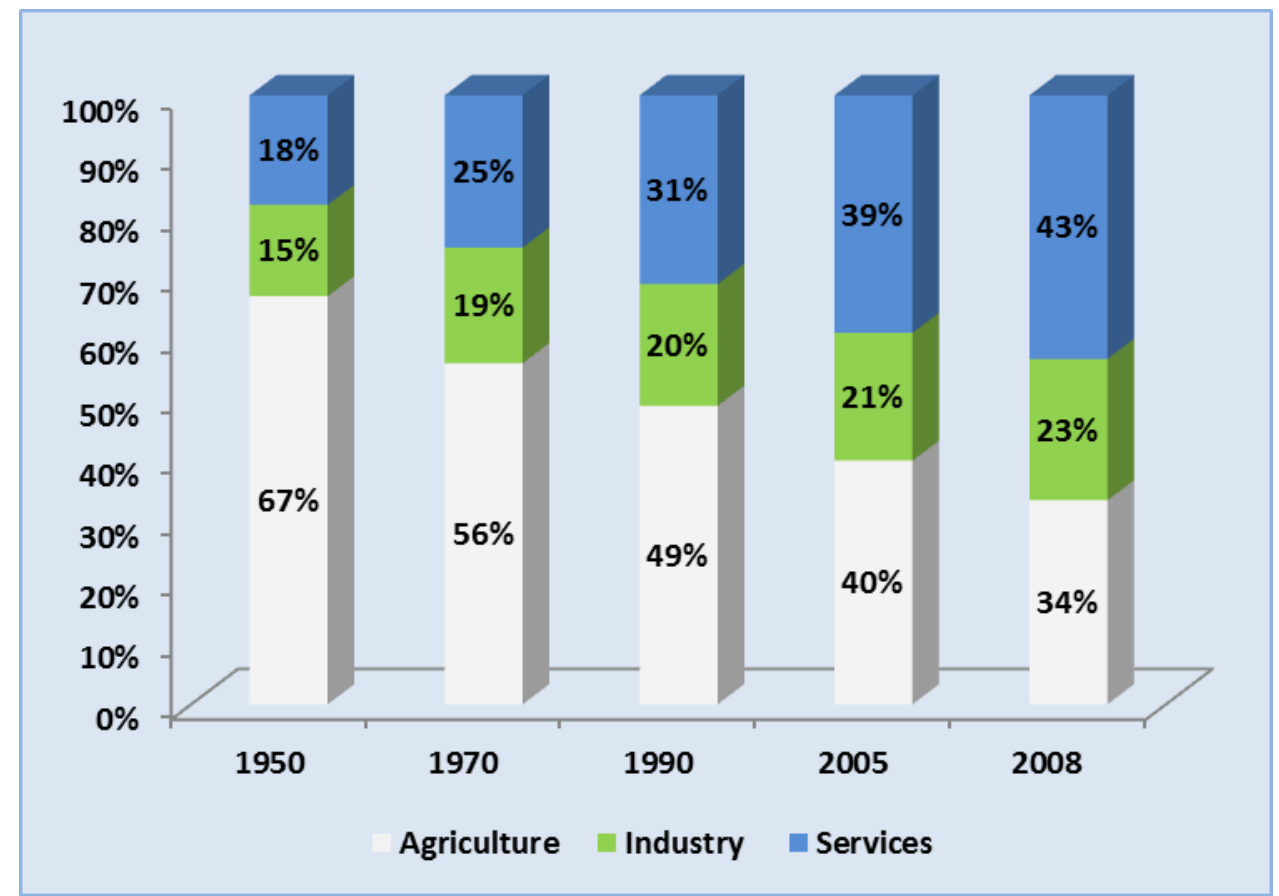

The recent trend in growth of service sector employment is likely to continue indefinitely. Contrary to common conception this trend does not represent a shift from higher skill manufacturing to low skilled, low-wage service jobs. A recent study by the US Bureau of Labor Statistics projects that during the period 2008-2018, 65\% of new jobs created in the fastest growing occupational categories will be those requiring medium to high levels of skill and education and $57 \%$ of all new jobs will be for workers with those qualifications, such as nurses, bookkeepers and accountants, teachers, management analysts and physicians.

\subsection{The Challenge of Full Employment}

In spite of the remarkable expansion of employment opportunities in recent decades, 212 million people globally were classified as unemployed by the International Labor Organization (ILO) in 2010 [45]. Real unemployment rates in many countries are probably at least twice the official figures, since unemployment data in many countries is notably unreliable and does not take into account those who have given up seeking work. These numbers also fail to take into account involuntary underemployment, which affects at least one billion workers globally.

The problem of unemployment and underemployment is closely linked to the problem of poverty. Unemployment relates to the productive utilization of human resources. Poverty relates to the economic welfare and well-being of human beings. Poverty itself is a relative, value-laden term, therefore measurement must always be somewhat arbitrary. Figure 8 depicts changes in the poverty levels of the world's population from 1981 to 2005 on five different measures. By all measures, there has been a substantial reduction in the percentage of the world living in poverty, much of it accounted for by dramatic improvements in China due to its huge population and high rates of economic growth. 
Figure 8. Poverty Levels over time. Left panel shows poverty levels of the world's population, and right panel shows poverty levels excluding China. Data from [47].

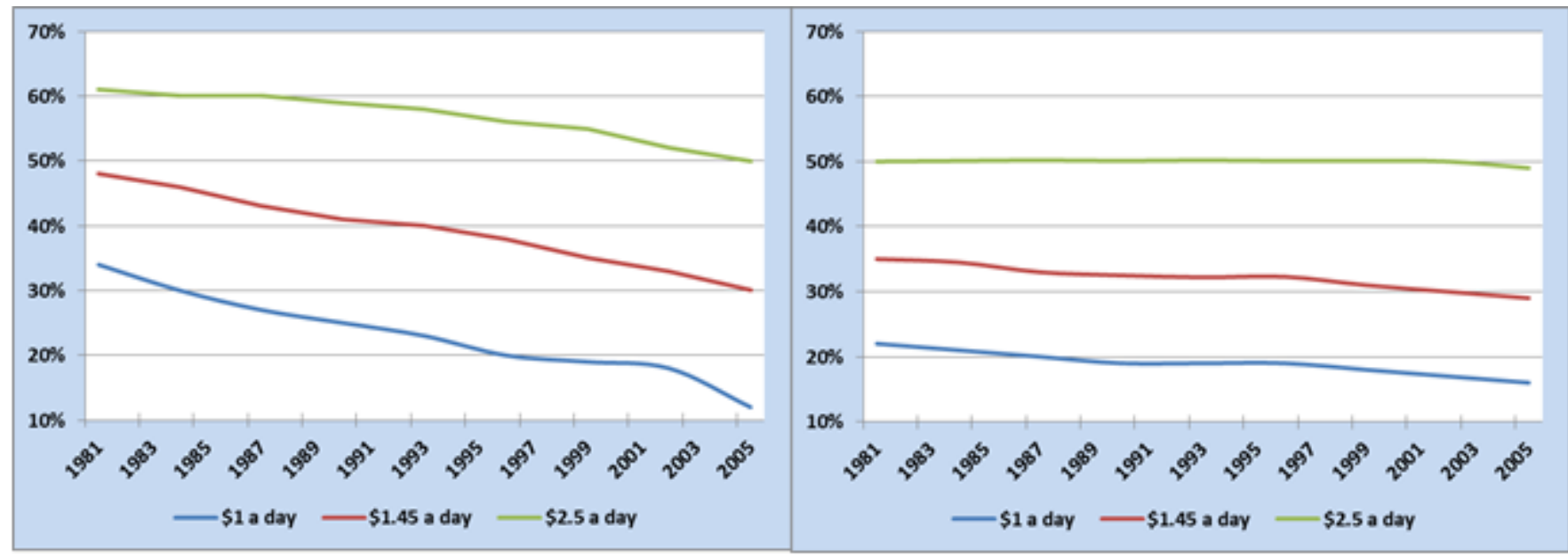

Nevertheless, these gains still leave more than three billion people living on incomes of less than $\$ 2.50$ a day, struggling to meet even their minimum economic needs, most of them unemployed or underemployed. World unemployment rose from $7 \%$ just prior to the recent financial crisis to $10 \%$ in mid-2010, although most of the increase was concentrated in high income OECD countries. Asian Development Bank estimates that Asia alone is home to nearly 500 million unemployed and underemployed [48]. Even in economically advanced nations, huge numbers of people-especially youth - are unable to find remunerative employment. Randall Wray estimates that the actual level of unemployment and underemployment in the U.S. is approximately $17.5 \%$ of the work force, representing some 25 million people [49]. Similar conditions persist in most OECD countries. Especially troubling is the high youth unemployment rate, which is presently $13 \%$ globally and much higher in many countries, e.g., around 35\% in Poland, Croatia and Slovakia, 30\% in Italy and Greece, $20-25 \%$ in France and Spain.

Today employment is the greatest challenge to the sustainability of human capital, and full employment is the only effective remedy. Figure 9 depicts growth of the working age population in G20 countries, including India and China, as projected by ILO in mid-2010. The working age population of these nations will increase by 440 million during the period 2010-2020. Of this increase, $30 \%$ will occur in India, whose working age population is just peaking. India needs to create about 135 million new employment opportunities in the coming decade just to absorb new entrants to the work force. To put this number in perspective, a study by the International Commission on Peace and Food in 1991 estimated that India would need to generate 100 million new employment opportunities during the 1990s in order to achieve full employment and proposed a strategy to achieve it which was adopted as official government policy, though only partially implemented [3]. While official employment and unemployment figures in India and most developing countries are unreliable, evidence suggests that the Indian economy did in fact generate sufficient jobs to prevent a swelling of unemployment during that period. Since then, India's economic growth rate has risen significantly and is projected to be even higher in the coming decade. 
Figure 9. Working age population in G20 countries, including India and China in mid-2010. Data from [50].

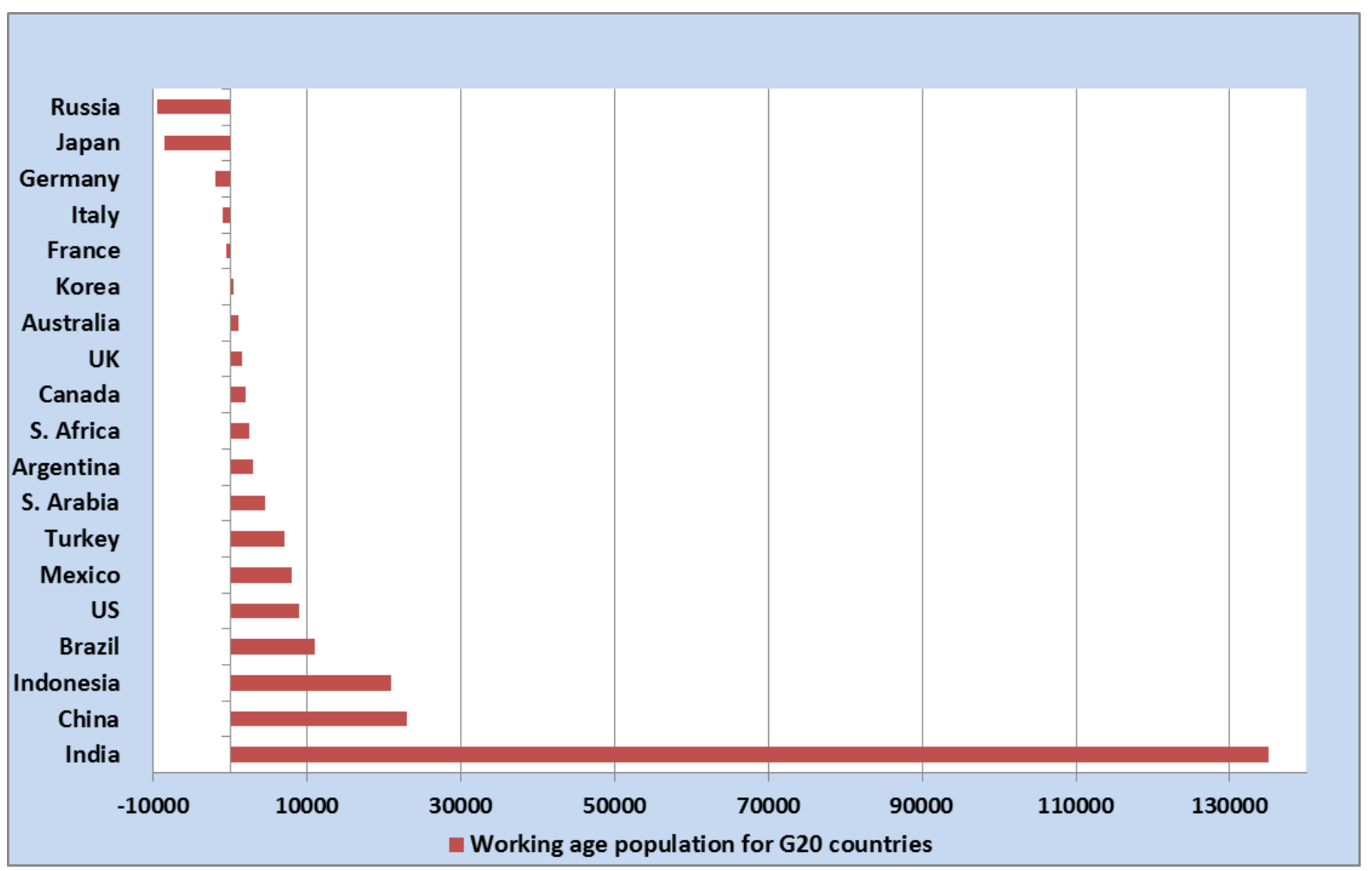

\subsection{Demographics of Full Employment}

The world is now in the early stages of another demographic revolution that is the result of a steep and steady decline in the birth rate and an increase in life-expectancy in the more economically-advanced countries. Figure 9 above also shows that the working age population will level off or decline in a number of G20 countries, reflecting a trend that is broadly applicable to Western Europe in general. Figure 10 shows that life expectancy in Western Europe rose from 46 years in 1900 to 67 years in 1950 and then to 80.3 years in 2010, while the birth rate declined from 30.8 per 1000 population, in 1900 to 17.3 in 1950 and then to 10 in 2010 . Following the same trend, the fertility rate in these countries has fallen from 4.1 in around 1900 to 2.4 in 1950 and then to 1.6 in 2010 [27,51].

These trends will have enormous impact on the future of employment. Under Eurostat's moderate scenario, the EU's labor force is expected to shrink by about $0.2 \%$ a year between 2000 and 2030 [52]. By 2030 there will be 110 million people over the age of 65 in the EU-25, up from 71 million in 2000. This means that the old age dependency ratio - the percentage of people aged 65 and above compared to the number of people aged 15-64-will increase from $23 \%$ in 2000 to $35 \%$ in 2025 and $45 \%$ to $50 \%$ in 2050 [53]. As the old age population grows, the working age population will shrink. By 2030 the working age population in the EU-25 will stand at 280 million compared to 303 million today. The EU-25 would lose an average of one million workers a year [54]. The proportion of OECD countries' population above age 65 is likely to increase from $13 \%$ in 2000 to $25.7 \%$ in 2050. Globally, the $65+$ population is projected to increase from 6.9 in 2000 to 16.2 in 2050 [55]. Obviously, as health and life expectancy increase, there is no sound rationale for limiting the working age to 15-64 [56]. 
Figure 10. Birth Rate and Life Expectancy in Western Europe 1900-2007. Data from [17,51].

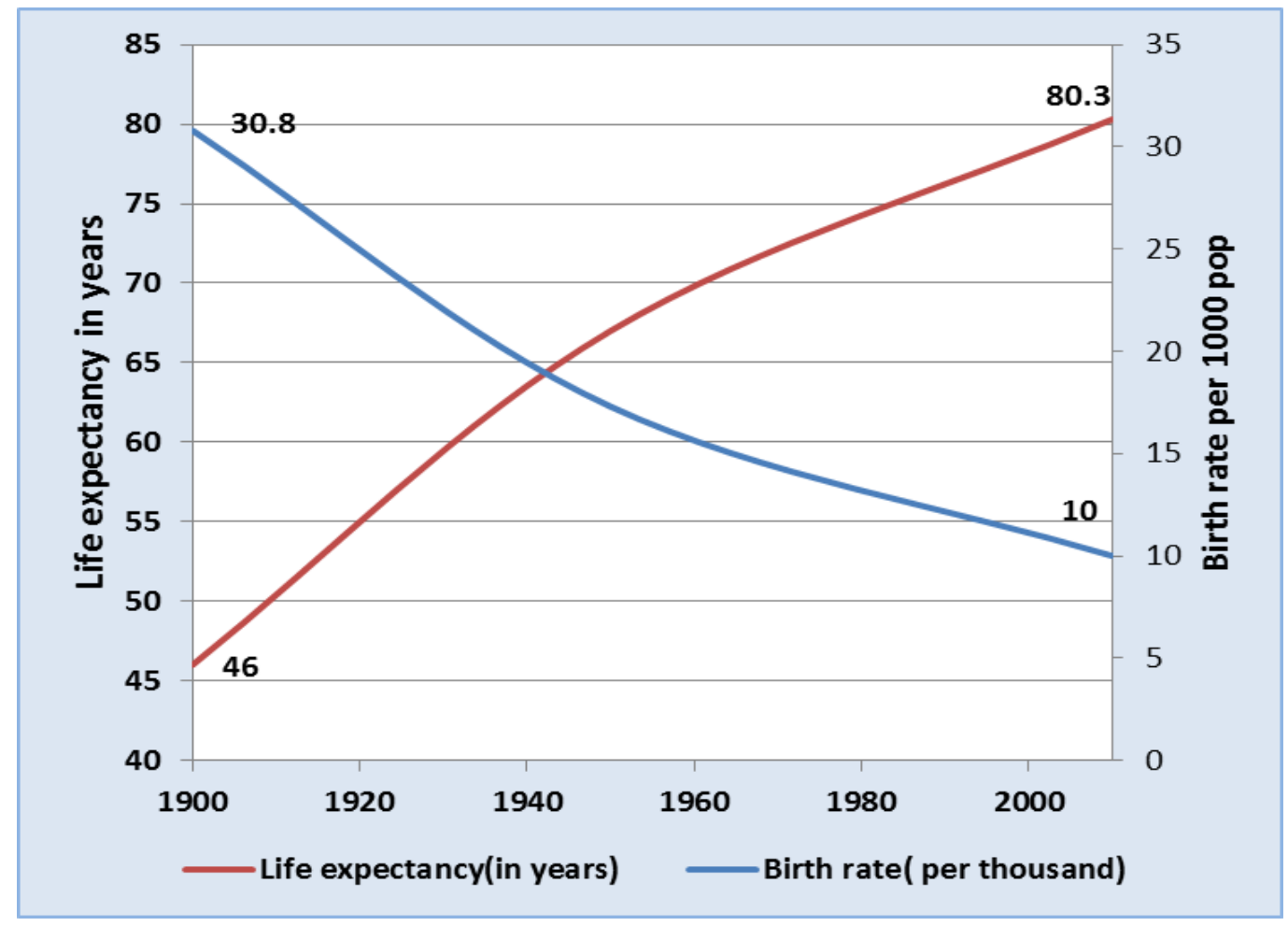

Table 2 shows the U.N.'s moderate scenario projections for growth in working age population by region from 2010 to 2050. This scenario projects an increase in the global workforce of 931 million or $21 \%$ from 2010 to 2030, 28\% lower than the increase from 1990 to 2010. Growth is positive in all regions other than Europe up to 2030, but it declines from 26\% to 8\% in North America and from 29\% to $1 \%$ in China. For 2030 to 2050, the projected increase in working age population declines dramatically to just over 400 million. Growth is $-11 \%$ in China, 2\% in Asia as a whole and under 10\% in all regions except Africa.

Table 2. Projected Change in Working Age Population 2010-2050. Data from [27].

\begin{tabular}{lccccccc}
\hline Region (in millions) & $\mathbf{1 9 9 0}$ & $\mathbf{2 0 1 0}$ & $\mathbf{1 9 9 0}-\mathbf{2 0 1 0}$ & $\mathbf{2 0 3 0}$ & $\mathbf{2 0 1 0}-\mathbf{2 0 3 0}$ & $\mathbf{2 0 5 0}$ & $\mathbf{2 0 3 0 - 2 0 5 0}$ \\
\hline Europe & 481 & 501 & $4 \%$ & 453 & $-10 \%$ & 398 & $-12 \%$ \\
L. America and C. & 261 & 385 & $48 \%$ & 463 & $20 \%$ & 463 & $0 \%$ \\
Africa & 334 & 582 & $74 \%$ & 937 & $61 \%$ & 1,311 & $40 \%$ \\
Asia & 1,950 & 2,797 & $43 \%$ & 3,318 & $19 \%$ & 3,388 & $2 \%$ \\
India & 503 & 781 & $55 \%$ & 1,022 & $31 \%$ & 1,098 & $7 \%$ \\
China & 755 & 973 & $29 \%$ & 983 & $1 \%$ & 870 & $-11 \%$ \\
North America & 187 & 236 & $26 \%$ & 255 & $8 \%$ & 274 & $7 \%$ \\
World & 3,230 & 4,524 & $40 \%$ & 5,455 & $21 \%$ & 5,866 & $8 \%$ \\
\hline
\end{tabular}

A UN study released in 2001 estimated that Europe would have to accept 161 million new immigrants over the period 2005-2050 in order to maintain present levels of working and tax-paying population [57]. A World Bank Study estimated that 68 million immigrants will be needed to meet labor requirements during the period from 2003-2050 [58]. These estimates may be challenged, but 
there is no doubt that, unless major policy initiatives are taken, the net result will be a dramatic decline in the relative size of the working age population in Europe and a shortage of workers to fill the available jobs [59].

Recognition of this fact is already prompting major policy shifts within the EU, which has adopted a goal of raising the employment rate within the region from $69 \%$ to $75 \%$ of those aged $20-64$ by 2020 [60]. It has also spurred efforts to increase participation of women in the workforce. The overall female employment rate for the EU-15 rose from $51 \%$ in 1991 to $64.7 \%$ in 2000 [46]. But employment rates remain around $20 \%$ points lower for women than for men in the EU-15 and the gap is around $25 \%$ points in Greece, Spain and Italy. Denmark, Finland, Norway and Sweden are the only nations that have a gender gap of less than 10 percentage points [61].

The UN study also estimated that Japan would need to admit 647,000 immigrants annually for the next 50 years in order to maintain the size of its working population at the 2000 level [62]. By 2013, labor-force growth in the United States will be zero. The US is forecast to have a shortage of 17 million working age people by 2020 . China will be short 10 million workers. India is expected to have a surplus of 47 million workers in 2020, but even this surplus may prove illusory [63]. Reliable data on employment growth in India is confined to the formal sector which represents less than $10 \%$ of total jobs.

The actual impact of demographic changes on working age population and employment over the next few decades may yet be influenced by technological developments, public policies regarding migration, and outsourcing, as well as unanticipated events, as the rise in unemployment in OECD countries as a consequence of the recent financial crisis demonstrates. Nevertheless, the broad trends indicate a growing shortage of workers in the most economically advanced nations, which will act as a counter-weight to the increasing number of working age youth in developing countries. Both historical trends and future projections support the view that full employment is an achievable goal.

\subsection{Right to Employment}

Economy is a social organization created by human beings to meet human needs and human welfare. A few centuries ago the vast majority of the world's population lived on the land and eked out a subsistence level existence by their own physical labor. Society has become so structured and economy so specialized that today the vast majority of human beings are dependent on employment outside the home for their survival and welfare [64]. Government policies, laws and regulations permeate virtually every aspect of modern economic and social life, effectively determining what types of activity can and cannot be carried out and thereby directly or indirectly determining the number and type of employment opportunities available to the population. Principles of justice necessitate that a government which controls economic activity must ensure conditions that support the basic economic rights of all its citizens.

The responsibility of government to ensure employment was a basic premise of the New Deal in U.S. during the 1930s. The US Employment Act of 1946 and similar legislation in Canada, U.K. and Australia acknowledge that responsibility. Articles 23 and 24 of the Universal Declaration of Human Rights (1948) affirm the right to work, free choice of employment, just and favorable working conditions and protection against unemployment. These in turn served as the foundation for the 
development of two human rights treaties in the 1960s concerned with civil, political rights, economic, cultural and social rights, which together are generally regarded as an International Bill of Human Rights. These culminated in the ILO's "Declaration of Fundamental Principles and Rights at Work" in 1998. In its report to the UN in 1994, ICPF argued that a firm commitment of governments to uphold this right is essential in order to generate the political will required to achieve full-employment: "Without access to jobs, people lack the ability to ensure their own survival and support in modern society. As government has assured the right to education-indeed, compels it - it can and must also ensure the right of every person to gainful employment. Our very concept of the rights of the individual and the responsibilities of the society must undergo radical change. ...employment is an absolute necessity for survival in modern society and must be recognized as a fundamental right of every human being...” [3].

Although the goal of full employment was embraced by all the OECD countries after World War II, in the mid-1990s it was difficult to imagine any country coming forward to seriously implement measures to achieve it. While classical economic theory commonly extols the value of moderate rates of unemployment as a counter to inflation, economists such as Wray argue that the costs of unemployment and the benefits of full employment are so high, that government-funded employment guarantee programs are financially feasible and economically justified. Argentina's Jefes program was a successful example of a temporary job guarantee program introduced to address a crisis. The program generated two million jobs, representing $14 \%$ of the labor force, and helped stabilize the nation's prices, output and currency. Wray argues that similar programs can be effectively applied in other countries as a cost-effective strategy to generate full employment. In 2005, India introduced the National Rural Employment Guarantee Scheme, designed to guarantee 100 days of employment to the poorest families in 50 districts of the country. In spite of the massive expenditure and enormous logistical challenges, the program was so successful that it was subsequently extended to the entire country and now provides 100 days of employment for approximately 45 million workers annually. The success of India's program is being studied by other countries as well as international organizations as a model for possible application elsewhere.

There is no inherent reason to believe that we cannot devise an economic system in which everyone that is willing to work and capable of productive activity is assured of an opportunity and means to do so. As long as human wants go unmet and human resources remain underutilized, there is the possibility of refashioning our economic system to utilize human capital in a more effective, sustainable manner. "There is a great deal of work that is not getting done in the world, work that would raise the other half of humanity to middle class status. Apart from this, humanity has an insatiable appetite for more education at all levels, improved health care, more and better attention to the needs of children and the aged, better community development, more research, new forms of entertainment, infrastructure improvements, etc." [65]. "The notion that there is a fixed or inherently limited number of jobs that can be created by the economy is a fiction. It is not just advances in technology that work in this fashion. Every major advance in social attitudes, institutions, values and lifestyles has a dual effect on employment, creating jobs in some areas and destroying them in others" [3].

Achieving full employment is absolutely essential for the sustainability of human capital. Apart from the possibility of a global level natural calamity or nuclear war, unemployment looms as the 
single greatest threat to sustainable development of human capital. Unlike most natural resources, human resources are perishable and rapidly deteriorate when left unutilized. Job-related knowledge and skills are lost or quickly become outdated. Socially, the long-term unemployed are looked down upon by employers and find it more difficult to find jobs. Psychologically, they lose their self-confidence and self-respect. Employment is not only the principal means for harnessing human potential; it is also the principal means for nourishing, sustaining and developing human capital. High levels of unemployment are directly linked to poverty, social isolation, crime, regional deterioration, health issues, family breakdown, school dropouts, social, political and economic instability, violence, ethnic hostility, and even terrorism. The cost of dealing with these social problems far outweighs the cost of public jobs programs designed to achieve full employment.

\section{Education and Training}

Education is the primary means for the progressive development and sustainability of human capital. More than 40 years ago, Nobel laureate economist Gary Becker highlighted the role of education and training in the development of human capital [6]. The complexity of modern life demands of the ordinary citizen a wide range of knowledge and skills. Knowledge of the plethora of laws affecting ordinary citizens, traffic rules for driving and parking, travel regulations for boarding a plane, skill in using cell phones, TV and computers or accessing the Internet would appear to our ancestors as signs of a genius, a magician or, like Galileo's telescope, deeds of the devil. Education is the single most reliable indicator of family size, because it raises social aspirations and motivates people to direct their energies for qualitative increase in living standards and quality of life. Recent studies identify female education as the main driver for bringing down child mortality, helping to improve the health of all family members and leading to a value change towards lower fertility goals as well as enabling better access to family planning [66].

Education is also the key to sustainable growth and employment. Figure 11 shows cross country studies indicating that an extra year of school is associated with a 30\% increase in per capita income. Throughout the world, higher levels of education are associated with higher levels of employment and higher income. In virtually every country of the world unemployment is significantly higher for those with the least education and lowest for those which have at least completed secondary education. An extra year of schooling increases earnings from 6 to 14\% [67]. 
Figure 11. Years of Schooling and Country GDP. Adapted from [68].

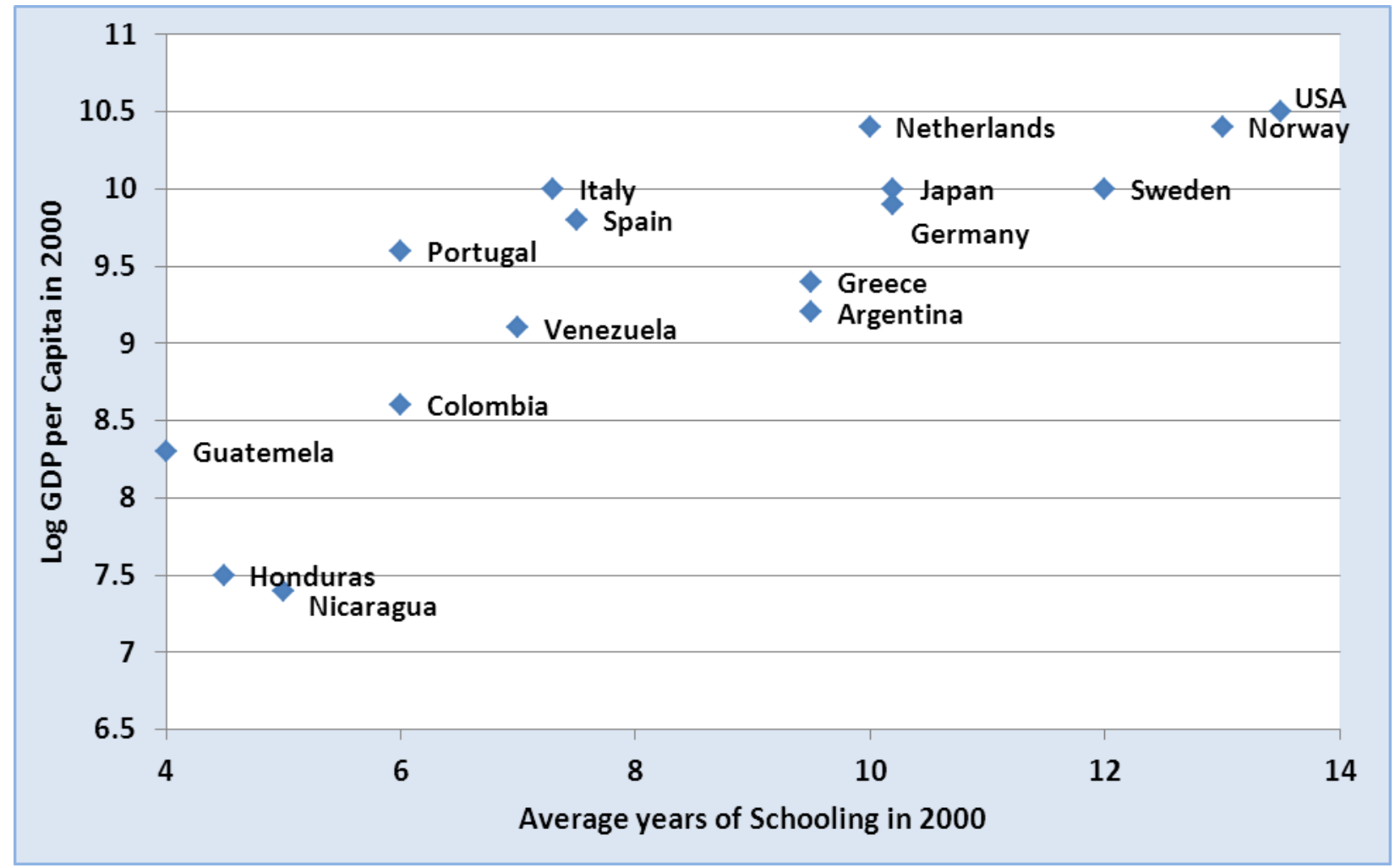

Figure 12 shows a very high correlation between education and per capita GDP in 20 developed and developing countries, as measured by UNDP's composite education index, which takes into account literacy and enrollment at primary, secondary and tertiary levels, and GDP index, which is based on PPP adjusted per capita GDP.

Figure 12. Education vs. per capita GDP (2007). Data from [69].

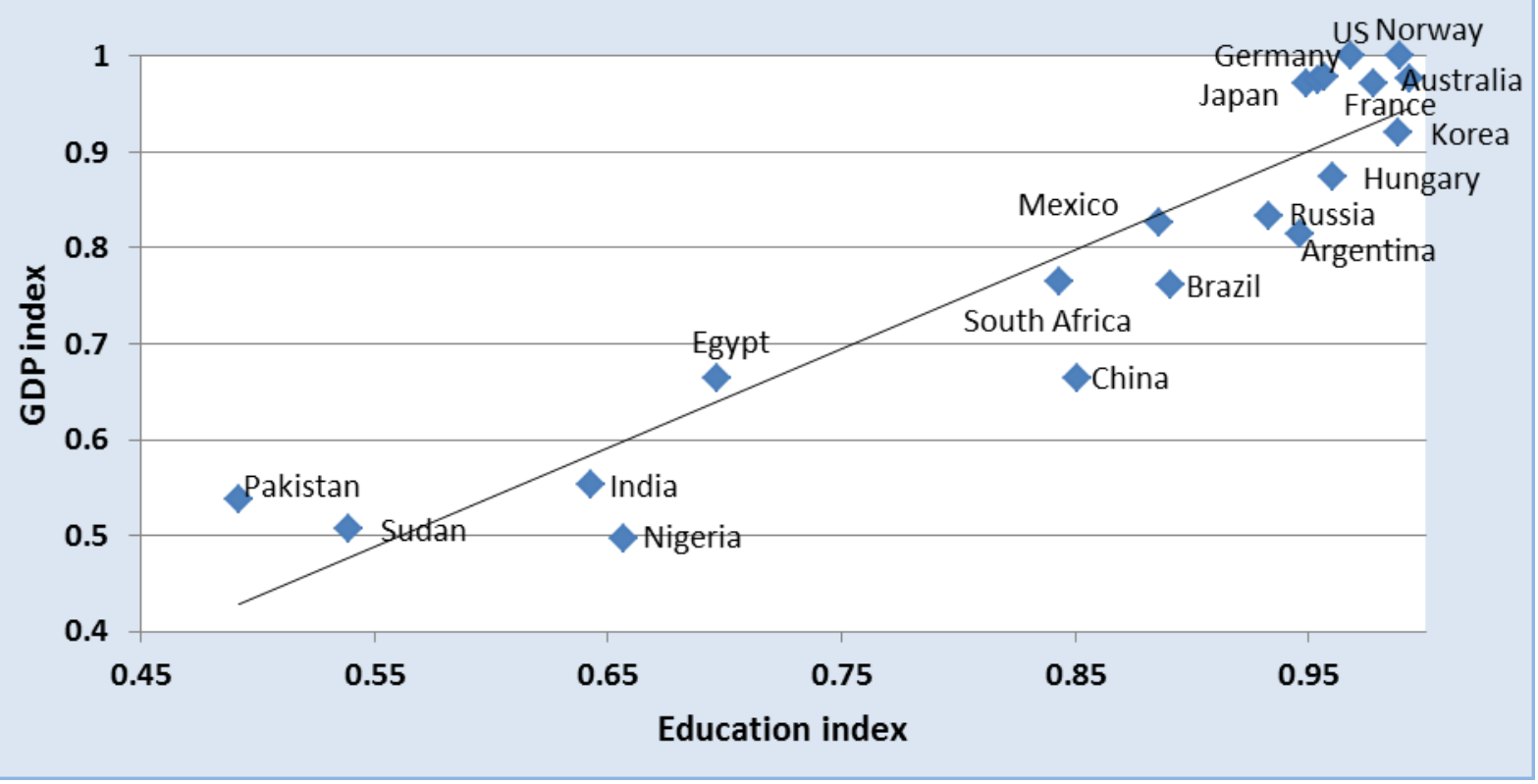


Although the correlation between education and income applies to all levels of education, tertiary education plays an increasingly important role in driving the emergence of the post-industrial service economy. Figures 13 and 14 depict the correlation between rising levels of tertiary enrollment and rising levels of per capita GDP over the past four decades for Korea and India, two countries with vastly different absolute levels of educational and economic development. In both instances the growth rates for higher education are closely correlated with the growth rates for per capita income.

Unemployment rates are closely connected with low levels of education. A study prior to the recent recession in the U.S revealed that those with a high school diploma earned $42 \%$ more and had an unemployment rate $36 \%$ less than those without a high school diploma [70]. In the Czech Republic, $23 \%$ of people who failed to finish secondary school are unemployed, compared to just $2 \%$ of university graduates [71]. University graduates in Norway enjoy a $26 \%$ earnings premium over people who only finished secondary school. In Hungary that figure rises to $117 \%$ [72]. Recent demographic studies confirm that education at all levels is the key driver of economic growth in both high and low income countries [73].

This same difference exists with respect to unemployment levels for skilled and unskilled workers. In the U.S., those aged 19 and under have an unemployment level that is four times higher than those aged 25 and above, who took the time and effort to improve their skills by training. The employment rate for people with low-skills is only $49 \%$ in Europe, compared to $83 \%$ for those with high levels of skill. The differential gap between these two categories of people is 35 points in Belgium, Ireland, Italy, Finland and the U.K. The employment rate for women with low-skills in Europe is only $37 \%$ and in Italy it is as low as $27 \%$.

Figure 13. Growth in Tertiary Enrollment and GDP per capita in Korea 1970 to 2008. Data from $[74,75]$.

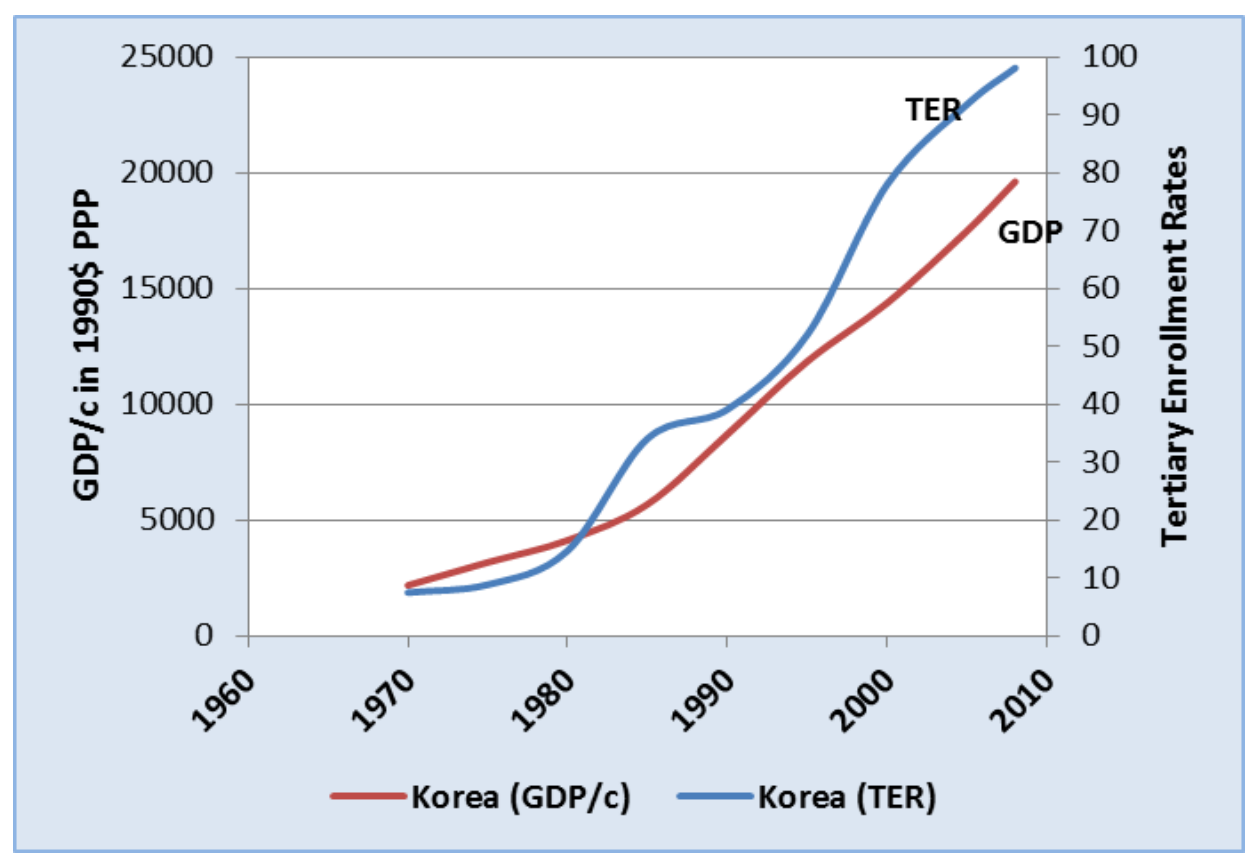


Figure 14. Growth in Tertiary Enrollment and GDP per capita in India 1970 to 2008. Data from $[74,75]$.

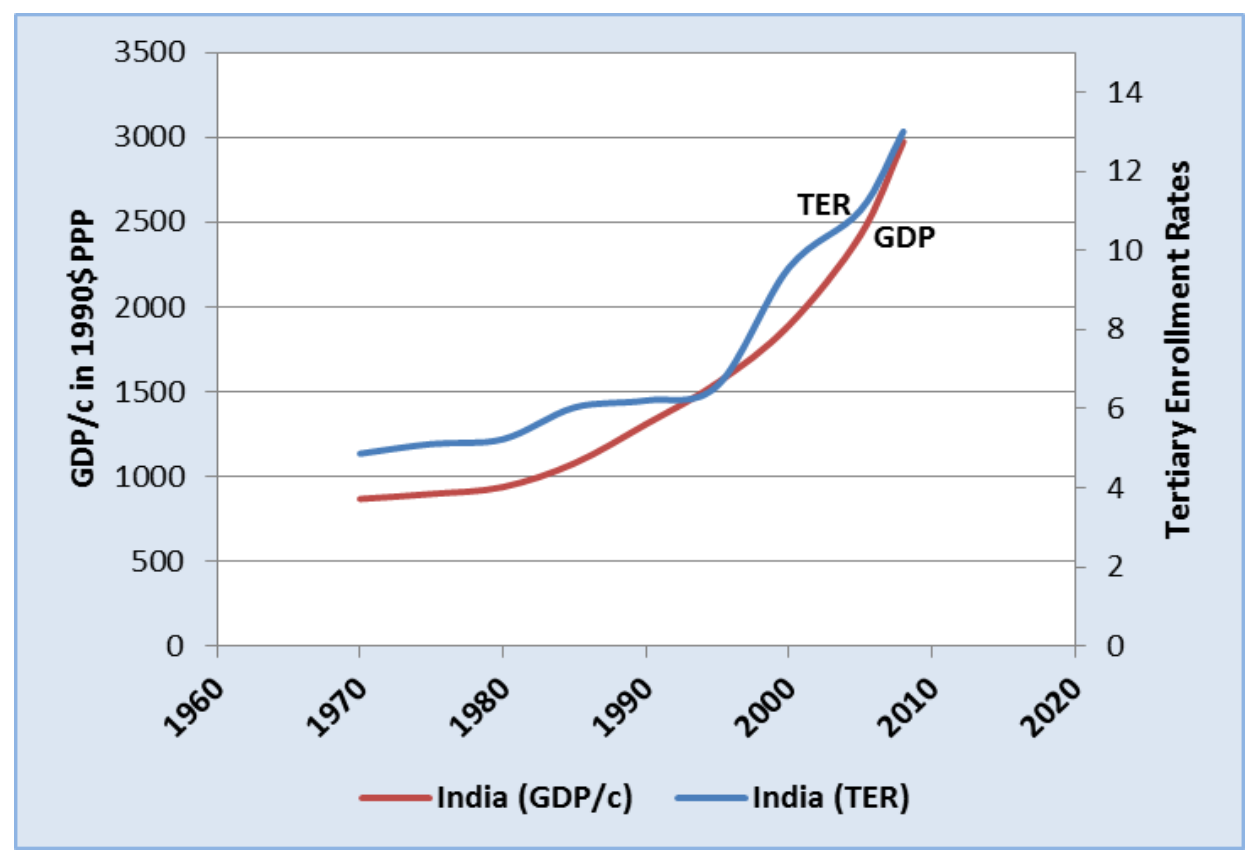

The problem of unemployment co-exists with a massive shortage of employable skills. Studies in OECD and developing countries reveal that high levels of unemployment and a severe shortage of skilled workers commonly exist side-by-side. Nor are skill shortages confined to the high tech industries. In the U.S., high tech industries employ only $5 \%$ of the work force. The skill shortage is also prevalent in basic manufacturing industries, such as the tool and die industry, that many companies are forced to invest in expensive, computer-based machines or outsource the work to overseas suppliers. Plumbers, electricians, masons, carpenters and other skilled craftsmen are also in short supply. By recent count there is a shortage of at least 126,000 nurses in the U.S. By the year 2020, a shortfall of 400,000 nurses and 200,000 doctors is projected [76,77].

The situation in most European countries is similar. A study conducted by International Data Corporation predicted a shortfall of networking skills to the extent of 615,000 personnel in Europe in 2008. Wall Street Journal reported that there were 600,000 unfilled jobs in Germany in 2007, of which 40,000 were jobs for engineers and other skilled people [78]. Another survey revealed that $80 \%$ of small firms in Germany find it very difficult to mobilize the skilled labor force that they require. The Cologne Institute for Business Research (IW) has projected that the labor shortage will reach alarming proportions by the year 2050, as it will be compounded by demographic changes that will shrink the labor force by another 30\% [79].

The developing countries present a similar situation. Though India produces more than 500,000 technical graduates annually, corporations are finding it difficult to recruit sufficient skilled personnel [80]. Here too, the skill shortage spans a wide spectrum of industries and types of jobs. A 2007 study by the Federated Indian Chambers of Commerce and Industry estimated a shortage of 500,000 MDs, one million nurses, and 500,000 engineers. They also projected a shortfall of $80 \%$ for doctorate and post doctorate scientists in biotechnology, 65 to $70 \%$ in food processing, 50 to $80 \%$ in banking and finance, and $25 \%$ for faculty in education. The study also found a severe shortage of top 
pharmaceutical scientists. Shortages also exist for middle-level and junior scientists, factory workers, machine operators, mechanics, carpenters, masons, painters and plumbers [81]. Figure 15 presents the results of global surveys conducted in 2010 by Manpower Inc., one of the world's largest recruiting and employment agencies, showing the percentage of employers reporting difficulties in finding people with the skills needed to fill vacant positions. Employers reporting the most difficulty finding the right people to fill jobs are those in Japan 76\%, Brazil 64\%, Argentina 53\%, Singapore 53\%, and Poland $51 \%$ as shown in Figure 16.

Figure 15. Global Skills Shortage (2010). Adapted from [82].

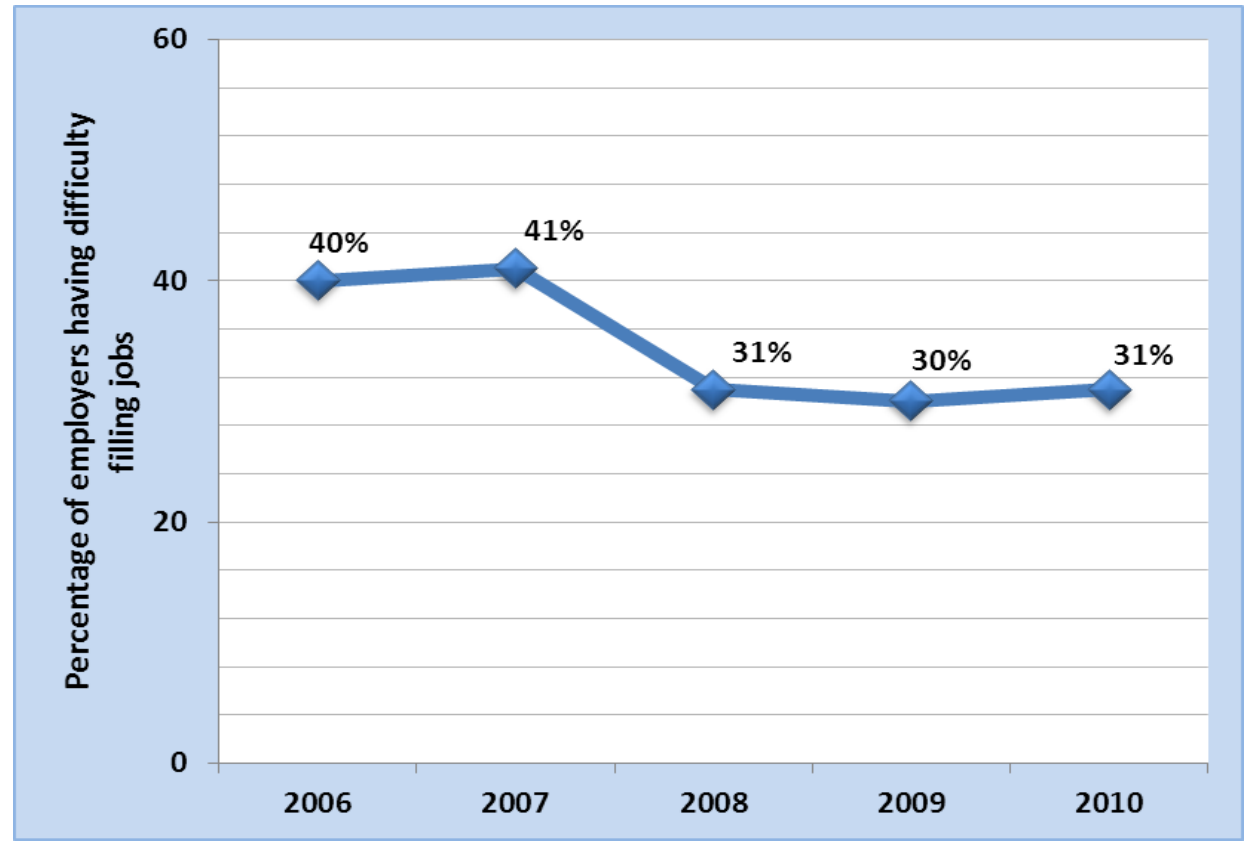

Figure 16. Skills Shortage by Country (2010). Adapted from [82].

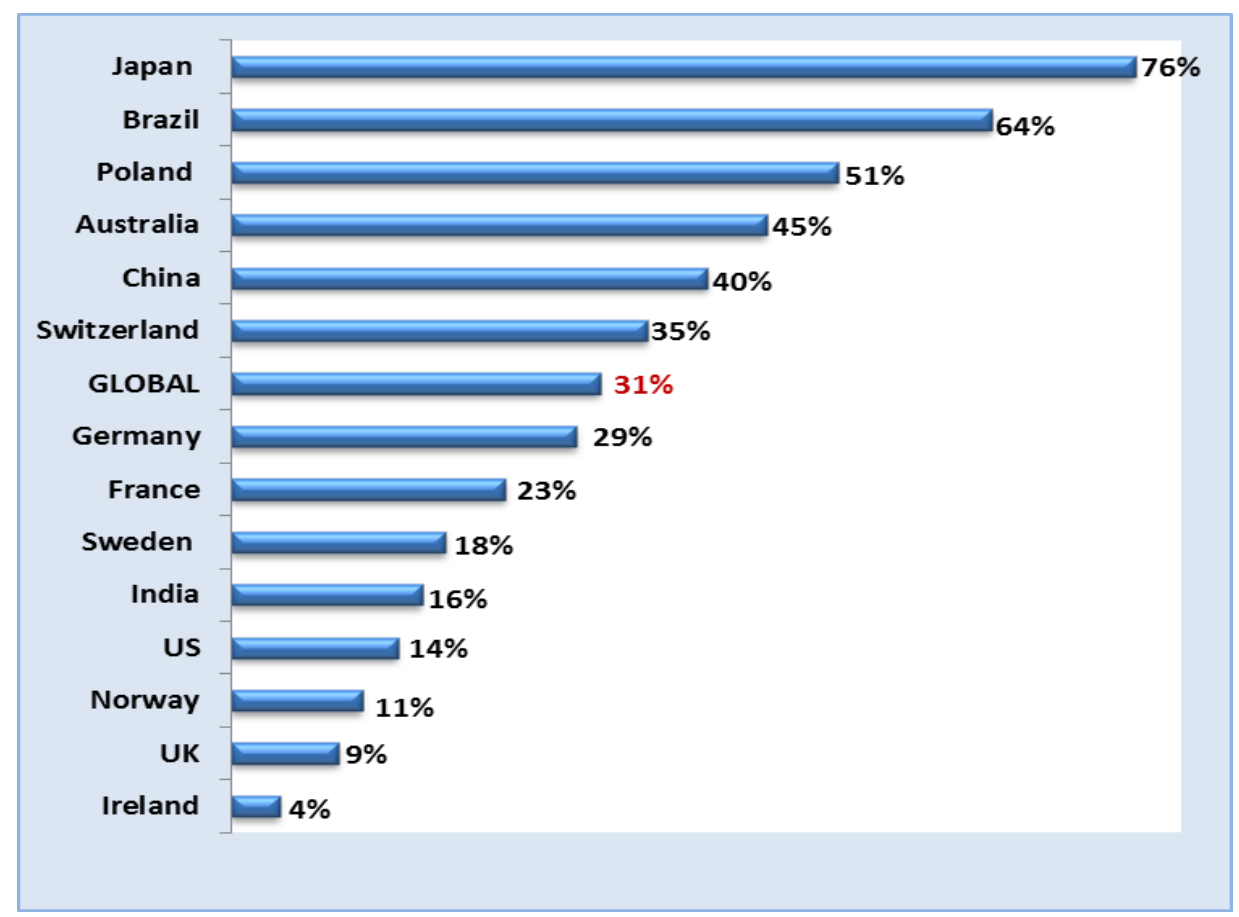


These skill shortages reflect the fact that the rate of social change brought globally far exceeds the rate of human resource development. All evidence points to an ever increasing rate of social change. Therefore, unless a concerted effort is made to consciously accelerate human capital formation, the gap will continue to increase. Left unaltered, this trend would be enough to account for rising levels of unemployment in the midst of unprecedented prosperity.

\subsection{New Delivery System for Higher Education}

Sustainable development of human capital necessitates a radical overhaul of the current systems of education and vocational training. According to UNESCO estimates, global enrollment in universities rose from 500,000 in 1900 to around 100 million in 2000 [83]. Raising global participation rates in higher education to the level prevalent in the U.S. would require the establishment of hundreds of thousands of new colleges and universities and the training of millions of qualified instructors. For India to raise participation rates to the current U.S. level through traditional means, the number of college students would have to rise from 14 million to 81 million, which would require creation of a few thousand new universities and about 100,000 new colleges in India alone.

The brick and mortar system of higher education prevalent throughout the world is a high cost, low-productivity delivery system that places quality education far beyond the means of most of the world's population. Of course, the internet is being used to extend the reach of traditional colleges and universities. In the U.S., which leads the world in on-line higher education, enrollment in fully online courses represents only $11 \%$ of total enrollments. By 2014 , this figure is expected to rise to $20 \%$. Still less than half of all US degree-granting institutions offer fully online courses [84].

Furthermore, these initiatives fail to take maximum advantage of the new technology. The potential now exists for creating a global virtual university capable of engaging the highest quality instructors and educational materials to deliver high quality education at a fraction of the cost of current systems. At a time when major bookstore chains were trying to figure out how to leverage the power of the web as an adjunct and extension of their brick and mortar stores, Amazon started from scratch and built an entirely new, exclusively web-based system designed for optimal reach, lowest cost, ease of use and quality of service. In less than half a decade, this scrappy start-up grew to become the largest bookseller in the world. A similar strategy can dramatically transform secondary and higher education worldwide. While the cost and expertise for producing high quality multi-media instructional materials may be prohibitive for private companies, a global consortium backed by national governments could elevate the quality of education globally to the highest levels now prevailing in the most advanced nations.

There is considerable evidence to support the view that computer based learning can be more effective than traditional classroom learning, with learning and retention rates as much as twice as high. With access to a global storehouse of information at one's fingertips, greater emphasis can be placed on stimulating thinking rather than on mere retention of facts. Multimedia computerized courses can use a mix of written, spoken and graphic materials along with video footage to impart lessons in a manner that cannot be done in a class room. Students can interact with the learning software and receive immediate feedback. Students are able to learn at their own pace. Computer-based learning also reduces the need for experienced teachers. Courses can be designed according to the highest 
possible standards and quality, whereas instructors in classrooms vary enormously in their teaching capacities. Moreover, through internet-based, multi-media courses, the very best instructors in the world for each subject can be made accessible to students everywhere. Computerized course materials can be more readily altered in response to changing requirements than printed textbooks. Uniform testing and evaluation can be done on-line. Even if computer-based learning becomes far more prevalent, the need for teachers and professors will increase by an order of magnitude, since both the number of students and the number of years of education continues to grow. Therefore, there is a need for more teachers and professors. The lifelong and life-wide education presumably implies that the ratio of teachers/professors to population will increase by a factor of 3-4 from the present situation.

\subsection{Vocational Training}

Globally there is an urgent need to expand vocational training facilities and programs across a broad spectrum of industries in order to cope with the rapidly changing demands of the new economy. The need is especially great in the fastest growing developing countries, India and China. Presently some eight million youth enter the Indian job market every year, but only $5 \%$ of Indian youth in the 20-24 age category receive any type of formal vocational training, compared to $28 \%$ in Mexico, 60 to $80 \%$ in most developed countries and $96 \%$ in Korea. The more trained job seekers are, the more readily the market absorbs them. Conversely, the less trained, the more difficult it becomes to get good jobs and the more expensive for employers to impart the required skill levels. Both the market value and the bargaining power of untrained job seekers are far lower. India has 4,200 industrial training institutes which impart vocational training to nearly 600,000 trainees in 43 engineering and 24 nonengineering trades. If all types of professions are included such as agriculture, medicine and law etc., the total number of trainees is 1.7 million per annum. Still this number represents only about $14 \%$ of new recruits to the labor force. The country needs other short training courses that people can take at their own time and at lower costs. Moreover, those already in employment also need training courses to upgrade their skills in tune with developments in their professions. The deficiency in vocational training covers a very broad range, including basic mechanical skills required for repairing machines to skills required for book keeping, insurance, marketing and journalism etc. Recognizing the need to radically expand and improve vocational training, India has recently formed a National Skills Development Corporation to impart skills training to 150 million workers over the next 15 years. The mission of this body is to make sure that by 2022 at least $30 \%$ of the work force is properly trained for employment.

Existing arrangements for vocational training are far from adequate to meet the changing demands of the workplace in both OECD and developing countries. Compare Denmark, for example, where workers receive almost 1,000 hours of non-formal job-related training over the course of their career with Italy where they receive less than 100 hours [85]. The huge size of the global labor force, the complex range of skills required and the high cost of training make it necessary to develop alternate training methods to increase the supply of skills to match the demand.

It is surprising to note that the most obvious solution to the general skills shortage has received very little attention until now - the use of computerized vocational training. It is surprising because computer-based training is already the prevalent means of providing instruction in a wide range of 
software and other computer-related skills. In spite of the fact that flight simulators have been around for decades and recent advances in video game technology make it possible to replicate a wide range of life and work related situations, computer-based vocational training is rarely used for imparting other types of vocational skills. Computerized simulation has been proven an effective training tool even for learning complex vocational skills such as flying an aircraft or handling sophisticated military equipment. This medium will lend itself to a very wide range of skills in such diverse fields as commerce, education, tourism, entertainment, media, language, health, environment and even agriculture. Computerized vocational courses will have world-wide demand. Therefore the cost of developing the courseware can be amortized over a very large number of trainees, reducing the cost of training per worker substantially.

\subsection{Education and Culture}

Science and technology can provide powerful instruments for improving sustainability, but ultimately it is human choices expressed in individual and collective action that will determine the future of our race and life on earth. Lured by profit or mandated by law, the introduction of new technologies can often be done quickly. But altering the pattern of human choices necessitates fundamental changes in the perceptions, understanding, values, attitudes and actions of countless individuals and myriad social organizations at the local, national and international levels. Therefore, issues related to long-term sustainability must be addressed at the fundamental level of our collective human consciousness, which is the basis of culture. Culture represents the quintessence of human learning distilled from the experience of the collective, acquired subconsciously, stored in our racial memory and enshrined in our deepest values, attitudes and perspectives. Changes in behavior can be imposed or occur in response to dramatic events, but cultural change normally occurs over long periods of time as changing circumstances, perceptions and understanding seep down into the fabric of our thought, emotion and relationships with the world around us.

Education is the primary instrument society has evolved that is capable of consciously effectuating changes in culture. Biopolitics International Organization has proposed a new model of universal higher education designed to promote an environmentally conscious society and developed a model syllabus. Of course, change in culture cannot be brought about merely by increasing the amount, expanding the range or altering the content of information and skills imparted to youth. It requires more fundamental changes at the level of individual and social character, which can only be effected by changes in the essential values enshrined in and communicated through our educational system. What is the essential change in culture needed for the long-term sustainable development of human capital and life on earth? What type of educational system is capable of bringing about that change? Elgin argues that global consciousness and culture are already in the midst of a radical transformation, which is reflected in the emergence of a global consciousness as a result of the global communications revolution, greater ecological awareness and concern, a shift toward post-modern social values and a shift toward more sustainable ways of living [21]. 


\subsection{Early Childhood Education}

Regardless of our answer to these questions, one thing is clear. In order to be effective, the change in educational content and method will have to commence at the earliest possible age, for it is in childhood that the most essential values and attitudes are communicated and the basic structure of human character acquires form. Many new approaches to early childhood education have been developed and successfully applied on a pilot scale in the U.S., Europe and elsewhere. The best of them share some common characteristics that are central to the optimal development of human capital. They are founded on a faith in the unlimited potential of the individual human being. They seek to create an environment of freedom in which that potential can naturally emerge.

One successful alternative model was developed by the American educationist Glenn Doman at the Institutes for the Achievement of Human Potential in Philadelphia. Doman has sold millions of books explaining methods for early childhood education that can be applied by parents teaching their children at home or by teachers in the classroom. Doman's methods have been culturally adapted and replicated in such diverse contexts as India, Italy, Japan and Mexico. At Primrose School in Pondicherry, South India, application of his methods in conjunction with computer-based, self-learning techniques has demonstrated that children before the age of six can learn to read two, three or even more languages, acquire a huge fund of general knowledge and develop the capacity for thinking and working independently out of native curiosity and for the sheer enjoyment of the learning process without homework, testing, or any competitive pressure on the students to learn.

Home schooling is another approach which can be very successful for education in families with educated parents, computers, internet and access to quality educational software. After the advent of the internet, home schooling has grown exponentially in the U.S. from 50,000 students in 1985 to about 2.5 million in 2009 and it is still increasing at a rate of 5-12\% annually. Since the mid-1990s, British Columbia has been offering financial incentives for home schooling averaging $\$ 4,000$ per family to subsidize the cost of educational materials. Much more can be done to promote home schooling as an alternative pathway to value-based, family-centered learning.

Education is the most effective means for constructively influencing human perceptions and behavior. Moreover, education, research, public policy and culture are interlinked. Learning fundamental concepts, vocational training, skills development, stimulating innovation and excellent teaching extended throughout our lifespan are imperative for the full sustainable development of human capital and the sustainability of our planet.

\section{Income Inequalities}

Development of science and technology combined with advances in social organization has created a global system capable of meeting the economic needs of the entire world population. But increasing productive capacity has not reduced or eliminated the gross inequalities of power and privilege that characterized earlier periods. Indeed, the disparities have in many cases increased. Income distribution is a crucial factor in the development and sustainability of human capital. Gross and increasing income inequalities are a pronounced characteristic of the modern age. Approximately one billion people living in high income nations, representing $16 \%$ of world population, consume about $75 \%$ of the total 
global product; whereas 1.3 billion living in low income developing countries, representing $20 \%$ of world population, consume only $1.4 \%$ of the world's global product. The average income in the richest 20 countries is now 37 times that in the poorest 20. This ratio has doubled in the past 40 years [47]. The inequalities within countries are also wide and increasing. Figure 17 shows the difference in incomes between the richest and poorest $20 \%$ of the population in a range of economically advanced nations.

Human beings are not equal, and complete equality would result in suffocation of free will and diminish human choices. However, there is strong evidence that large income inequalities severely retard the development and sustainability of human capital. High levels of inequality result in decreasing life expectancy, poorer educational performance, increasing crime rates, higher levels of corruption, and increased macro-economic instability. In 2006, average life expectancy in the $10 \%$ of countries with the lowest of income inequalities was 77.4 years, compared with only 60 years in the $10 \%$ of countries with the highest level of inequality. Wilkinson and Pickett have shown that the incidence of health and social problems is higher in countries with higher levels of inequality in Figure 18. Japan and the Scandinavian countries report very low levels of income inequality combined with the lowest levels of health and social problems. The correlation holds good for all 20 countries shown in the chart. Nor can the variations in health and social problems be accounted for by different absolute levels of per capita income. Countries at the same level of per capita income vary widely in health and social problems. Income inequality is a more accurate predictor of problems than actual level of income [42].

Figure 17. Income inequalities in selected countries. Data from [86].

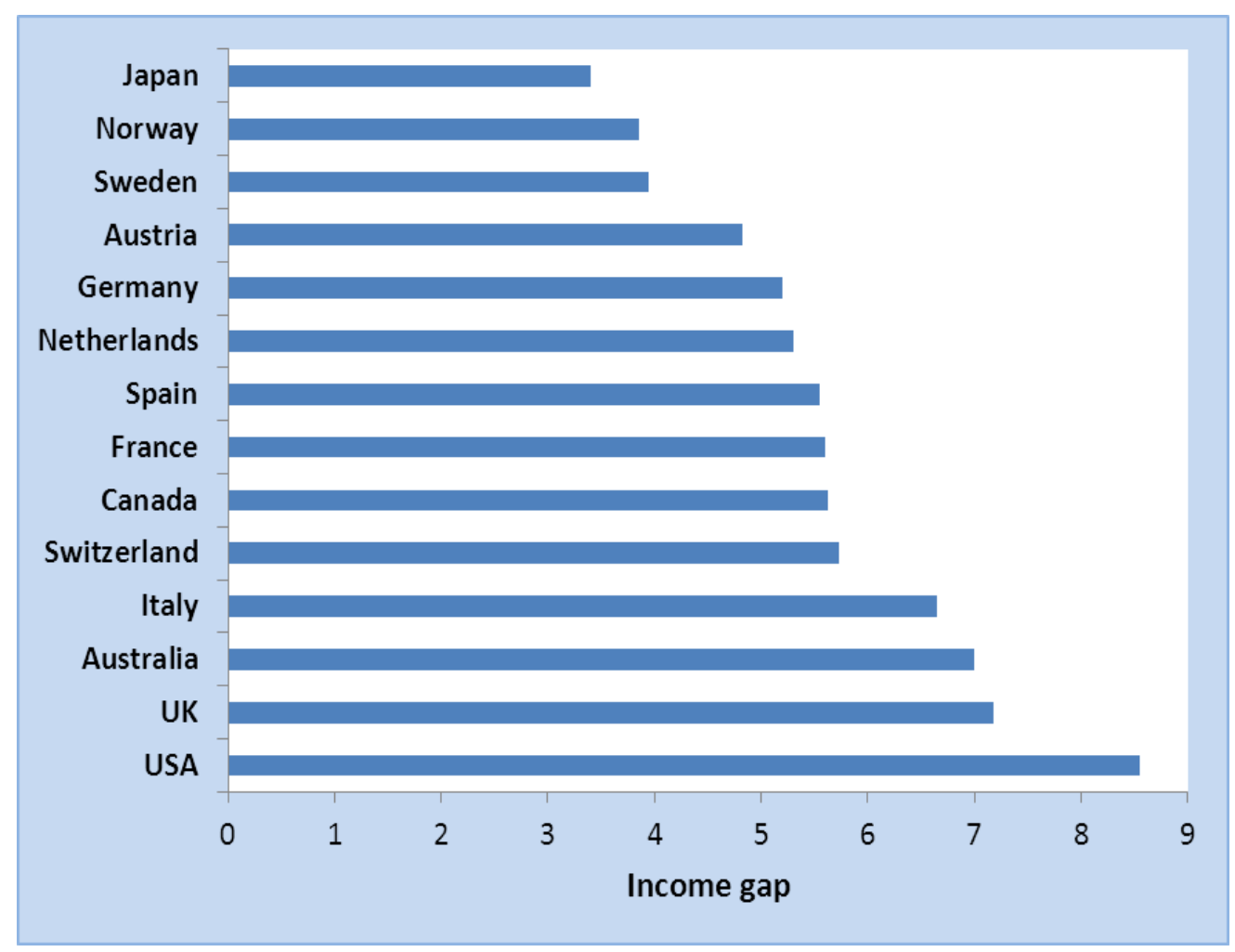


Figure 18. Impact of income inequality on health and social problems. Data from [86].

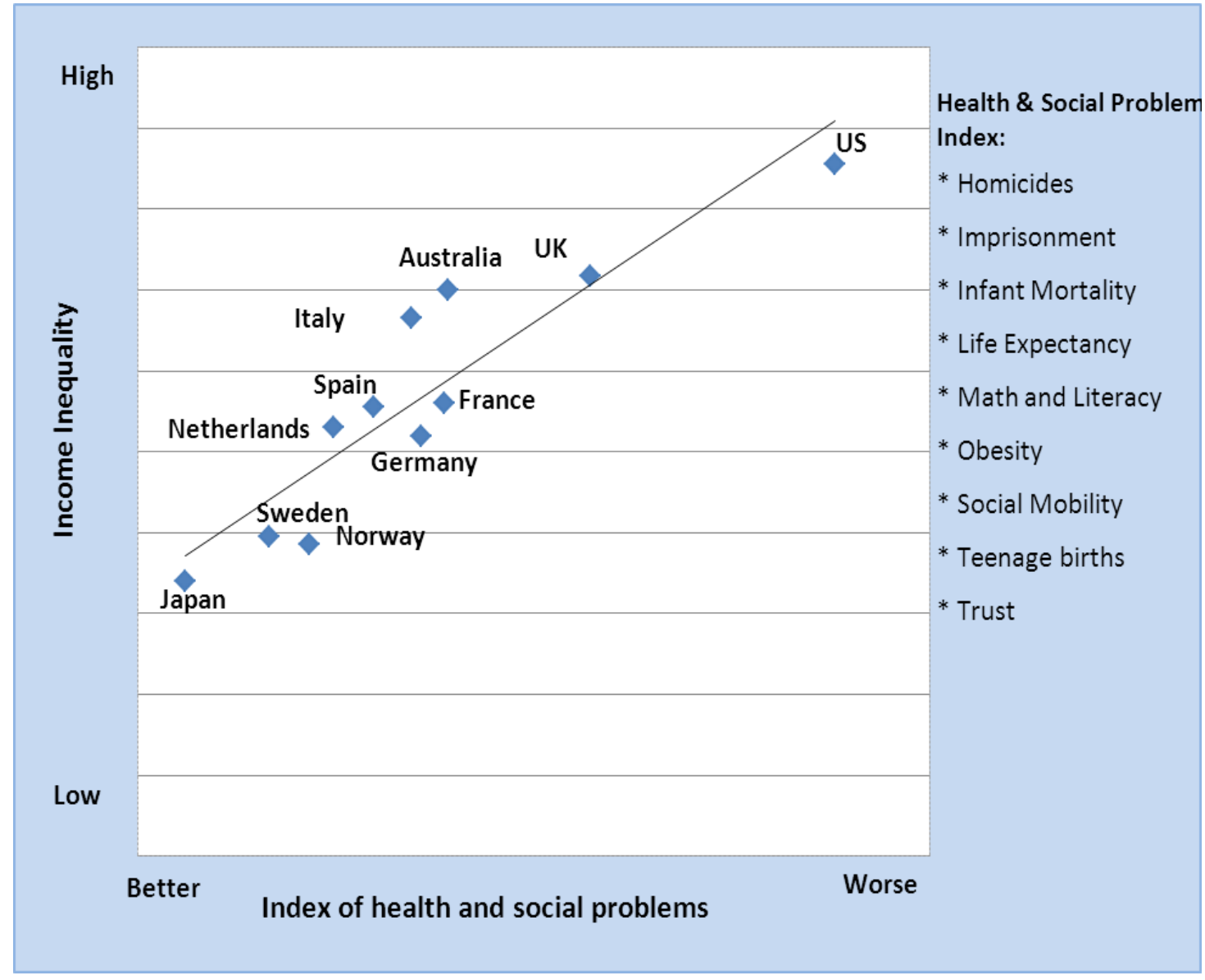

Health is not only a fundamental requirement for a full human life. It is also an important determinant of the productivity of human capital. World Bank and others have drawn attention to health as a factor in economic development [87,88]. Fogel found that one third or more of the economic growth in England over the last two centuries was attributable to improvements in nutrition which result in greater height and weight [89]. Healthy individuals are more efficient at assimilating knowledge and, in consequence, obtain higher productivity levels [90]. Another study by the same authors found that an extra year of life expectancy is associated with a $4 \%$ rise in per capita GDP in the long run [91].

Inequality is not merely a question of social justice. It has profound impact on the sustainability of society. Inequality results in unsustainable life styles among both those who consume excessively as well as among those who are compelled to ravage their environment for their very survival. As Indian Prime Minister Indira Gandhi said at the first UN Conference on the Human Environment in 1972, "Poverty is the worst form of pollution." Widening income disparities have also been linked to social unrest and violence in developing countries, threatening the sustainability of society itself. In an age of mass communication, rising prosperity in one section of the population raises expectations of a better life everywhere. Indeed, a global revolution of rising expectations has been a major driving force for change over the past five decades. Television carries images of luxurious life in the metropolis and overseas to impoverished urban slums and outlying rural villages. When this growing awareness is not accompanied by growing opportunities, it gives rise to increasing frustration, social tensions and 
violence, as expressed by the increasing incidents of violence in China and India, the two fastest growing major economies in the world. A rising tide of protest among ethnic groups and factory workers is sweeping across China, which goes largely unreported in the press. A Carnegie Endowment study reported a ten-fold increase in social unrest based on economic causes between 1993 and 2003, a period of rapid economic growth, as shown in Figure 19 [92].

Figure 19. Mass incidents of social unrest in China 1993-2003. Adapted from [93].

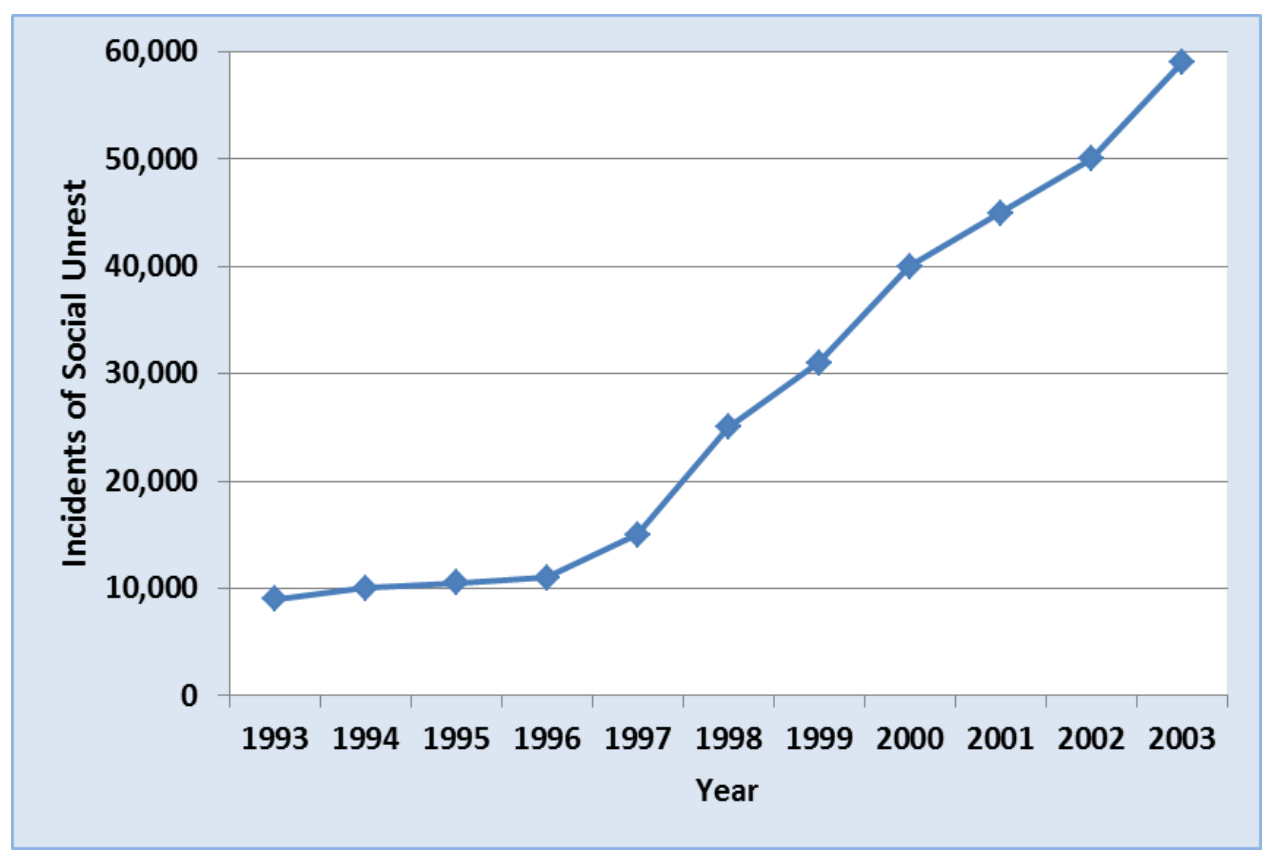

The Naxalite insurgency in eastern India has been around for decades, but is spreading more rapidly than ever before in poor tribal areas at the very time when prosperity is blooming elsewhere [94]. Naxalites are believed to number from 10,000-20,000, and are active on a large scale in as many as 13 of India's 28 states, mainly Andhra Pradesh, Jharkand, Bihar, Maharashtra, Orissa and Chhattisgarh. Both the rebels and the government concur that the roots of this conflict are primarily economic. Andhra Pradesh is one of the poorest regions in India and suffers from extreme wealth inequality. Conflict over resources is growing with India's increasing demand for coal-fired electricity: 85\% of India's coal reserves come from the five states most affected by the Naxalite uprising [95,96]. In both India and China, disparities between rural and urban incomes are increasing and rapid economic growth is associated with a dramatic increase in social unrest, especially among those who have not been beneficiaries of that growth [97].

Inequality plays an essential role in social development [98]. It creates an urge for upward social mobility, which is a driving force of social innovation and higher accomplishment. In his recent book Fault Lines, former IMF Chief Economist Raghuram Rajan observes, "Not all forms of income inequality are economically harmful. Higher wages serve to reward the very talented and hardworking, identify the jobs in the economy that need the most skills, and signal to the young the benefits of investing in their own human capital. A forced equalization of wages that disregards the marginal contribution of different workers will deaden incentives and lead to a misallocation of resources and effort" [99]. On the other hand, IMF research confirms the "growing recognition that an excessively 
unequal income distribution may itself be detrimental to sustainable growth" [100]. High inequality reduces economic development by slowing poverty eradication, retarding investments in education, and inhibiting entrepreneurship [101]. World Bank and others have drawn attention to health as a factor in economic development [88].

In recognition of this fact, Cornia and Court postulate that there is an 'efficient inequality range' which is most conducive to economic growth [102]. However, the level of inequality that is optimal for economic growth may not be optimal for social stability and development of human capital. More research is required to determine what may constitute the optimal level of inequality for overall social welfare and well-being. But there is abundant evidence to support the view that lower levels of income inequality are essential for achieving optimal and sustainable development of human capital. In recognition of this fact, UNDP has incorporated a measure of inequality in the 2010 version of the Human Development Index [103]. More than two thousand years ago Plato extolled the virtue of limiting the ratio between the lowest and highest income strata to 1:5. A century ago financier J. P. Morgan favored a maximum disparity of 1:20. In 2007, the ratio was as high as 1: 500 [104].Wilkinson and Pickett have shown that in countries such as U.S. and U.K., they can be directly attributable to changing public policies, especially those related to taxation [105]. But, opportunity for access to gainful employment represents the single most important determinant of income inequalities. While employment rates and incomes levels tend to be high for educated and skilled workers, levels of unemployment or underemployment remain high, especially among youth, the poor and unskilled, in many countries. Thus, generating remunerative employment opportunities for all job seekers remains the greatest single challenge to sustainable human development.

\section{From Welfare to Well-Being}

One element of the culture change that is needed is already clearly evident to most serious thinkers, only the means of effectuating it are in doubt. Humanity needs to evolve from a culture preoccupied by quantitative growth and ever-increasing consumerism to one which places primary value on qualitative improvements derived from harmonious, fulfilling human relations. That shift would mark a fuller transition of humanity from the physical stage of material preoccupations and the vital stage of social competition to a more enlightened and fulfilling way of life, a change that can be best characterized as a shift from preoccupation with welfare to the pursuit of well-being.

The present energy-intensive pattern of consumption typified by the most prosperous nations is unnecessary for ensuring a reasonable level of human development for all in terms of education, health and incomes. Figure 20 shows that a number of countries achieve very high performance on the Human Development Index with less than half the energy consumption of the most energy intensive countries. Even taking into account differences in climate and geography, it indicates that high levels of human development are compatible with far lower levels of per capita energy consumption. Granted the HDI measures only the most basic criteria for development, the data amply demonstrates the scope for improving energy efficiency without sacrificing quality of life. The earth may be able to support nine or ten billion people at high levels of material comfort, but it surely cannot support waste of precious resources or avoidable inefficiency. A change in attitude is imperative for sustainability. 
Figure 20. Relationship between Energy Consumption and Human Development Index. Data from [106,107].

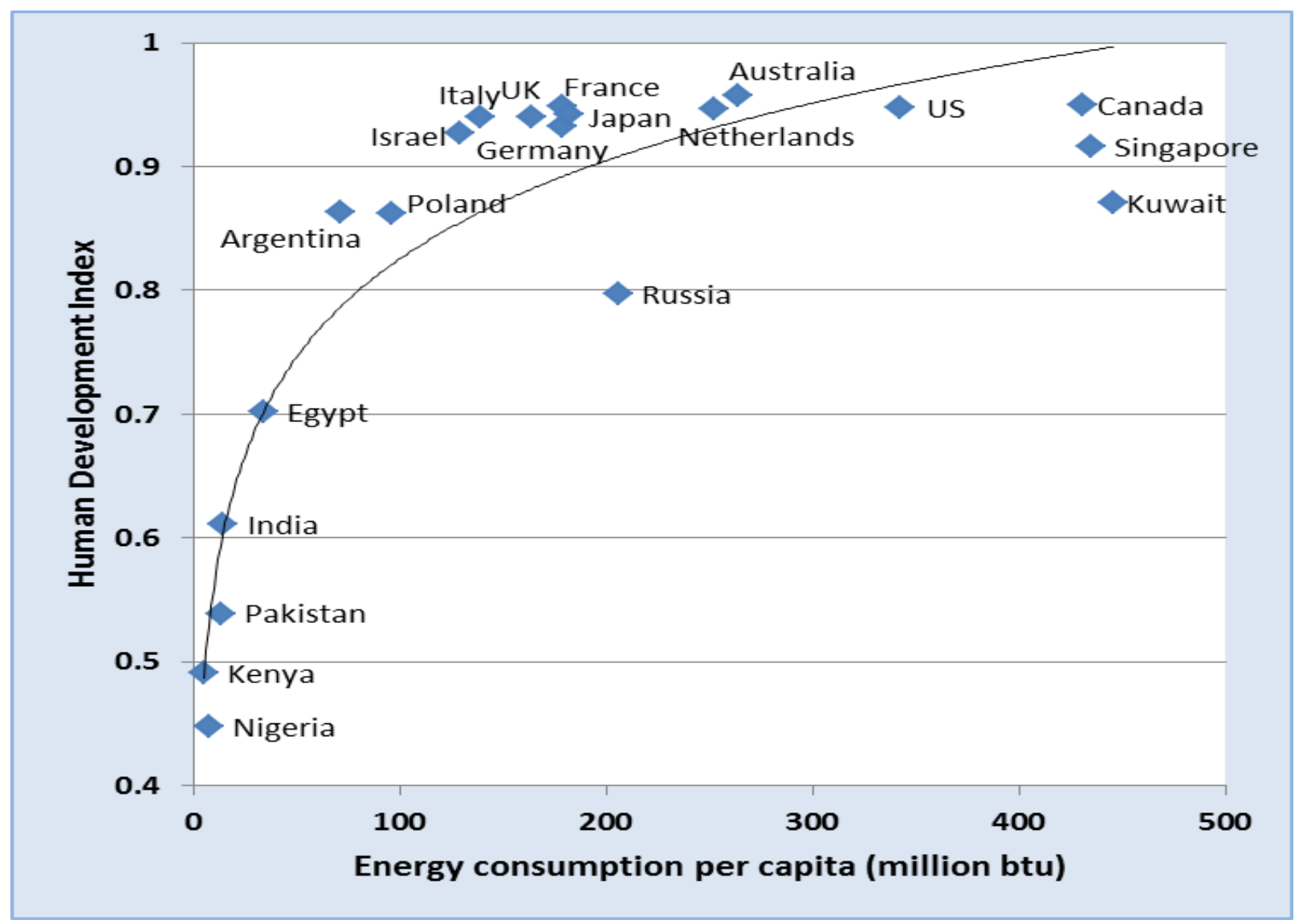

Left to itself, this prevailing pattern of resource-intensive consumption might persist for decades or even longer, unless a concerted effort is made to alter it. Such an endeavor may seem daunting or even impossible to many, but it is not without precedent. Indeed, radical shifts in values have occurred in the past, but the process governing these changes has been largely subconscious and therefore difficult to document or replicate. The sudden rise of the Hippy Movement among American youth during the 1960s marked a drastic change in values relating to materialism, conspicuous consumption, authority, social conformity, racial and social tolerance, war, environment, sexuality, marriage and human relations. The movement arose among the first generation of baby boomers born after the Second World War, youth who had never experienced the traumas of war or economic depression. This was a generation raised in unprecedented prosperity, confused and outraged by the sudden onset of war in Vietnam, disturbed by the vast inequalities between rich and poor, and baffled by artificial social barriers and arbitrary power structures. The underlying values expressed by this movement resonated powerfully with educated youth not only in America, but in Europe, South America and even behind the Iron Curtain. Although the most visible signs of that movement gradually receded as the baby boomers aged and moved into the work force, essential elements were retained and formed the basis for radical social changes over the past four decades. Prominent among them are the human rights movement, global environmental movement and the movement for abolition of nuclear weapons, which persist with increasing vigor even today. 
Social and cultural changes of this magnitude are possible and can be consciously initiated. But doing so requires a deeper understanding of the process of social development, the process by which human society evolves and human capital develops. Over the past decade, collaborative research by The Mother's Service Society and The World Academy of Art and Science has been striving to elucidate that process. "The essential knowledge of that process is embodied in social and cultural values. Values represent the essential knowledge of experience condensed into ultimate principles of successful functioning...Presently society transmits these values without being fully conscious of why they are so essential for success. The same knowledge when made fully conscious and consciously transmitted will be far more effective" [18].

The magnitude of the challenge appears less daunting when we recognize that it is to be done by a social process. Every change in fashion that sweeps across the world from San Francisco to Mumbai is an example, though at a superficial level. The very sudden worldwide concern with climate change that has arisen over the past decade is a more profound instance. One striking element of this process is that it originates from points of highest social prestige and gradually spreads from there to other levels where people aspire to rise in status and prestige. As advertisers know well, the key to effecting widespread rapid change is to reach the trend-setters.

The shift in human aspirations from welfare to well-being is far more profound than a change in fashion or even a move to environmental sustainability. Just three years ago most advocates of total nuclear disarmament were so disheartened that they were ready to give up the quest. Then Korea detonated its first nuclear tests and evidence emerged of a covert nuclear program in Iran. A few months later, G. Schultz, W. Perry, S. Nunn and H. Kissinger, former US cabinet secretaries from both political parties, announced their support for total abolition of nuclear weapons. The following year for the first time in history, the goal of nuclear disarmament was endorsed by all three democratic candidates for the US Presidency. After his election, President Obama reversed the policies of his predecessor and announced the intention of his government to work seriously to achieve this goal. Other nuclear weapon states such as India came forward to endorse and support. Today nuclear disarmament has been pushed to the top of the international policy agenda.

Abolition of nuclear weapons is a political issue under the direct purview of governments. A change in social values related to conspicuous consumption and life style is a social issue under the purview of the world's intellectual and social leaders. That is where the change must start and once ignited can rapidly gain momentum. But it cannot be brought about solely by individual leadership. The real mechanism for the shift lies in changing the values implicitly communicated by the educational system. The environmental movement really gained momentum when graduates of the hippy generation became parents, teachers and government officials, and when, as a result of their concern, sustainability infiltrated into the educational curriculum and the legal system. But a change in values must come first. Law represents the codification of public conscience.

\section{Human Choice and Resource Constraints: Case Study of Water Demand in India}

Nature forms the physical and biological foundation for human evolution and sustainability. Based on the way human beings are presently interacting with the environment, there is no doubt that increasing scarcity of water, depletion of soil and climate-related changes pose serious physical 
challenges to sustainability. A central thesis of this paper is that the real limits are not natural. They are limits to our knowledge and willingness, limits imposed by human choice. The sustainable development of human society and our natural environment will depend on the choices we make, which in turn depend on our social and psychological evolution. Therefore, the ultimate solution to the most pressing and immediate material problems depends on necessary changes in our consciousness and choices. Sri Aurobindo identified seven types of ignorance that presently limit the knowledge and effectiveness of human action. Ironically, the last and most difficult to overcome of the seven is our practical ignorance regarding precisely what to do at the very next moment. That is because precise knowledge in the here-and-now is constrained by ignorance at all the other levels. Because of our egoistic ignorance, people tend to approach every issue from the perspective of their own personal self-interest and it is difficult to make them comprehend, let alone accept and act, from a wider point of view that encompasses the perspectives of other people, nations and the world as a whole. Because of our temporal ignorance, it is easy to forget the lessons of the past and ignore the coming future, preferring to live blindly in the moment or focused on the short-term. However slow this process has been in the past, once we are fully conscious of the process of social development, we will possess the power to accelerate that evolution.

The potential for viewing and addressing ecological issues as problems of human consciousness and human capital formation can be illustrated by the problem of water shortages in India. India possesses 16 per cent of the world's population but just $4 \%$ of its water resources. Although current water resources are more than sufficient to meet total demand at the national level, tens of millions of people in different parts of the country are already impacted by water shortages. As population, food production, industrialization and living standards continue to rise over the next few decades, total water consumption is expected to increase by $20-40 \%$, making the problem even more acute [108]. While total water availability in India still exceeds demand, the gap between the two is closing rapidly as depicted in Figure 21. Since population and water supply are not evenly distributed, this means that hundreds of millions of people will be living in water deficit regions as the gap closes further.

Figure 21. Utilizable Water and Demand in India 1997-2050. Adapted from [109].

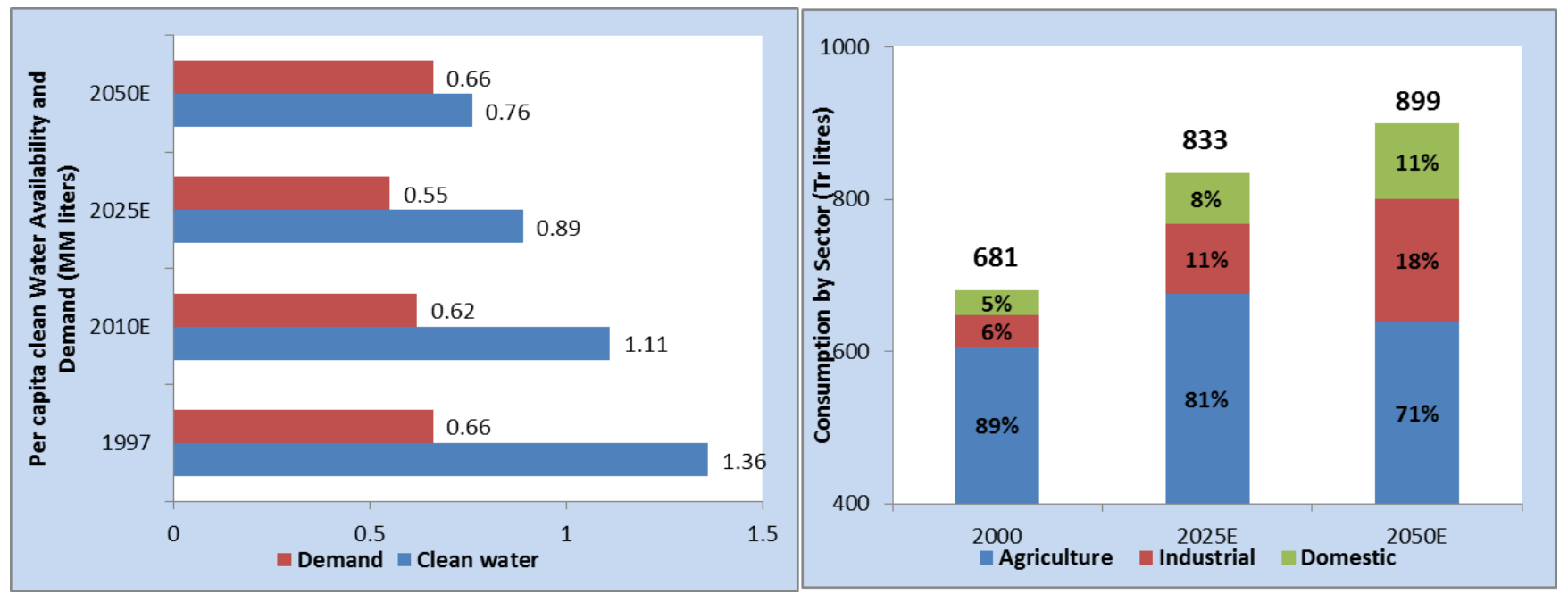


Yet a closer examination reveals vast potential for addressing the problem. Agriculture presently accounts for more than $85 \%$ of water consumption in India, as shown in Figure 22. Increasing population will necessitate continuous efforts to raise food production. On the other hand, crop productivity levels in India are far below international averages. Average maize yields in India are less than $25 \%$ of levels in U.S. and only $40 \%$ of those achieved in China. Rice yields are $40 \%$ of the U.S. and $50 \%$ of China's average. High water consumption combined with low crop productivity means that the productivity of water in Indian agriculture is extremely low. California Agricultural Consulting Services estimated that water consumption for cotton cultivation in India was 35 times higher per unit of crop output than cotton cultivation in California. Raising crop yields by 50 to $100 \%$, which is technically feasible and economically attractive, can by itself substantially improve water productivity in India, freeing up to $40 \%$ of the nation's total consumption for other purposes.

Excluding desert regions, water scarcity in India and most parts of the world is the result of unthinking, unplanned, wasteful human behavior, not an inevitable and irreversible result of population growth. There are innumerable ways to address and reverse the growing problem of scarcity, but they require a change in human awareness, attitude and behavior - in other words, the further development of human capital. For example, the town of Cherrapunji in northeast India records the highest rainfall in the world, averaging 450 inches annually, yet frequently suffers from acute water shortages during summer months due to indiscriminate deforestation and the absence of measures to capture and store the rainwater. Rainwater harvesting, check dams and other conservation measures designed to prevent run-off and recharge the water table have demonstrated the capacity to significantly enhance the groundwater supply in both urban and rural areas of India [110].

Water wastage is aggravated by a policy of free or subsidized electricity supply to farmers in most of India, encouraging indiscriminate use of irrigation capacity. The efficiency of canal irrigation systems in the country is also far below international standards. Revising government policies to provide incentives for the efficient use of water can substantially improve water utilization. Furthermore, control of water resources in India resides with the states, rather than with the central government. Given the necessary public support and political will, the potential exists for implementation of major projects, including creation of a national, integrated system of inland waterways, to redirect excess water flows from flood prone to drought prone areas.

The problem of water scarcity in India is real, but it is a human problem and there is a human solution for it. The problem and the solution depend on knowledge, attitudes, values, social organization and actions. The solution lies in educating youth about the precious value and measures for conserving water, applying proven technologies, generating greater public awareness of the problems and solutions, instituting sound public policies such as mandatory rainwater harvesting, and rewarding constructive behavior. A study of India's water problem led the government to conclude that "Given the vision and political will, India can convert the present water problem into a huge opportunity" [108].

\section{Future Scenarios for Sustainable Human Capital}

The objective of this paper has been to examine a broad spectrum of issues related to human capital and sustainability, with emphasis on the linkages between employment, health, education, economy, 
social welfare and ecology. Examined individually, each of these issues is sufficiently complex. Examined as aspects of a greater whole which encompasses the entire humanity and its environment, the task is challenging and even daunting. The authors have argued that solutions to these complex challenges are possible, if and only if, human choice and development of human consciousness - not only technology, policy, economy or any other factor - are made the central focus and lever for change. It is beyond the scope of this paper to project scenarios or solutions to address the totality of these challenges. Nevertheless, a brief examination of opportunities for substantial progress over the next few decades may serve as an example of a more comprehensive approach to a sustainable future.

This paper examines the interrelationship between several crucial determinants of sustainabilitypopulation, employment, education, health, social equity, social stability and energy consumption-in the context of a gradual and progressive evolution of consciousness toward the mental stage. Granted that expectations of higher standards of living will continue to rise globally, is there any possible scope for meeting the aspirations of a still growing world population? This paper argues that global society does possess the capability to generate employment opportunities for all job seekers and achieve full employment, provided that the central importance of employment is recognized as a fundamental human right. Contrary to popular belief, the principal source of new jobs is social development, not economic policy. Public stimulus programs, manipulation of the money supply and interest rates can certainly have short-term impact, but it is the growth and development of society that serves as the foundation and context for economic growth. Full employment can be achieved by broad-based social strategies that accelerate social development, including measures that improve the quality and quantity of education and training, promote entrepreneurship and self-employment, increase the speed of communication and transportation, encourage research and innovation, and more fully utilize the power of social organization, e.g., the Internet.

Of all these measures, education and training are the most crucial, both for generating employment and facilitating the evolution of social consciousness and culture to a more mental and environmentally-conscious, less materialistic basis. The trend from material-intensive manufacturing to human-intensive services is one expression of this movement that is already well underway and will continue for the foreseeable future, generating more, better quality and better paying job opportunities for people with the required education and skills. Over the next decade, $57 \%$ of the new jobs created in the U.S. will fall in this category. This paper cites studies supporting the view that availability of workers with the requisite education and skills is a major impediment to new job creation, not only in economically advanced countries, but in lower income developing countries as well. Delivering world-class higher education to hundreds of millions of youth is a direct means for accelerating the transformation of economy and society. As described earlier, the Internet offers an ideal platform for global delivery of low-cost, high quality education. Higher levels of education at all levels will also reduce fertility rates and significantly improve health and longevity, thereby determining the point in time at which world population levels off and begins to decline. 
Figure 22. Working Age Population. (15+) for 120 Countries by Educational Attainment 1970-2030. Data from [111].

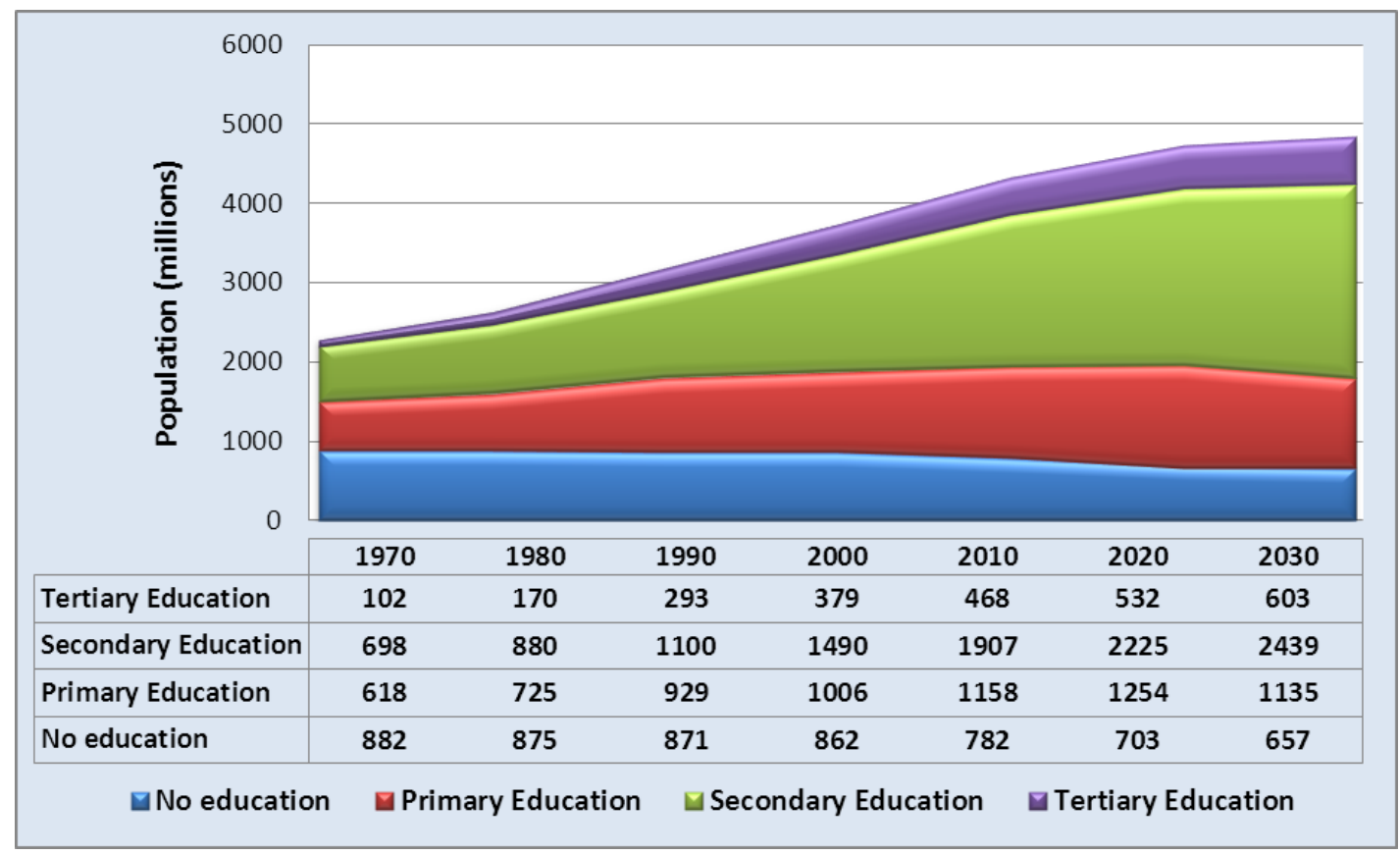

Education is an investment in the future. Figure 22 is a projection of the working age population aged 15 years and above for 120 countries by educational attainment for the period 1970 to 2030, based on the mildly optimistic educational scenario. It shows that the past decades have seen great progress in education. Whereas over the past 40 years the number of people without education or with only primary education has remained roughly constant, those with secondary or higher education have increased almost fourfold. The population with only primary or no education reached a peak around 2010 and will decline slowly hereafter. The population with secondary and tertiary education is likely to double over the coming four decades (increasing by a factor of seven compared with 1970) [112]. Of course, the profile for individual countries will vary enormously.

Figures 23A and B show the profile of the population of South Korea in 1970 and 2010. The blue portion represents the proportion of each age group only primary education, the red and green represent those with secondary or tertiary education. Tertiary enrollment rose from a mere $7 \%$ in 1970 to $98 \%$ in 2008 , highest in the world followed by U.S. at $83 \%$ [113]. Note that while Korea's current educational enrollment is the highest; its workforce still lags behind the U.S. and other economically advanced nations in educational attainments. During the period 1970-2008, Korea's per capita GDP multiplied eight-fold to reach $\$ 25,500$ (2005 intl. dollars). At the same time, employment in services underwent a dramatic transformation, rising from $31 \%$ to $69 \%$. Manufacturing jobs also rose from $19 \%$ to a peak of $37 \%$ in 1991 before declining to $24 \%$ in 2009 . Over the past decade Korea has had one of the lowest unemployment rates in the world. Figure $23 \mathrm{C}$ is a projection of Korea's population and educational profile in 2030. It shows that virtually the entire workforce will possess either secondary or tertiary education, quite possibly making it the best educated in the world.

Korea's investment in education provides optimal conditions for growth of employment, growth of GDP and a shift to less-material-intensive economy and life styles. Figure 24 shows that over the past three decades, fossil fuel energy intensity per unit GDP has declined by $77 \%$ in the U.K., by $71 \%$ in 
the US and by 33\% in Japan. After rising dramatically as manufacturing expanded in the late 1980s, over the past ten years, energy intensity in Korea declined by $14 \%$ and fossil fuel energy intensity (total fossil fuel energy consumption divided by total GDP measured in 2005 intl. dollars) fell $16 \%$. Still there is enormous scope for further improvement. While Korea derives a slightly higher proportion of its energy from fossil fuel sources than Japan (85.5\% vs. 83\%), Korea's fossil fuel energy intensity is 48\% higher than Japan's and 66\% higher than U.K.'s. At its current rate of change, Korea will reach the U.K. level of fossil fuel intensity by 2020.

Figure 23. Republic of Korea-Population by Age and Educational Attainment in the Year (A) 1970; (B) 2010; and (C) 2030. Data from [111].

A

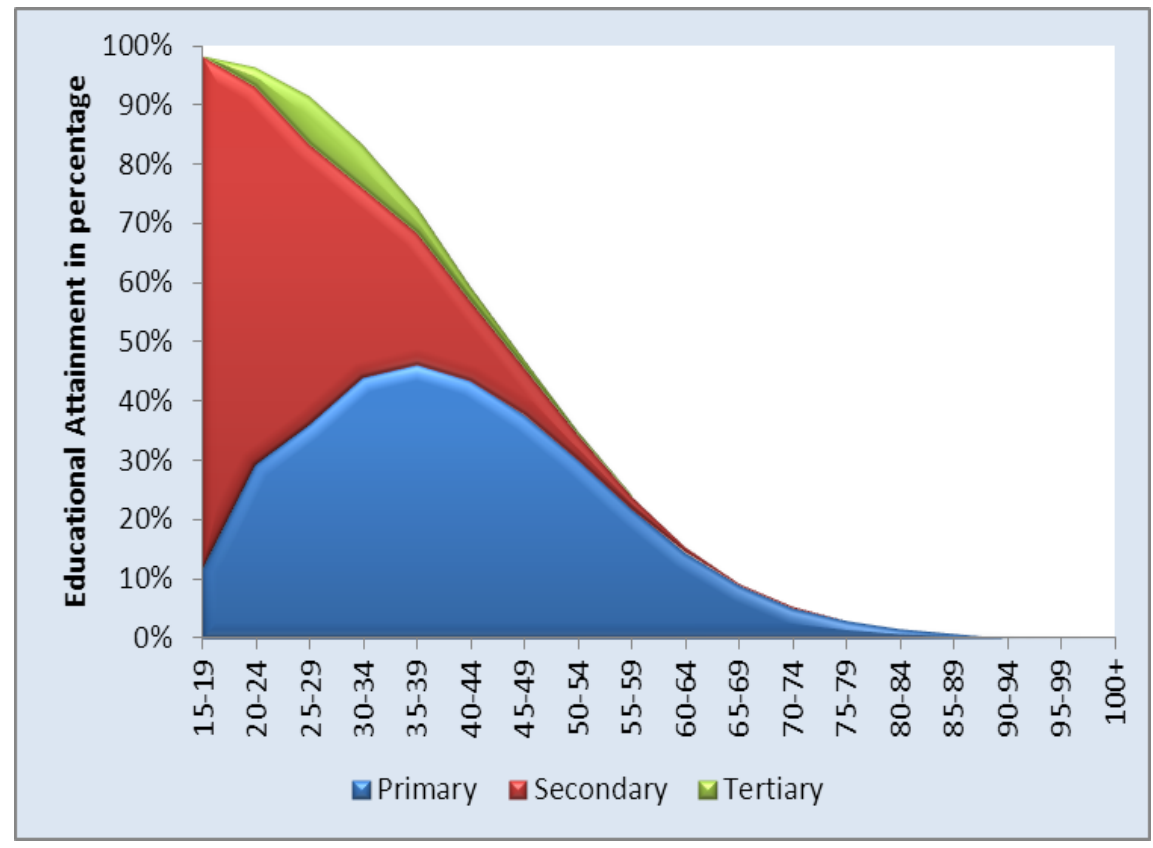

$\mathrm{B}$

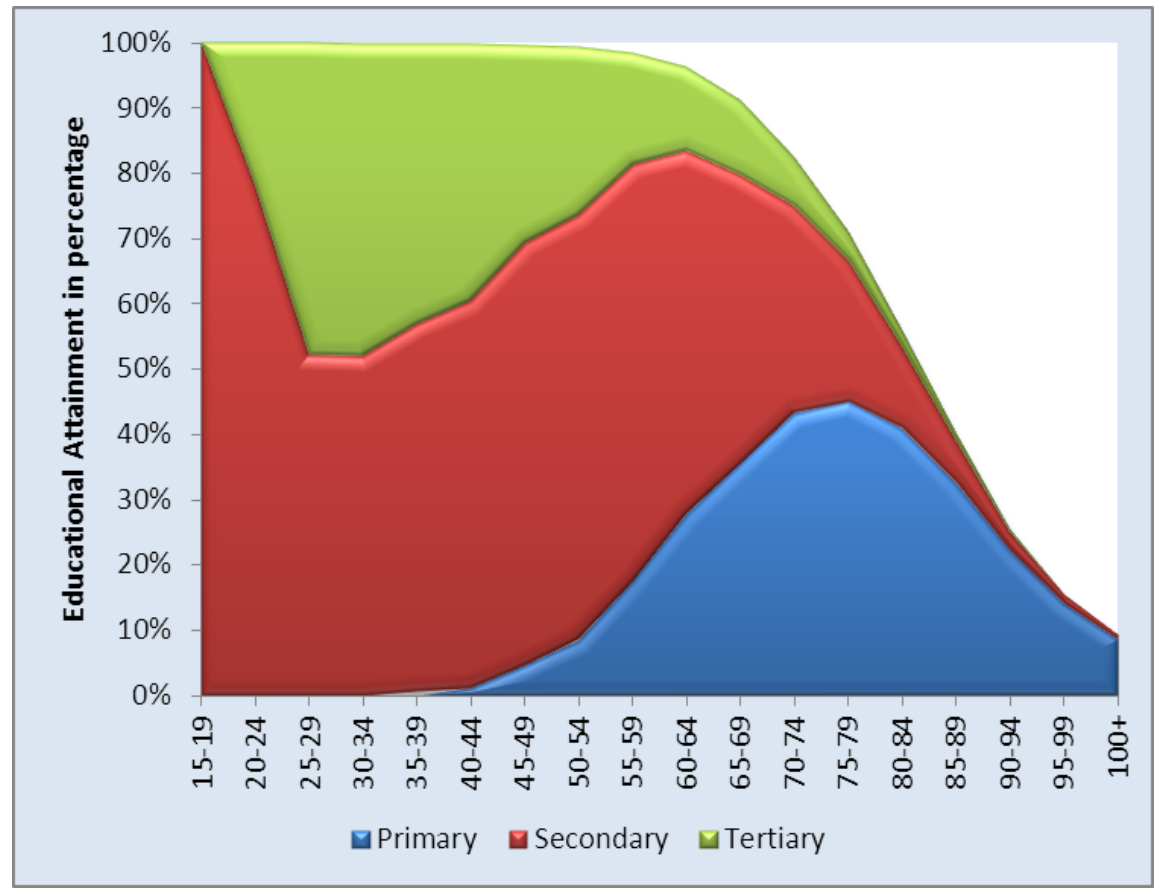


Figure 23. Cont.

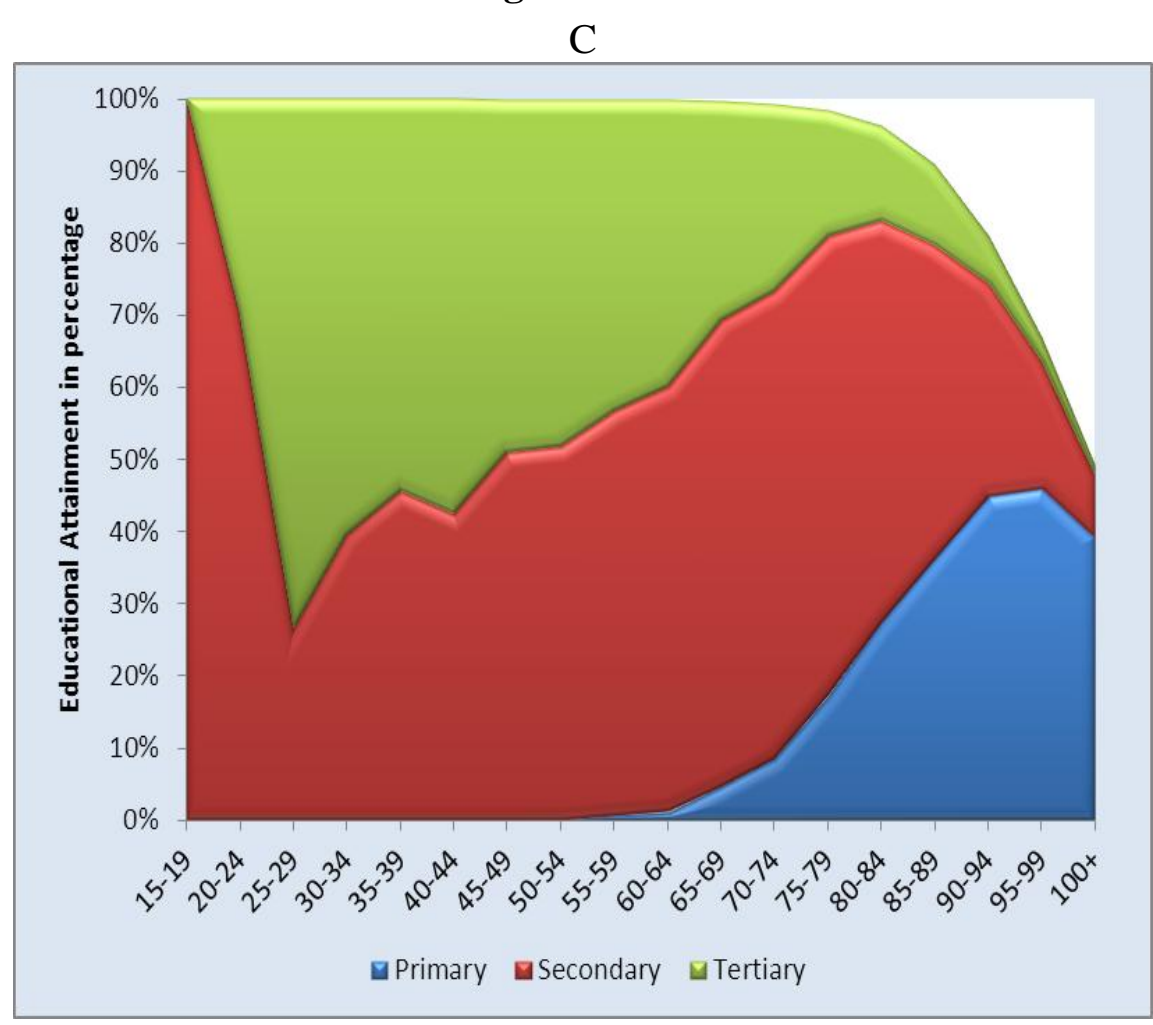

Numerous factors contribute to overall energy intensity, but the development of human capital is central to them all. The capacity to evolve from a low-cost manufacturer of volume goods to a high end manufacturing and service economy producing higher value with lower energy inputs depends very much on the quality of human resources available and the social support for innovation. Similarly, the shift to more environmentally-conscious life styles referred to by Elgin is related to education and evolution of a more mentally conscious society. The example of Korea highlights the macro-level relationship between human capital development and sustainability at the national level. Much more research is required before similar analysis and projections can be made at the global level.

Figure 24. Fossil Fuel Energy Intensity for Select Countries 1980-2008. Data from [74,114].

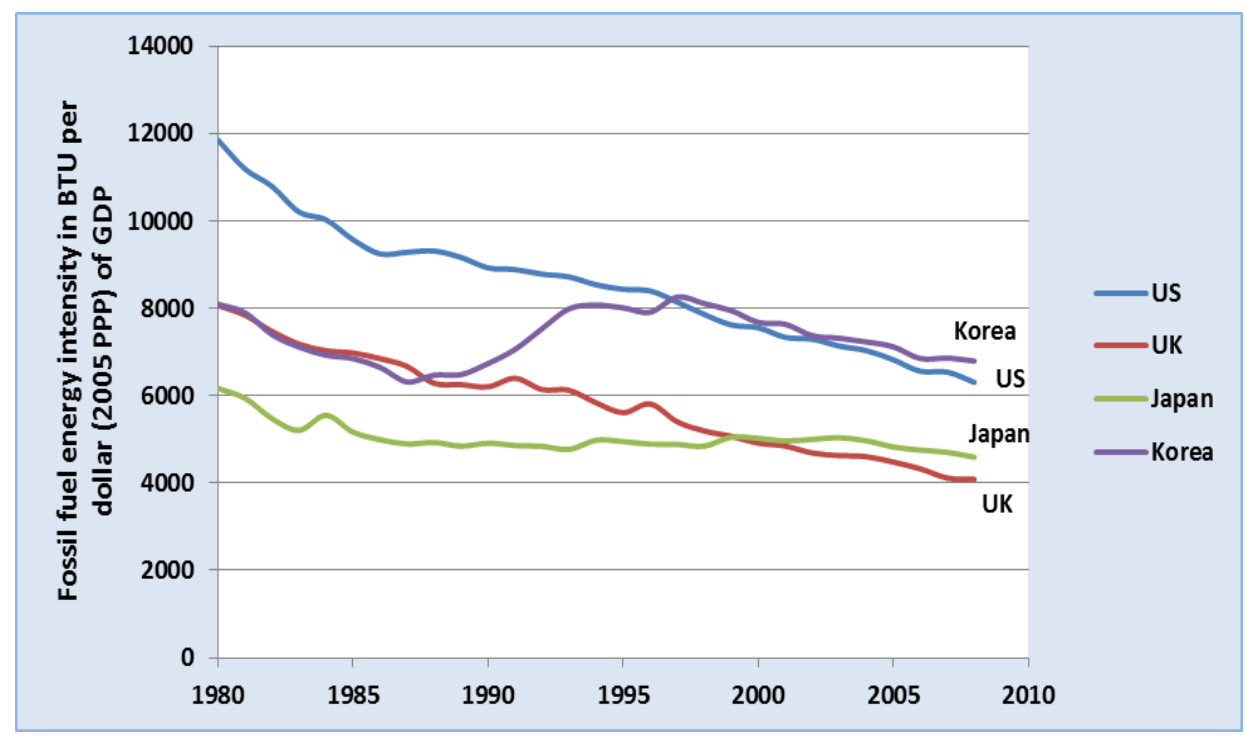




\section{Projecting World Population}

Population provides the most reliable insights into the long-term relationship between human capital and sustainability. The size of the human population determines the demand for food, water, forest products, ocean fisheries, energy and other non-renewable resources, and affects the very climate of planet earth. This paper argues that the qualitative development of human resources is truly the key to sustainability, because it is the quality or consciousness of people that determines their creativity, capacity for invention and technological innovation, employability, fertility rates and life expectancy, capacity for governance and peaceful co-existence, moderation of material life-styles, awareness of the environment and responsible action.

Recent studies by Wolfgang Lutz and associates at IIASA present new evidence supporting the direct relationship between the quality of human capital (as measured by level of education), fertility rates and population growth. These studies conclude that raising the general level of education of the world's population is the single most powerful and effective means for controlling population and enhancing the sustainability of human settlements. When they projected world population in 2050 based on several different educational scenarios, they found that higher levels of education could reduce the growth of population by one billion over the next four decades.

While long-term population projections are subject to extreme uncertainty, education will unquestionably have a profound impact on demographic trends. Already more than half of world population has a fertility rate below the replacement level of two surviving children per woman [115]. Figure 25 shows the ten countries with the lowest fertility rates. Fertility rates in East Asia are already $50 \%$ below the replacement level. Most European countries are either slightly or below the replacement level.

Figure 25. Ten Countries with Lowest Fertility Rate (births per woman) 1960-2008. Data from [74].

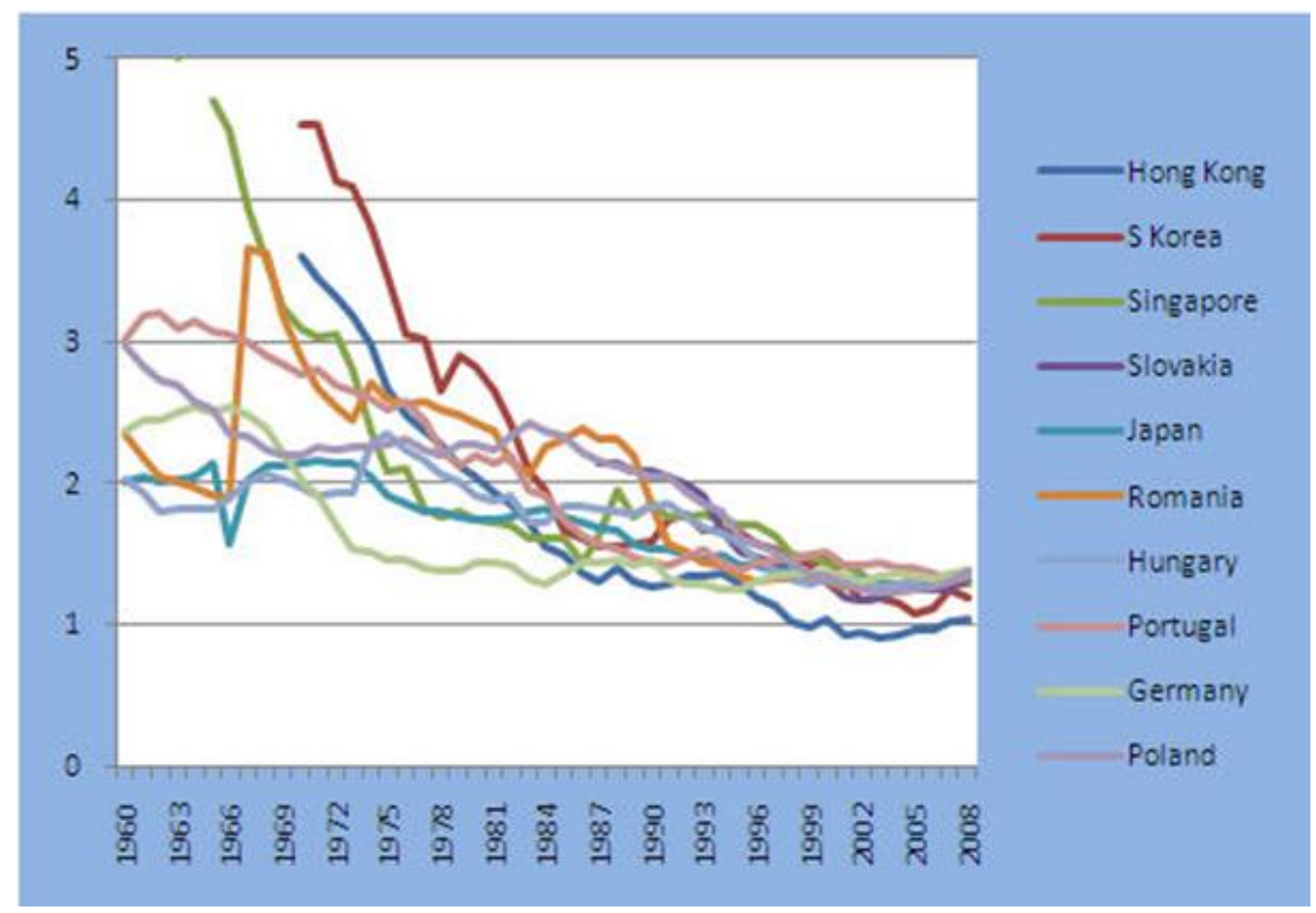


Stochastic projections of world population published by the IIASA show a $80-85 \%$ chance that the world population will peak and start to decline before the end of the 21 st century [116]. Other studies project that if global fertility rates were to fall to the level already prevalent in Europe for the past decade, then world population could decline to the range of 3.5 to 4.4 billion in 2200 and 1.1 to 1.7 billion in 2300 [117]. These findings prompted Lutz to conclude that "education is probably the single most important determinant of empowerment for coping with and adapting to the dangerous consequences of climate change" [112]. Regardless of whether these projections are realized, they illustrate the extent to which future sustainability will depend on population size, which in turn depends on level of education and human choice. The development and evolution of human consciousness will be the ultimate determinant of the sustainability of human capital and life on earth.

\section{Individuation of Human Capital}

Human beings have inherited a conscious capacity to learn from their experiences, systematically accumulate and transmit knowledge, and evolve from physical and vital to mental ranges of consciousness and beyond. This evolution directly impacts on the sustainability of human society and the environment. The process of interaction between the individual and the collective is not symmetrical. During early stages of evolution, the collective plays a dominant role, imposing its will on its members and demanding strict adherence in thought and deed. The individual is a dispensable member of the collective destined to sub-serve social aims. But as humanity evolves from the physical to the vital and mental stages, the collective comes to recognize that its own maximum development is only possible when it accords maximum freedom to each individual member for expression, variation, dissent, innovation, creativity and development of his or her unique capabilities. In the vital stage, this expresses as increasing latitude for the pursuit of self-interest and personal accumulation, independent from and often in disregard of the welfare of others, leading some to conclude that individuality is synonymous with selfish egoism.

In the physical stage people learn how to survive and discover the resources in the environment around them. In the vital stage they learn how to interact with one another for mutual benefit and discover the creative powers of human relationship and social organization. In the mental stage, they learn about their place in the larger universe, the context that includes everything. People become self-conscious and discover the untapped resources that are the source and essence of human capital. They consciously evolve by changing themselves, the way they think, their attitudes and their values.

Rising levels of education, information, scientific knowledge, technological capacity and social organization are characteristics of the transition to the mental stage, but they are not the sole or even its most central characteristics. In earlier stages the individual is subordinate to the collective in thought, values and actions. In the mental stage a process of individuation occurs in which the individual progressively replaces the values, beliefs and behaviors imposed externally by society with his or her own self-determined values, understanding and behaviors. New capacities emerge, including original thinking freed from the trammels of social acceptability, the ability to take other people's point of view freed from the subjectivity of our own ego-centric perspective, and the courage to differ and withstand the pressure to conform. This is a creative stage in which people individually become conscious of the 
infinite resources they possess within themselves. In contrast to the preoccupation with survival characteristic of the physical stage and the competitive pursuit of self-interest characteristic of the vital stage, in this stage the individual pursues personal fulfillment and well-being by consciously identifying - rather than subconsciously conforming — with the aspirations of the collective, and strives to fulfill them by making a unique contribution that is both self-fulfilling and serviceable to society. The true individual is not one who merely serves a social ideal selflessly or idealistically, but one whose ideals and values transcend the limitations of society in pursuit of something more true and absolute. Leading psychologists of the 20th century, including Jung, Maslow and Rogers, have applied various terms to describe this process, such as individuation, self-realization and self-actualization. Maslow describes it as an evolutionary process leading eventually to a future society in which self-actualized individuality would become prevalent. "The evolution of a synergistic society is a natural and essential process. This is a society in which all individuals may reach a high level of self-development, without restricting each other's freedom" [118].

The researcher, explorer, pioneer, inventor, social innovator, entrepreneur, artist and original thinker are some of the prominent expressions of this process of individuation at different levels and in different fields. A few people invent. A few people think originally. The pressure for social conformity remains very strong. In the past it most commonly took the form of threats or actual physical punishment or ostracism. Today it survives in the form of peer pressure, the need for social acceptance, respect and approval, the drive to compete and keep up with others. But the creative initiatives, the new ideas, the social and technological innovations that change the world originate from those who develop their own internal frame of reference and act from there on the world around them. Increasing mental development in society as a whole enhances the receptivity and responsiveness of the collective to these pioneering initiatives.

Figure 26 presents data for a selection of countries surveyed repeatedly from 1981 to 2006 to measure changes in social and cultural values. The surveys reveal a sharp increase in the value accorded to individuality, self-expression, and freedom of choice. Although countries vary significantly in the relative importance accorded to these values, similar trends are shown for $80 \%$ of the countries surveyed. Somewhat surprisingly the change in values is even greater among the more educated sections of many non-Western nations than it is in Europe and North America. Self-expression is linked with the transition from industrial society to post-industrial societies. Most significantly, this shift to more individualistic, self-expressive values is associated with increasing emphasis on environmental protection, greater tolerance and trust, and rising demands for participation in decision making in economic and political life - changes associated with evolution to the mental stage of social consciousness that are essential to achieve more sustainable public policies and life styles [112].

When human beings and society more fully comprehend the process of their own development, they will realize that conscious efforts to promote individuation are important means for the sustainable development of human capital. Then fostering individuation will become a principal objective of both the individual and the collective. Each will pursue a concept of welfare and well-being that is consistent with the fulfillment of others and sustainable for all. Then the true self-augmenting character of human capital will come fully to the fore. Each individual becomes a center for self-development and the sustainable development of the collective. A society that succeeds in releasing this potential of 
individuality will learn and adapt swiftly. Sustainability is ultimately about becoming conscious of ourselves, the characteristic ways in which people see, think and act, and the inner potentials for their own conscious evolution. Sustainability and human evolution go hand in hand. As Aurelio Peccei put it, "The most valuable assets humankind can count on...to stop the decline and to prepare for the future are to be found in the still untapped resources of comprehension, vision and creativity inherent in every human being" [119].

Figure 26. Change in Self-Expressive-Individualistic Values 1981-2006. Data from [120].

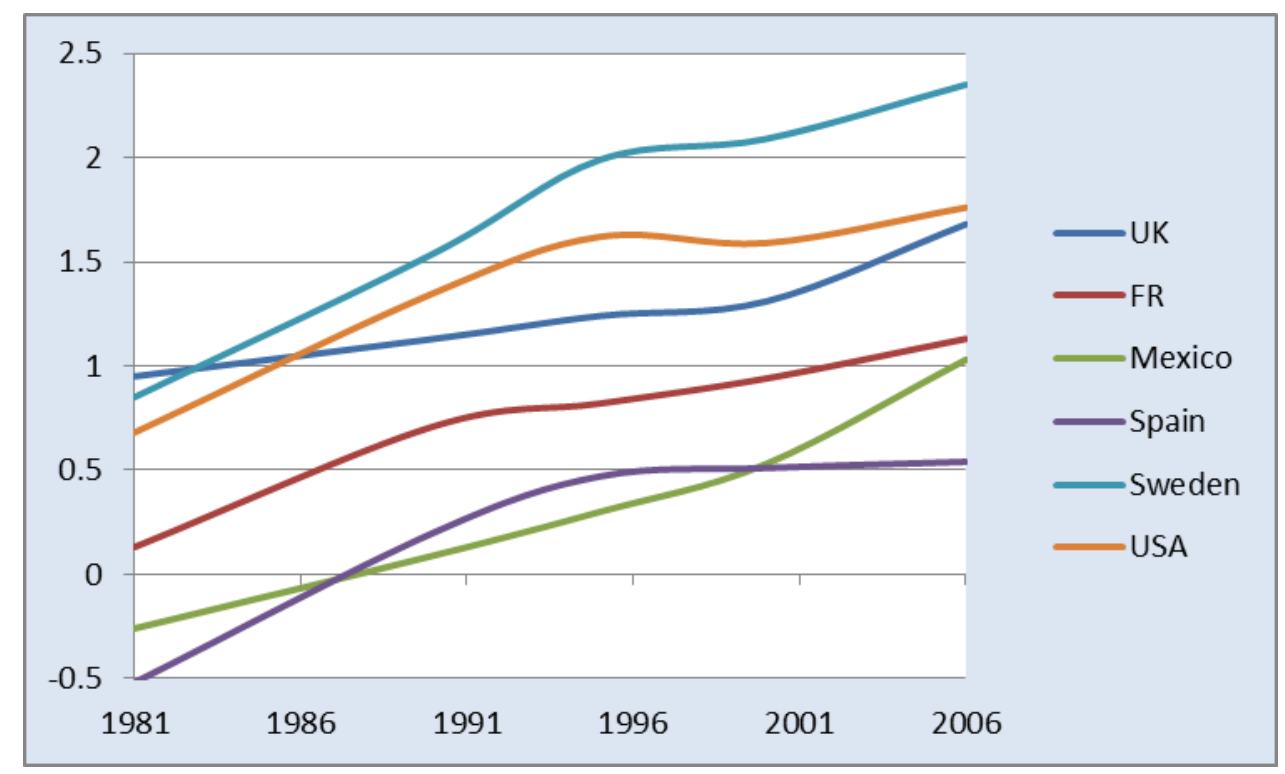

\section{Conclusions}

Throughout this paper, the authors have drawn attention to the central role of education in human development. Education influences virtually every aspect of human existence, including fertility rates, infant mortality, health, life expectancy, population growth, employability, income levels, economic growth, patterns of consumption, technological and social innovation, entrepreneurship, public awareness, social values, public policy, type of government and quality of governance. Education is the means by which society passes on to future generations in an organized and condensed form the sum total and essence of knowledge and experience it has acquired over millennia. The basic skills and information imparted in primary school and the wider range of knowledge incorporated in the secondary curriculum is further enhanced by the development of higher order mental capacities at the tertiary level. But even a complete education as it is delivered by formal institutions today does not exhaust the potential for education. Along with academic knowledge, mental and vocational skills, education can be utilized to transmit values, interpersonal and psychological skills that are essential for higher accomplishment, welfare and well-being. It also has the potential to serve as a conscious medium for character and personality development and for individuation. Educational systems are not yet oriented to develop this higher range of human capacities, yet it is precisely this aspect of education that offers the greatest potential for the future evolution of human consciousness and sustainability of earthly life. 
The problem today is not physical limitations, but rather limitations imposed by the quality of our choices and our actions. Rapid economic development and rising levels of consumption are taking a severe toll on the natural environment, which can only be partially mitigated by technological solutions. Sustainable development appears to be a contradiction in terms, a paradox, which can be fully resolved only by the evolution to a higher level of human consciousness. As Carl Jung expressed it, "In the history of the collective as in the history of the individual, everything depends on the development of consciousness" [121]. Today economic development is generating pressure for evolution to the mental stage in which human beings increasingly seek greater fulfillment in harmonious relationships, psychological gratification and cultural enrichment, rather than ever increasing material consumption. Thus, the progressive development of human capital made possible by the continuous evolution of human consciousness is the ultimate determinant of sustainability. This article calls for a much more profound shift in thought and action to make the development of human capacities and fostering of human welfare and well-being the centre-piece of sustainable development strategy.

\section{Acknowledgements}

The authors gratefully acknowledge the research assistance provided by R. Lakshmipriya, Ranjani Ravi and Saraswathi Mukkai of The Mother's Service Society, India.

\section{References}

1. Smith, A. Book II: On the Nature, Accumulation, and Employment of Stock. In An Inquiry into the Nature and Causes of the Wealth of Nations; Random House: New York, NY, USA, 1776.

2. Giarini, O. Dialogue on Wealth and Welfare: An Alternative View of World Capital Formation, a Report to the Club of Rome; Elsevier: Rome, Italy, 1980; p. 171.

3. Swaminathan, M.S.; Ariyaratne, A.T.; Avramovic, D.; Carter, R.; Colombo, U.; Dessau, E.; Harten, R.V.; Ingram, J.; Jacobs, G.; Jayawardena, L.; et al. Uncommon Opportunities: Agenda for Peace and Equitable Development: Report of International Commission on Peace and Food; Zed Books: London, UK, 1994.

4. Menger, C. On the Origins of Money; Ludwig von Mises Institute: Auburn, AL, USA, 2009; p. 8.

5. Mises, L. Human Action: A Treatise on Economics; Fox \& Wilkes: San Francisco, CA, USA, 1949; pp. 96, 494.

6. Becker, G. Human Capital; Columbia University Press: New York, NY, USA, 1964.

7. Laroche, M.; Mérette, M. On the Concept and Dimensions of Human Capital in a Knowledge-Based Economy Context. Can. Public Policy 1999, XXV, 87-100.

8. Akintoye, I.R.; Adidu, F.A. Optimising National Growth Through Human Resources Investments. Eur. J. Sci. Res. 2008, 22, 433-443.

9. Harbison, F.H. Human Resources as Wealth of Nations; Oxford University Press: London, UK, 1973.

10. Putnam, R. Bowling Alone; Simon \& Schuster: New York, NY, USA, 2000.

11. Farr, J. Social Capital: A Conceptual History. Polit. Theory 2004, 32, 6-33. 
12. Rummel, R.J. 20th Century Democide. Available online: http://www.hawaii.edu/powerkills/ 20TH.HTM (accessed on 11 May 2010).

13. Schultz, T.W. Investment in Human Capital. Am. Econ. Rev. 1961, 1, 1-17.

14. Crutzen, P.J. Geology of Mankind: The Anthropocene. Nature 2002, 415, 23.

15. Steffen, W.; Crutzen, P.J.; McNeill, J.R. The Anthropocene: Are Humans Now Overwhelming the Great Forces of Nature? Ambio 2007, 36, 614-621.

16. Huxley, J. New Bottles for New Wine, 1st ed.; Chatto and Windus: London, UK, 1957; pp. 13-17.

17. Maddison, A. The World Economy: A Millennial Perspective; OECD: Paris, France, 2001.

18. Cleveland, H.; Jacobs, G.; Macfarlane, R.; van Harten, R.; Natrajan, A. Human Choice: The Genetic Code for Social Development; World Academy of Art \& Science: Minneapolis, MN, USA, 1999.

19. Peccei, A. Congressional Record, Senate S 8690, 1984.

20. Sri Aurobindo. The Life Divine; All India Press: Pondicherry, India, 1970; pp. 898-899.

21. Elgin, D.; LeDrew, C. Global Consciousness Change: Indicators of an Emerging Paradigm; Millennium Project: San Anselmo, CA, USA, 1996.

22. Daly, H. Beyond Growth; Beacon Press: Boston, MA, USA, 1996.

23. Ott, K.; Doering, R. Strong Sustainability and Environmental Policy: Justification and Implementation. In Sustainable Life on Earth: Environmental and Human Health through Global Governance; Soskolne, C.L., Ed.; Lexington Books: Lanham, MD, USA, 2007.

24. Norton, B.G.; Toman, M.A. Sustainability: Ecological and Economic Perspectives. Land Econ. 1997, 73, 553-568.

25. Brand, F. Critical Natural Capital Revisited: Ecological Resilience and Sustainable Development. Ecol. Econ. 2009, 68, 605-611.

26. Dietz, S.; Neumayer, E. Weak and strong sustainability in the SEEA: Concepts and measurement. Ecol. Econ. 2007, 61, 617-626.

27. World Population Prospects: The 2008 Revision; United Nations Department of Economic and Social Affairs, Population Division: New York, NY, USA, 2009. Available online: http://data.un.org/Data.aspx?d=PopDiv\&f=variableID:77 (accessed on 1 May 2010).

28. Šlaus, I. Facing Demographic Transition. Eur. Pap. New Wel. 2008, 9, 8-17.

29. Kapitza, S.P. Global Population Blow-Up and After; Nauka: Moscow, Russia, 2004.

30. Brundtland Commission. Our Common Future: Report of the World Commission on Environment and Development; Oxford University Press: London, UK, 1987; p. 383.

31. Drucker, P. The Post Capitalist Society; Harper Paperbacks: New York, NY, USA, 1994; p. 1.

32. Giarini, O.; Stahel, W. The Limits to Certainty; Kluwer Academic Publishers: Boston, MA, USA, 1993.

33. Kowalski, M.F.; Weisz, H. Transition to a Globally Sustainable Metabolism-Possible and Impossible Futures. Presented at the 2008 Conference of the International Society for Ecological Economics, Nairobi, Kenya, August 2008; p. 7.

34. U.S. Department of Energy. Energy Intensity Indicators in the U.S., Energy Efficiency \& Renewable Energy, 2008. Available online: http://www1.eere.energy.gov/ba/pba/ intensityindicators/total_energy.html (accessed on 2 May 2010). 
35. Weizsacker, E.; Desha, C.; Hargroves, K.; Stasinopoulos, P.; Smith, M. Factor Five: Transforming the Global Economy Through 80\% Improvements in Resource Productivity; Earthscan: London, UK, 2009; p. 38.

36. U.S. Energy Information Administration. International Energy Annual 2006. Available online: http://www.eia.doe.gov/iea/ (accessed on 2 May 2010).

37. Stahel, W. Performance Economy, 2nd ed.; Palgrave Macmillan: Hampshire, UK, 2010; pp. 5-25.

38. U.S. Census Bureau. U.S. and World Population Clocks, 2010. Available online: http://www.census.gov/main/www/popclock.html (accessed on 20 May 2010).

39. World Employment Report 2004-05: Employment, Productivity and Poverty Reduction; International Labor Office: Geneva, Switzerland, 2005; p. 111. (World employment in 1950 is based on economically active population for age 15+ assuming unemployment averaged 6.4\%).

40. Laborsta EAPEP. Economically Active Population Estimates and Projections 1980-2020). (World Employment for 1980-98 is based on economically active population aged 15+ assuming unemployment averaged $6.4 \%$ during the period). Available online: http://laborsta.ilo.org/ applv8/data/EAPEP/eapep_E.html (accessed on 27 December 2010).

41. Global Employment Trends: January 2010; International Labour Office: Geneva, Switzerland, 2010.

42. International Monetary Fund. World Economic and Financial Surveys, 2006. Available online: http://www.imf.org/external/pubs/ft/weo/2006/02/data/index.aspx (accessed on 21 May 2010).

43. Global Employment Trends: January 2008; International Labour Office: Geneva, Switzerland, 2008; p. 10.

44. Services and Global Competitiveness: Growth Opportunities for Developing Economies; IBM Governmental Programs: Armonk, NY, USA, October 2006; pp. 2, 4.

45. Global Employment Trends: January 2009; International Labour Office: Geneva, Switzerland, 2009.

46. OECD Stats Extracts. Available online: http://stats.oecd.org/Index.aspx (accessed on 10 May 2010).

47. World Development Report 2008: Agriculture for Development; World Bank: Washington, DC, USA, 2007.

48. Felipe, J. Inclusive Growth through Full Employment. Presented at the Live Webcast Series for the E-Conference in Global Employment Challenge, The World Academy of Art \& Science, April 2010. Available online: http://www.worldacademy.org/files/INCLUSIVE\%20GROWTH \%20LAUNCH\%20Jesus\%20Felipe.pdf (accessed on 10 May 2010).

49. Wray, R. Full Employment Through Direct Job Creation. Presented at the Live Webcast Series for the E-Conference in Global Employment Challenge, The World Academy of Art \& Science, November 2009. Available online: http://www.worldacademy.org/files/Job\%20Guarantee\%20 Wray\%20presentation\%20on\%20Nov\%2010\%2009.pdf (accessed on 8 May 2010).

50. Weak Employment Recovery with Persistent High Unemployment and Decent Work Deficits: An Update on Employment and Labour Market Trends in G20 Countries; International Labour Office: Geneva, Switzerland, 2010; p. 10.

51. Therborn, G. Between Sex and Power: Family in the World, 1900-2000; Routledge, Taylor \& Francis Group: Florence, KY, USA, 2004. 
52. Eberstadt, N.; Groth, H. Healthy old Europe. International Herald Tribune, April 2007. Available online: http://www.iht.com/article/2007/04/19/opinion/edeber.php (accessed on 18 May 2010).

53. Münz, R. Migrants, Labour Markets and Integration in Europe: A Comparative Analysis; Global Commission on International Migration: Geneva, Switzerland, 2004; p. 19.

54. Kok, W.; Dell'Aringa, C.; Lopez, F.D.; Ekström, A.; Rodrigues, M.J.; Pissarides, C.; Roux, A.; Schmid, G. Jobs, Jobs, Jobs: Creating More Employment in Europe; European Commission Employment Taskforce: Brussels, Belgium, 2003; p. 10.

55. OECD Factbook 2009; OECD: Paris, France, 2009.

56. Communication from the Commission to the Council, the European Parliament, the European Economic and Social Committee and the Committee of the Regions, on Immigration, Integration and Employment; European Commission: Brussels, Belgium, 2003; p. 12.

57. Fotakis, C. Demographic Ageing, Employment Growth and Pensions Sustainability in the EU: The Option of Migration; Expert Group Meeting on Policy Responses to Population Ageing and Population Decline; United Nations Secretariat: New York, NY, USA, 2000; p. 6.

58. Raihan, A. Temporary Movement of Natural Persons: Making Liberalisation in Services Trade Work for Poor. Presented at the World Bank Annual Bank Conference on Development Economics, Brussels, Belgium, May 2004.

59. Šlaus, I. European Institute of Technology-An attempt of Euclidean Justification. Croat. Int. Relat. Rev. 2007, 12, 45-50.

60. Europe 2020: A Strategy for Smart, Sustainable and Inclusive Growth; European Commission: Brussels, Belgium, 2010.

61. OECD Employment Outlook 2006: Boosting Jobs and Incomes; OECD: Paris, France, 2006; pp. 249-250.

62. Replacement Migration: Is It a Solution to Declining and Ageing Populations? United Nations: New York, NY, USA, 2000.

63. Ramachandran, S. Doubts over India's 'teeming millions' advantage. Asia Times, May 2006. Available online: http://www.atimes.com/atimes/South_Asia/HE05Df01.html (accessed on 25 May 2010).

64. Nagan, W. Human Rights and Employment. Presented at the Live Webcast Series for the EConference in Global Employment Challenge, The World Academy of Art \& Science, November 2009. Available online: http://www.worldacademy.org/forum/human-rights-and-employmentwinston-nagan (accessed on 20 May 2010).

65. Giarini, O.; Jacobs, G.; Šlaus, I. Wealth of Nations Revisited. Eur. Pap. New Wel. 2010, Paper No. 15. Special Issue on Wealth and Welfare. Available online: http://eng.newwelfare.org/ 2010/04/18/introductory-paper-for-a-programme-on-the-wealth-of-nations-revisited/ (accessed on 7 May 2010).

66. Lutz, W. Global Demographic Challenges and the Role of Education. Presented at the Club of Rome International Conference on Concerted Strategies for International Development in the 21st Century, Bern, Switzerland, 17 November 2010; p. 2. 
67. Card, D. The Causal Effect of Education on Earnings. In Handbook of Labor Economics; Ashenfelter, O., Card, D., Eds.; Elsevier: Amsterdam, The Netherlands, 1999; Volume 3, pp. 1801-1863.

68. Glaeser, E.G. Education Last Century, and Economic Growth Today. The New York Times, October 2009. Available online: http://economix.blogs.nytimes.com/2009/10/20/education-lastcentury-and-economic-growth-today (accessed on 12 May 2010).

69. Overcoming Barriers: Human Mobility and Development; Human Development Report 2009; Palgrave Macmillan: Hampshire, UK, 2009.

70. Bureau of Labor Statistics, United States Department of Labor. Education Pays. Available online: http://www.bls.gov/emp/emptab7.htm (accessed on 12 May 2010). Data is based on weekly median earnings of full-time wage and salary workers in 2006.

71. OECD. Unemployment rates and educational attainment (2004), Table A8.2b, Education at a glance, 2006. Available online: http://statlinks.oecdcode.org/962006061P1-A8.XLS (accessed on 11 May 2010).

72. OECD. The returns to education: Education and earnings (2004), Table A9, Education at a glance, 2006. Available online: http://statlinks.oecdcode.org/962006061P1-A9.XLS (accessed on 12 May 2010).

73. Lutz, W.; Cuaresma, J.; Sanderson, W. The Demography of Educational Attainment and Economic Growth. Science 2008, 319, 1047-1048.

74. World Bank. World Development Indicators. Available online: http://databank.worldbank.org/ (accessed on 24 December 2010).

75. Maddison, A. Statistics on World Population, GDP and Per Capita GDP, 1-2008 AD. Available online: http://www.ggdc.net/MADDISON/Historical_Statistics/horizontal-file_02-2010.xls (accessed on 24 December 2010).

76. Cooper, R.A. Weighing the Evidence for Expanding Physician Supply. Ann. Intern. Med. 2004, 141, 705-714.

77. Buerhaus, P.I. Implications of an Aging Registered Nurse Workforce. JAMA 2000, 283, 2948-2954.

78. Europe's Labor Shortage. The Wall Street Journal, June 2007. Available online: http://online.wsj.com/article/SB118176922956534351.html?mod=opinion\&ojcontent=otep (accessed on 21 May 2010).

79. German Experts Warn of Alarming Lack of Skilled Workers. Cited by Deutsche Welle, May 2004. Available online: http://www.dw-world.de/dw/article/0,2144,1219935,00.html (accessed on 21 May 2010).

80. Liu, M. The Mythical Million, Newsweek, August 2007. Available online: http://www.newsweek.com/2007/08/15/the-mythical-million.html (accessed on 22 May 2010).

81. FICCI Survey on Emerging Skill Shortages in the Indian Industry; FICCI: New Delhi, India, July 2007. Available online: http://www.ficci-hen.com/Skill_Shortage_Survey_Final_1_.pdf (accessed on 21 May 2010).

82. Manpower. Supply Demand, 2010 Talent Shortage Survey Results. Available online: http://files.shareholder.com/downloads/MAN/941594442x0x375392/7a757c36-85af-4cc4-b81950be86798382/2010_global_shortage_survey_results_A4_lo.pdf (accessed on 21 May 2010). 
83. Human Capital: How What You Know Shapes Your Life; OECD: Paris, France, 2007; p. 32. Available online: http://www.oecd.org/dataoecd/35/51/37967294.pdf (accessed on 22 May 2010).

84. Garrett, R. Online Higher Education Market Update 2010-U.S. and New York Data. Presented at the SUNY Learning Network Summit, Syracuse, NY, USA, February 2010. Available online: http://www.slideshare.net/alexandrapickett/richard-garretts-eduventures-online-higher-educationmarket-update-2010-us-and-new-york-data (accessed on 22 May 2010).

85. Life Long Learning and Human Capital, Policy Brief; OECD: Paris, France, July 2007; p. 6. Available online: http://www.oecd.org/dataoecd/43/50/38982210.pdf (accessed on 22 May 2010).

86. Wilkinson, R.; Pickett, K. International Inequality Data; The Equality Trust: London, UK.

87. Aguayo-Rico, A.; Guerra-Turrubiates, I.A.; Montes, R. Empirical Evidence of the Impact of Health on Economic Growth. Issu. Polit. Econ. 2005, 14, August 2005.

88. Rivera, B.; Currais, L. The Effect of Health Investment on Growth: A Causality Analysis. IAER 2003, 9, 312-324.

89. Fogel, R.W. Nutrition, Physiological Capital, and Economic Growth. Presented at the Senior Policy Seminar on Health, Human Capital and Economic Growth: Theory, Evidence and Policies of the Pan American Health Organization (PAHO) and Inter-American Development Bank (IADB), Washington, DC, USA, October 2002. Available online: http://www.paho.org/English/HDP/HDD/fogel.pdf (accessed on 10 May 2010).

90. Bloom, D.E.; Canning, D. The Health and Wealth of Nations. Science 2000, 287, 1207-1209.

91. Bloom, D.E.; Canning, D.; Sevilla, J. The Effect of Health on Economic Growth: A Production Function Approach. World Dev. 2004, 32, 1-13.

92. Keidel, A. The Economic Basis for Social Unrest in China. Presented at the Carnegie Endowment for International Peace for The Third European-American Dialogue on China, Washington, DC, USA, May 2005. Available online: http://www.carnegieendowment.org/ files/Keidel_Social_Unrest.pdf (accessed on 11 May 2010).

93. Ministry of Public Security Statistics. Chinese Social Protest ("Mass Incidents") 1993-2003. Available online: http://www.uscc.gov/hearings/2005hearings/written_testimonies/05_04_14 wrts/smyth_frank_wrts_clip_image002.gif (accessed on 12 May 2010).

94. Rogers, P. China and India: Heartlands of Global Protests. Open Democracy, August 2008. Available online: http://www.opendemocracy.net/article/china-and-india-heartlands-of-globalprotest (accessed on 5 May 2010).

95. Armed Conflicts Report; Project Ploughshares: Ontario, Canada, 2010. Available online: http://www.ploughshares.ca/libraries/ACRText/ACR-IndiaAP.html (accessed on 10 May 2010).

96. Singh, A.K.; Dhawan, S.B. Weekly Assessments \& Briefings, South Asia Intelligence Review of the South Asia Terrorism Portal. SAIR 2010, 8, No. 39. Available online: http://www.satp.org/satporgtp/sair/Archives/sair8/8_39.htm (accessed on 10 May 2010).

97. Jaffrelot, C. Emerging States: The Wellspring of a New World Order; Columbia University Press: West Sussex, UK, 2009; p. 86.

98. Jacobs, G.; Šlaus, I. Indicators of Economic Progress: The Power of Measurement and Human Welfare. Cadmus J. 2010, 1, 53-113.

99. Rajan, R. Fault Lines; Princeton University Press: Princeton, NJ, USA, 2010; p. 183. 
100. Camdessus, M. Income Distribution and Sustainable Growth: The Perspective from the IMF at Fifty . Presented at the Conference on Income Distribution and Sustainable Growth, Washington, DC, USA, 1 June 1995. Available online: http://www.imf.org/external/np/sec/mds/1995/ mds9509.htm (accessed on 7 July 2010).

101. Ramcharan, R. Inequality Is Untenable. Finance Dev. IMF 2010, 47, 24-25.

102. Cornia, G.A.; Court, J. Inequality, Growth and Poverty in the Era of Liberalization and Globalization; UNU/WIDER: Helsinki, Finland, 2001.

103. Human Development Report 2006; Palgrave Macmillan: Hampshire, UK, 2006; p. 87.

104. World of Work Report 2008: Income Inequalities in the Age of Financial Globalization; International Institute for Labour Studies: Geneva, Switzerland, 2008; p. xi.

105. Wilkinson, R.G.; Pickett, K. The Spirit Level: Why More Equal Societies Almost Always Do Better; Allen Lane: London, UK, 2009.

106. US Energy Information Administration, EIA. International Total Primary Energy Consumption and Energy Intensity. Available online: http://www.eia.doe.gov/emeu/international/ energyconsumption.html (accessed on 22 May 2010).

107. Human Development Report 2010; Palgrave Macmillan: Hampshire, UK, 2010.

108. India Vision 2020: The Report plus Background Papers; Planning Commission, Government of India, Academic Foundation: New Delhi, India, 2002; p. 75.

109. Water: The India Story. Grail Research, March 2009. Available online: http://www.grailresearch.com/pdf/ContenPodsPdf/Water-The_India_Story.pdf (accessed on 22 May 2010).

110. Central Ground Water Board, Ministry of Water Resources, Government of India. Success Stories of Artificial Recharging Schemes in State of Tamil Nadu. Available online: http://cgwb.gov.in/GroundWater/AR/TamilNadu.pdf (accessed on 5 May 2010).

111. World Population Program, International Institute for Applied Systems Analysis. Population Projections by Level of Education. Available online: http://www.iiasa.ac.at/Research/POP (accessed on 22 December 2010).

112. Lutz, W. Editorial: Towards a World of 2-6 Billion Well Educated and Therefore Healthy and Wealthy People. J. R. Statist. Soc. 2009, 172, 701-705.

113. Data on Tertiary Enrollment Rates is taken from UNESCO database. Available online: http://stats.uis.unesco.org/unesco/TableViewer/tableView.aspx?ReportId=167 (accessed on 22 May 2010).

114. U.S Energy Information Administration. International Energy Statistics. Available online: http://tonto.eia.doe.gov/cfapps/ipdbproject/iedindex3.cfm?tid=3\&pid=26\&aid=2\&cid=\&syid=19 80\&eyid=2009\&unit=QBTU (accessed on 22 May 2010).

115. Wilson, C. Fertility Below Replacement Level. Science 2004, 304, 207-209.

116. Lutz, W.; Sanderson, W.; Scherbov, S. The Coming Acceleration of Global Population Ageing. Nature 2008, 451, 716-719.

117. Lutz, W.; O’Neill, B.C.; Scherbov, S. Europe's Population at a Turning Point. Science 2003, 299, 1991-1992.

118. Maslow, A.H. Motivation and Personality, 3rd ed.; Kindersley, D., Ed.; Harper Collins Publishers: New York, NY, USA, 1987; pp. 35, 99. 
119. Peccei, A. Agenda for the End of the Century; The Club of Rome: Rome, Italy, 1984.

120. World Values, World Values Survey database. Available online: http://www.wvsevsdb.com/ wvs/WVSAnalize.jsp (accessed on 22 May 2010).

121. Jung, C. Four Archetypes; Routledge: New York, NY, USA, 2003; p. 179.

(C) 2011 by the authors; licensee MDPI, Basel, Switzerland. This article is an open access article distributed under the terms and conditions of the Creative Commons Attribution license (http://creativecommons.org/licenses/by/3.0/). 